\title{
Die Röntgenmikroanalyse von Lignin als Untersuchungsmethode für Holz und Holzwerkstoffe
}

\author{
Dissertation \\ Zur Erlangung des Doktorgrades \\ Der Fakultät für Forstwissenschaften und Waldökologie \\ Der Georg-August-Universität Göttingen
}

Vorgelegt von Klaus Schindel

Geboren in Göttingen

Göttingen 1998 
D7

1. Berichterstatter: Prof. Dr. A. Hüttermann

2. Berichterstatter: Prof. Dr. E. Roffael

Tag der mündlichen Prüfung: 25.09.1998 
Look at me friend!

I come to ask for your dress.

You have come to take pity on us,

for there is nothing for which you cannot be used,

because it is your way that there is nothing

for which we cannot use you,

for you are really willing to give us your dress.

I come to beg you for this, Long Live Maker,

for I am going to make a basket for lilly roots out of you.

Gebet der Kwakiutl-Indianer der Pazifikküste Kanadas vor der Ernte von Zedernbast (übersetzt, Stewart, 1984) 


\section{EINLEITUNG 1}

1.1 Die Ultrastruktur von Holz 1

1.2 Die Lignifizierung auf Zellniveau, Nutzen von Holzfasern in Natur und Technik

1.3 Delignifizierung der verholzten Zellwand durch Fäulepilze 4

1.4 Biotechnologie des Lignins und Ligninstoffwechsels 6

1.4.1 Ligninolytische Enzyme 6

1.4.2 Lignin, vom Abfallstoff zum Rohstoff 7

1.5 Isolierung und Nachweis von Lignin 9

1.5.1 Übersicht über Ligninnachweismethoden 9

1.5.2 UV-Mikroskopie $\quad 10$

1.5.3 Interferenz-Mikroskopie 11

1.5.4 Transmissions-Elektronen-Mikroskopie mit elektronendispersiver Röntgenmikroanalyse (TEM-EDXA) 11

1.6 Ziel der Arbeit 13

2 MATERIAL UND METHODEN 15

2.1 Herkunft des Probenmaterials 15

2.1.1 Buchenholz und Kiefernholz 15

2.1.2 Fichtenholz 15

2.1.3 Industriefasern und Bioleim-Faserplatten $\quad 15$

2.1.4 Lignifizierte Späne und Bioleim-Spanplatten 16

2.1.5 Lignifiziertes Filterpapier $\quad 16$

2.1.6 Lignifiziertes Sulfitzellstoff-Vlies $\quad 17$

2.2 Inkubation von Probehölzern mit Weiß- und Braunfäulepilzen 17

2.2.1 Screening $\quad 18$

2.2.2 Zeitlicher Verlauf der Infektion von Holz mit Fäulepilzen $\quad 20$

2.3 Mikroskopie 21

2.3.1 Transmissions-Elektronen-Mikroskopie (TEM) und Röntgenmikroanalyse

(Electron Dispersive X-Ray Analysis, EDXA) von Holz und Holzwerkstoffen 21

2.3.2 Lichtmikroskopie (LM) 25

2.3.3 Raster-Elektronen-Mikroskopie (Scanning Electron Microscopy, SEM)

2.4 Analyse chemischer, mechanischer und physiologischer Parameter pilzinfizierter Probehölzer 26

2.4.1 Klason-Lignin-Bestimmung 26

2.4.2 Gewichtsverlustbestimmung 27

2.4.3 Scherfestigkeitsbestimmung 28

2.4.4 CO2-Produktion 28

2.4.5 Wärmeproduktion 29 
3 ERGEBNISSE 30

3.1 Lignin- und Elementverteilung in gewachsenem Holz 30

3.1.1 Ligninverteilung in Buchenholz 30

3.1.2 Elementkonzentrationen in Buchenholz 32

3.1.3 Ligninverteilung in Kiefernholz 33

3.1.4 Elementkonzentrationen in Kiefernholz 35

3.2 Lignin in pilzinfiziertem Holz 36

3.2.1 Buchenholz nach kontrollierter Infektion mit Fäulepilzen 36

3.2.2 Kiefernholz nach kontrollierter Infektion mit Fäulepilzen 43

3.2.3 Rotfaules Fichtenholz aus dem Freiland 51

3.3 Lignin in biotechnologischen Holzwerkstoffen 58

3.3.1 Ligningehalt in Thermomechanischem Faserstoff (TMP) und daraus hergestellten Mitteldichten Faserplatten (MDF) 58

3.3.2 Verteilung von Lignin-Bioleim auf Spänen und in Spanplatten 63

3.3.3 Ligninverteilung in Werkstoffen aus Zellstoff und appliziertem Lignin

4 DISKUSSION 75

4.1 Die quantitative Bestimmung von Lignin in situ 75

4.2 Die Ultrastruktur der verholzten Zellwand in Buche und Kiefer 77

4.2.1 Ligningehalt 77

4.2.2 Elementkonzentration 77

4.3 Mikromorphologische Veränderungen im Frühstadium des Holzabbaues durch Fäulepilze 79

4.3.1 Ligningehalt und mechanische Festigkeit 79

4.3.2 Veränderungen der Elementkonzentration in Holz bei Pilzbefall

4.4 Lignin in der Leimfuge biotechnologischer Faserplatten $\quad 84$

4.5 Enzymatisch aktiviertes Lignin als Bioleim in Spanplatten 86

4.6 Lignin als Imprägniermittel von biologisch abbaubarem Verpackungsmaterial

5 ZUSAMMENFASSUNG 91

6 LITERATURVERZEICHNIS 93

7 DANKSAGUNG 100

8 LEBENSLAUF 101 


\section{EINLEITUNG}

\subsection{Die Ultrastruktur von Holz}

Holz wird aus den Naturstoffen Lignin, Hemicellulose und Cellulose aufgebaut. Alle drei Stoffe bestehen aus den Elementen Kohlenstoff, Wasserstoff und Sauerstoff, doch unterscheiden sie sich sehr in ihrer molekularen Organisation. Lignin entsteht als ein dreidimensionales Netzwerk durch radikalische Polymerisation aus den Phenylpropanolen Coniferylalkohol, Sinapylalkohol und Cumarylalkohol (Abb.1). Der relative Anteil der verschiedenen Phenylpropanole variiert stark zwischen verschiedenen Pflanzengruppen. Laubholzlignin weist einen weit höheren Sinapylanteil auf als Nadelholzlignin, das fast ausschließlich aus Coniferylalkohol aufgebaut wird. Das Lignin in der verholzten Zellwand der Gräser ist durch einen hohen Cumarylanteil charakterisiert.

Hemicellulose ist ein heterogenes Gemisch aus Polysacchariden. Grundbausteine sind Pentosane (Xylose, Arabinose) und Hexosane (Glucose, Galactose, Fucose, Mannose), die zu kurzen, teilweise verzweigten Ketten verknüpft werden.

Cellulosemoleküle sind in Fibrillen organisiert, die sich aus unverzweigten 1,4- $\beta$-GlucanKetten zusammensetzen. Intramolekulare und intermolekulare Wasserstoffbrücken sorgen für eine dichte Packung und parallele Ausrichtung der Glucanketten in den Fibrillen, die in kristallinen Bereichen die höchste Ordnung der Cellulose zeigen. Auf mindestens vier Konstruktionsebenen sind die Cellulosefibrillen zu Fasern verdrillt.

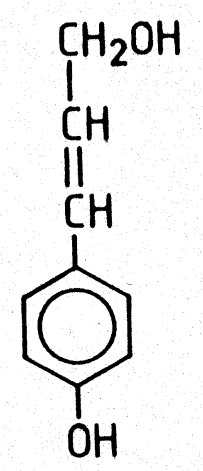

I

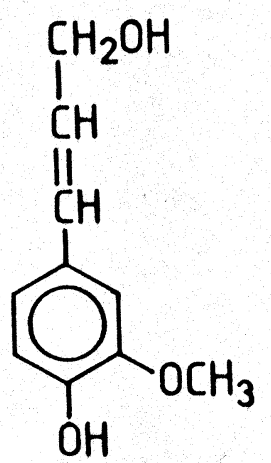

II<smiles>COc1cc(C=CCO)cc(OC)c1O</smiles>

III

\section{Abbildung 1}

Die Phenylpropanol-Grundbausteine des Lignins p-Cumarylalkohol (I), Coniferylalkohol (II) und Sinapylalkohol (III) 
Erst die Anordnung und Verknüpfung der drei Bestandteile Lignin, Hemicellulose und Cellulose auf der Ebene der Ultrastruktur der verholzten Zellwand verleihen Holz die besondere mechanische Stabilität, die Landpflanzen ihr Höhenwachstum ermöglicht. Hohe Druckfestigkeit wird durch die amorphe, harte Matrix aus Lignin gewährleistet, während die Zugfestigkeit auf die in der Matrix eingebetteten elastischen Cellulosefasern zurückzuführen ist (Abb.2). Da Lignin und Cellulose in der Natur wahrscheinlich keine Bindungen eingehen, ist im Verbundstoff "Zellwand" außerdem noch ein Kontaktvermittler zwischen Faser und Matrix nötig. Diese Aufgabe wird gemäß zahlreichen Modellen dem Hemicellulose-Anteil der verholzten Zellwand zugeschrieben (vgl. Fengel und Wegener, 1989). Eine kovalente Bindung von Lignin mit Hemicellulosen, vor allem mit Arabinose, Xylose und Galactose in Holz ist belegt (Eriksson et al., 1980, Koshijima et al., 1989). Es wird angenommen, dass diese Bindung nach Aktivierung des Lignins zu OligolignolChinonmethiden zustandekommt (Higuchi, 1997). Zwischen Hemicellulose und Cellulose sorgen Wasserstoffbrücken für eine stabile Bindung. Nach neuesten Erkenntissen wird eine Aufgabenteilung vorgeschlagen, derzufolge xylanhaltige Hemicellulose vor allem mit Lignin assoziiert ist und glucomannanhaltige Hemicellulose für den stabilen Kontakt zur Cellulose verantwortlich ist (Salmen und Olsson, 1998).

Das von der Natur für verholzte Gewebe entwickelte und bewährte Prinzip des Verbundstoffes von Fasern und Matrix ist inzwischen von der Technik erfolgreich adaptiert worden. Stahlbeton, Glasfaser- und Karbonfaser-Kunstoffe folgen diesem Bauprinzip.
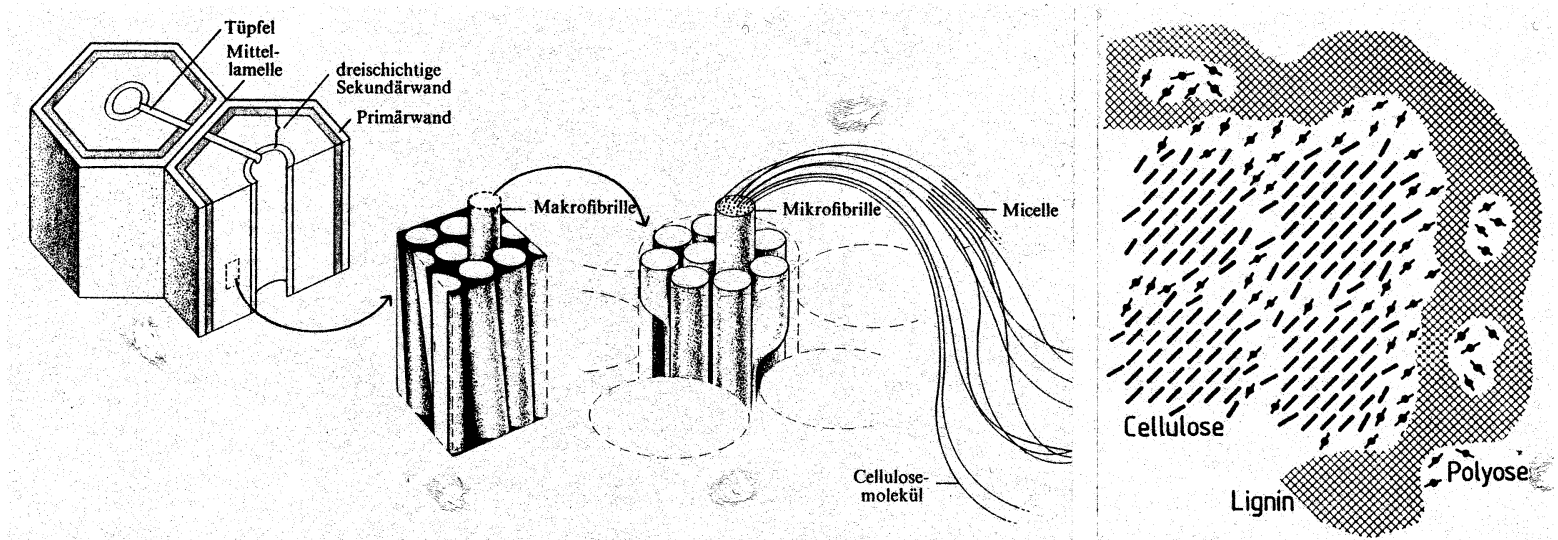

Abbildung 2

Die Ultrastruktur der verholzten Zellwand (verändert nach Raven et al., 1988, Fengel und Wegener, 1989) 


\subsection{Die Lignifizierung auf Zellniveau, Nutzen von Holzfasern in Natur und Technik}

Die lignifizierte Zellwand ist ein Sekretionsprodukt des Symplasten. Während des Wachstums der Zellwand scheidet die lebende Zelle über das Plasmalemma Cellulosefibrillen, Hemicellulose und Vorläufer der Ligninmatrix aus. Die Cellulosefibrillen werden bei schichtweise wechselnder Orientierung auf die Mittellamelle aufgetragen (Apposition). Die monomeren Ligninbausteine werden zunächst extrazellulär enzymatisch zu Radikalen aktiviert, die anschließend spontan zum Ligninmakromolekül polymerisieren. Die Resonanzstabilisierung des monomeren Radikals erlaubt dabei sehr viele verschiedene Verknüpfungen zur wachsenden Ligninmatrix. Weil Lignin bevorzugt in den Poren zwischen den Cellulosefibrillen polymerisiert, wird dieser Prozess Inkrustierung oder Intussuszeption genannt (Mohr und Schopfer, 1992).

Die Volumenzunahme der Zellwand ist nur möglich bei gleichzeitiger Rückbildung des Zellsackes bis hin zum geplanten Zelltod nach Abschluss der Lignifizierung. Im Holz der Gymnospermen und Dikotylen geht damit eine Differenzierung der Zellen einher, an deren Ende spezialisierte Zellen stehen, die dem gesamten Organismus Stabilität verleihen und teilweise die Aufgabe des Wasserferntransportes übernehmen. Den größten Anteil am Volumen und am Gewicht des Holzes bilden die Zellwände abgestorbener Zellen mit faserartigem Charakter (Wagenführ, 1984). Über die gemeinsame Mittellamelle sind benachbarte Faserzellen von ihrer Entstehung an sehr fest verbunden. Während der Lignifizierung wird in der Mittellamelle mehr Lignin eingelagert als in jedem anderen Bereich der Zellwand (Donaldson, 1985b). Mit verschiedenen Methoden wurde ein Ligningehalt in der Mittellamelle von 50-100\% gemessen (Fergus et al., 1969, Saka und Thomas, 1982, Westermark et al., 1988). Auf einer höheren Konstruktionsebene ist hier wiederum das biologische Prinzip des Verbundstoffes aus elastischer zugfester Faser (Faserzelle) und harter amorpher Matrix (ligninreicher Mittellamelle) verwirklicht. Zusätzlich verleiht die Imprägnierung mit Lignin der Zellwand eine geringere Benetzbarkeit und erleichtert so den Wasserferntransport.

Die natürlichen Fasern im Holz werden vom Menschen auf vielfältige Weise genutzt. Die Holzfasern müssen jedoch zuvor mit technisch aufwendigen Methoden voneinander getrennt werden. Für die Bereitstellung von Faserstoff für die Faserplattenindustrie werden im Thermomechanischen Pulping (TMP) hoher Druck, hohe Temperaturen und Scherkräfte 
eingesetzt, um das Mittellamellen-Lignin zu verflüssigen und die Holzfasern voneinander zu trennen. Für die Produktion von Zellstoff, einem wichtigen Rohstoff der Papierindustrie, werden in verschiedenen Verfahren starke Säuren, mineralische Zusätze oder organische Lösungsmittel zusammen mit hohen Temperaturen zur Trennung und zur möglichst vollständigen Delignifizierung der Holzfasern eingesetzt. Die Fasern verlieren bei der Delignifizierung zwar ihre Druckfestigkeit, ihre Zugfestigkeit bleibt jedoch erhalten.

\subsection{Delignifizierung der verholzten Zellwand durch Fäulepilze}

Lignin ist nicht nur mechanisch ein äußerst stabiles Polymer, es ist auch chemisch und biologisch nur schwer abbaubar. Weil es die kohlenhydrathaltigen Bestandteile der Zellwand umschließt, ist es für die Langlebigkeit verholzter Pflanzenteile verantwortlich. Es ist kein Bakterium und auch keine Pflanze oder Tier bekannt, das Lignin abbauen kann. Schon früh wurden von Willkomm (1866) jedoch in der Klasse der Basidiomyceten Pilze identifiziert, die bevorzugt lignifiziertes Gewebe befallen und abbauen. Von Hubert (1924) stammt die Unterteilung holzabbauender Pilze in Weißfäulepilze und Braunfäulepilze wegen der Farbe des befallenen Holzes. Lignin ist aufgrund seiner aromatischen Untereinheiten ein bräunlicher Farbstoff, während Cellulose und Hemicellulose farblos sind. Eine Farbänderung während des fortschreitenden Abbaues spiegelt daher eine Veränderung der relativen Verhältnisse der Zellwandkomponenten wider: Einer Entfärbung des zuvor gelblichbräunlichen Holzes entspricht ein bevorzugter Abbau des Lignins. Einer Braunfärbung entspricht eine Einlagerung von Pigmenten und Anreicherung des Lignins nach Celluloseund Hemicelluloseabbau. Chemische Untersuchungen pilzinfizierten Holzes rechtfertigten diese Einteilung (Falck, 1926).

Mittlerweile liegen zahlreiche Beschreibungen des Holzabbaues durch Weiß- und Braunfäulepilze von Forschergruppen aus der ganzen Welt vor (zusammengefasst von Levy, 1987, Blanchette, 1991, Blanchette, 1994, Green und Highley, 1997). Aufgrund vieler chemischer und mikroskopischer Untersuchungen werden bei Weißfäulepilzen zwei Abbaustrategien unterschieden: Der einen Strategie zufolge bauen die Pilze gleichzeitig Lignin und Kohlenhydrate in der verholzten Zellwand ab (simultane Weißfäule), nach der anderen erfolgt zunächst ein bevorzugter Abbau des Lignins und erst in späteren Stadien 
ein Kohlenhydratabbau (selektive Weißfäule). Allerdings ist eine strikte Zuordnung für jeden Weißfäulepilz nicht möglich. Die bevorzugte Strategie ist unter anderem von den Kulturbedingungen wie Wirtsgewebe und Nährstoffzusätzen oder von der Dauer der Infektion abhängig (Ander und Eriksson, 1977). Auch können Bereiche selektiver und simultaner Delignifizierung durch denselben Pilz direkt nebeneinander im Wirtsgewebe auftreten. Dieses Phänomen wurde schon im vergangenen Jarhundert von Hartig (1878) beschrieben, wobei er allerdings noch nicht die heutige Terminologie benutzte.

Die Besonderheit der Weißfäulepilze ist ihre Fähigkeit zur Produktion von extrazellulären Enzymen, deren Beteiligung beim Abbau von Lignin oder Ligninmodelsubstanzen nachgewiesen werden konnte (zusammengefasst bei Ruel et al., 1994, Joseleau et al., 1994). Bisher wurden drei dieser Enzyme isoliert und näher charakterisiert. Aus Kulturen des Weißfäulepilzes Phanerochaete chrysosporium wurde eine Peroxidase gewonnen, die in relativ unspezifischer Reaktion Seitenketten und Benzolringe von Ligninmodellsubstanzen oxidiert (Tien und Kirk, 1983, Glenn et al., 1983). Ein Merkmal dieser Peroxidase, die den Namen Ligninperoxidase erhielt, ist, dass sie monomere Aromaten als Radikal-Carrier zur Oxidation von Phenolen benötigt (Kersten et al., 1985). Die Ligninperoxidase ist ein HämGlykoprotein mit einem Molekulargewicht von 41 kDa. Eine andere hämhaltige Peroxidase aus Weißfäulepilzen benötigt zur Oxidation von phenolischen Modellsubstanzen die Anwesenheit von Mangan-II und $\mathrm{H}_{2} \mathrm{O}_{2}$. Diese Manganperoxidase oxidiert zunächst Mn-II zu Mn-III; das Mn-III diffundiert im Komplex mit einer organischen Säure daraufhin vom Enzym ab und oxidiert seinerseits das phenolische Substrat (Glenn und Gold, 1985). Als drittes Enzym wurde in Kulturen vieler Weißfäulepilze eine sauerstoffabhängige kupferhaltige Polyphenoloxidase (Laccase) nachgewiesen (Reinhammar, 1984). Auch sie katalysiert wahrscheinlich wie Manganperoxidase nur indirekt die Oxidation von phenolischen und nicht-phenolischen Aromaten, indem sie Radikal-Kationen erzeugt, die in nicht-enzymatischer Reaktion Aromaten oxidieren (Kersten et al., 1990).

Von Braunfäulepilzen wurde lange Zeit angenommen, dass sie nicht in der Lage sind, polymerisiertes Zellwandlignin $\mathrm{zu}$ metabolisieren. Mittlerweile mehren sich aber die Anzeichen dafür, dass zumindest manche Vertreter dieser Gruppe Veränderungen am Gerüst bewirken können. Beispielsweise konnte Schmidt (1994) eine Demethylierung von Lignin durch Braunfäule nachweisen. In vitro gelang bisher auch schon der Nachweis für 
die Mineralisierung von dehydropolymerem Lignin (DHP-Lignin) (Haider und Trojanowski, 1980) und pulverisiertem Kraft-Lignin (Milstein et al., 1992). Der Beweis für eine tatsächliche Delignifizierung von gewachsenem Holz durch Braunfäulepilze steht allerdings noch aus.

\subsection{Biotechnologie des Lignins und Ligninstoffwechsels}

\subsubsection{Ligninolytische Enzyme}

Schon bald nach ihrer Entdeckung wurden ligninolytische Enzyme aus Weißfäulepilzen auf ihre Einsetzbarkeit bei der biotechnologischen Delignifizierung von Faserstoff hin untersucht (vgl. Eriksson et al., 1990, Messner und Srebotnik, 1994, Kerem und Hadar, 1998). Großes Interesse an einem schonend und kostengünstig delignifizierten Faserstoff besteht sowohl in der Zellstoff- und Papierindustrie als in der Landwirtschaft, die hofft, sich auf diese Weise bisher unzugängliche Kohlenhydratreserven in Fasern einjähriger Pflanzen als Futtermittel zu erschließen. In zahlreichen verschiedenen Ansätzen wurden lignocellulosehaltige Rohstoffe und Zwischenprodukte des Faseraufschlusses entweder direkt mit selektierten Pilzstämmen inkubiert oder mit zellfreien Enzymextrakten behandelt. Als Ergebnis war in den meisten Fällen eine Abnahme des Ligningehaltes des Fasermaterials zu beobachten. Eine Vorbehandlung von Weizenstroh mit dem Weißfäulepilz Lentinula edodes ermöglichte zusätzlich eine Reduzierung des Energieeinsatzes beim Faseraufschluss um 50\% bei verbesserten Fasereigenschaften des Endproduktes (Sermanini et al., 1994). Durch vorherige Inkubation mit dem Weißfäulepilz Ceriporiopsis subvermispora konnten ähnliche Ergebnisse auch beim Aufschluss von Pappel- und Kiefernhackschnitzeln erzielt werden (Akhtar et al., 1992). Die Vorbehandlung von Hackschnitzeln mit Weißfäule- und Braunfäulepilzen für die Produktion Mitteldichter Faserplatten (MDF) sparte nicht nur Energie beim Faseraufschluss, sondern ermöglichte ferner eine Reduktion des Bindemitteleinsatzes ohne Qualitätseinbußen des Endproduktes (Wagenführ, 1988, I. Körner, 1990, S. Körner, 1990).

Der Einsatz pilzlicher ligninolytischer Enzyme, aber auch von Cellulasen und Xylanasen als Ergänzung oder Ersatz konventioneller Faserbehandlungsmethoden hat sich inzwischen 
unter den Namen Biopulping und Biobleaching in Wissenschaft und Technik fest etabliert. Mittlerweile wurden auch Verfahren entwickelt, die es ermöglichen, ligninolytische Enzyme von Weißfäulepilzen in technisch nutzbaren Mengen produzieren zu lassen (Hüttermann et al., 1990).

Ligninolytische Enzyme können außerdem erfolgreich bei der Klärung ligninhaltiger Abwässer von Zellstoff-Fabriken eingesetzt werden (Ek und Eriksson, 1980). Wegen ihrer teilweise geringen Substratspezifität eignen sich diese Enzyme aber auch zum Abbau ähnlicher Aromaten, deren Entsorgung in anderen Bereichen ein Problem darstellt. Viele Forschergruppen untersuchen derzeit die Verwendung von ligninolytischen Enzymen beim biotechnologischen Abbau (Bioremediation) von Polyzyklischen Kohlenwasserstoffen (PAK), Polychlorierten Biphenylen (PCB) und weiteren ähnlichen Giftstoffen in Abluft und kontaminierten Böden (vgl. Hüttermann und Majcherczyk, 1998).

Enzyme des Ligninstoffwechsels der Weißfäulepilze erwiesen sich nicht nur beim Abbau von phenolischen Stoffen als geeignete Werkzeuge, sie vermochten auch auspolymerisiertes Lignin auf Faseroberflächen wieder zu reaktivieren (Kharazipour et al., 1991, Yamaguchi et al., 1992). Thermomechanischer Faserstoff (TMP) konnte nach Inkubation mit Laccase oder Peroxidase ohne Zugabe weiterer Bindemittel zu Mitteldichten Faserplatten verpresst werden, deren mechanische Stabilität weit über derjenigen von unbehandelten bindemittelfreien Kontrollen lag (Kharazipour et al., 1997, Kharazipour et al., 1998). Die Ultrastruktur dieser neuen Faser-Faser-Bindung wurde bisher noch nicht untersucht.

\subsubsection{Lignin, vom Abfallstoff zum Rohstoff}

Lignin ist nach Cellulose der zweithäufigste Naturstoff der Biosphäre, die Jahresproduktion wird weltweit auf 20 Mrd. t geschätzt (Little, 1991). Bemerkenswerter-weise vermochte der Mensch bis vor kurzem nicht, diesen Naturstoff in seiner isolierten Form zu nutzen. Wahrscheinlich liegt darin auch der Grund dafür, dass Lignin in der Bevölkerung im Gegensatz zu Cellulose oder Zellstoff unbekannt ist und auch die deutsche Spache dafür kein eigenes Wort geprägt hat. Während Cellulose aus schwach-lignifizierten oder delignifizierten Pflanzenfasern schon lange als Futtermittel für Wiederkäuer und als Rohstoff für die Papier-, Faser- und Kunstfaserindustrie in großem Maße verwendet wird, 
stellte Lignin, das im Abwasser von Zellstoff-Fabriken in großen Mengen anfällt, sogar lange Zeit ein Entsorgungsproblem dar. Der Ausstoß der Zellstoffindustrie an technischem Lignin beläuft sich auf jährlich etwa 20 Mio. t Kraft-Lignin aus dem Sulfatverfahren und etwa 10 Mio. t Ligninsulfonat aus dem Sulfitverfahren, wovon nur etwa 6\% industriell weiterverarbeitet werden (Little, 1991). Beispielsweise wird Sinapyl-Lignin in kleinen Mengen zur Synthese des Aromastoffs Vanilin eingesetzt. Mittlerweile wird wenigstens die Energie, die im Ligninmolekül gespeichert ist, beim Verbrennen der angedickten Ablaugen in Zellstoffwerken thermisch genutzt.

Auf der Suche nach einer sinnvollen Verwendungsmöglichkeit für diesen ungenutzten, billigen Naturstoff waren es Pedersen und Rasmussen (1962), die zuerst versuchten, Lignin dort einzusetzen, wo es auch in der Natur seine wichtigste Funktion wahrnimmt, nämlich als Bindemittel zwischen Fasern oder Partikeln. Sie entwickelten ein Verfahren, das Sulfitablauge als Kleber in Spanplatten verwendete. Wegen der erforderlichen teuren Nachbehandlung der Spanplatten (Tempern) konnte sich dieses Verfahren jedoch nicht dauerhaft in der Praxis etablieren. Nimz und Mitarbeiter (1972) waren die ersten Wissenschaftler, die Peroxidasen einsetzten, um Sulfitablaugen-Lignin auf Holzwerkstoffen erneut zu reaktivieren, bevor es in neuen Gefügen verpresst wurde. Sicherheitsbedenken wegen des Einsatzes von $\mathrm{H}_{2} \mathrm{O}_{2}$ und die eingeschränkte Verfügbarkeit von Peroxidase begrenzten jedoch die technische Umsetzung dieses Verfahrens. Roffael und Rauch (1971, 1974) konnten durch mineralisches Umsalzen von Calcium-Ligninsulfonat zu Natrium- und Ammonium-Ligninsulfonat aus Sulfitablaugen ein Bindemittel gewinnen, das als preisgünstige Zugabe in einem Anteil von bis zu 30\% zu Phenol-Formaldehyd-Kunstharz ohne gravierende Qualitätseinbußen beigemischt werden kann. Ammonium-Ligninsulfonat wird mittlerweile von mehreren industriellen Herstellern Harnstoff-FormaldehydKunstharzen zugesetzt. Auch Schwarzlauge, das Kraft-Lignin-haltige "Abfallprodukt" des Sulfatverfahrens, kann wenigstens als Zugabe zu Phenol-Formaldehyd-Kunstharz technisch genutzt werden (Pecina et al., 1991). Die Unlöslichkeit von Kraft-Lignin in Wasser und die Reaktionsträgheit technischer Lignine erschweren ihre Verarbeitung in neuen Werkstoffen allerdings in solchem Maße, dass bisher noch keine großtechnische Applikation für Ligninablaugen entwickelt wurde.

Neuerdings stehen mit den ligninolytischen Enzymen der Weißfäulepilze jedoch Werkzeuge zur Verfügung, die es erlauben, ohne teuren Energie- und Chemikalieneinsatz 
das Kohlenstoffgrundgerüst des reaktionsträgen Lignins $\mathrm{zu}$ manipulieren und neuen Stoffkreisläufen zuzuführen. Eine Einsatzmöglichkeit bietet sich beispielsweise bei der Entwicklung neuer biologisch-abbaubarer Verpackungsmaterialien auf der Basis nachwachsender Rohstoffe. Dieses aktuelle Forschungsgebiet sucht nach Methoden, stärkeoder zellstoffhaltige Werkstoffen durch Imprägnierung mit Lignin eine bessere Nassfestigkeit zu verleihen (Baumberger et al., 1997). Erste Versuche, dafür ligninolytische Enzyme von Weißfäulepilzen zusammen mit Ligninsulfonat und Kraft-Lignin einzusetzen, erzielten vielversprechende Ergebnisse (Hüttermann et al., 1998, Schröter, 1998). Die anatomische Struktur dieser neuen Werkstoffe, speziell die Ligninverteilung in den Kontaktzonen künstlicher Gefüge, ist noch weitgehend unbekannt. Ihre Aufklärung kann möglicherweise einen wichtigen Beitrag zum Verständis der molekularen Prozesse leisten, die auf einer höheren Ebene den Werkstoff mit neuen Eigenschaften ausstatten.

\subsection{Isolierung und Nachweis von Lignin}

\subsection{1 Übersicht über Ligninnachweismethoden}

Zur Lokalisierung von Lignin und zur Beschreibung seiner Bindungsverhältnisse in der Ultrastruktur der Holzfasern, bei der biologischen, technischen und biotechnologischen Delignifizierung und in neuartigen ligninhaltigen Werkstoffen sind stets spezifische Nachweismethoden für Lignin erforderlich. Am schnellsten ist der mikroskopische Nachweis von Lignin nach selektiver Anfärbung. Mehr als 150 Farbreaktionen sind von Lignin bekannt (Nakano und Meshitsuka, 1992). Am bekanntesten ist die Rotfärbung lignifizierter Gewebe mit salzsaurem Phloroglucinol (Wiesner Reaktion), die schon lange auf molekularem Niveau aufgeklärt ist (Adler et al., 1948). Die TransmissionsElektronenmikroskopie nutzt bevorzugt die Reaktion von Lignin mit Kaliumpermanganat (Bland et al., 1971), um Lignin in Schnitten zu kontrastieren. Die erhöhte Absorption von Elektronen bietet jedoch nur ein unzureichendes Maß für die Quantifizierung von Lignin.

Zur Bestimmung der Größe und Menge von Lignin und seiner intramolekularen und intermolekularen Verknüpfung hat die chemische Analytik eine Vielzahl an Methoden 
entwickelt (vgl. Lin und Dence, 1992). Apparativ aufwendige Analysen wie KernspinResonanz (NMR), Elektronenspin-Resonanz (ESR), Ultraviolett-Spektrophotometrie, Fourier-Transformations-Infrarot-Spektroskopie (FTIR), Raman-Spektroskopie, GasChromatographie-Massen-Spektrometrie (GC-MS), Matrixassisierte Laser-Deionisierungs Massenspektroskopie (MALDI) oder Hochdruck-Flüssigkeits-Chromatographie (HPLC) konnten ebenso wichtige Informationen liefern wie die gravimetrische Bestimmung säureunlöslichen Lignins (Klason-Lignin) nach vollständiger Hydrolyse jeglicher Kohlenhydrate. Keine dieser Messmethoden ist allerdings geeignet, natives Lignin im gewachsenen oder zusammengefügten Gewebeverband zu beschreiben, denn Lignin muss zuvor jeweils isoliert werden. Die Isolierung führt aufgrund der stabilen Verbindung der Ligninuntereinheiten untereinander und $\mathrm{zu}$ Bindungspartnern stets $\mathrm{zu}$ einer Veränderung oder Verunreinigung des Lignins. Drei mikroskopische Messmethoden sind jedoch bekannt, die Lignin in situ identifizieren und quantifizieren können. Diese drei Methoden werden im folgenden eingehender beschrieben.

\subsubsection{UV-Mikroskopie}

Lange (1954) nutzte erstmalig die Absorption von Lignin in Querschnitten von Fichtentracheiden, um den Ligningehalt in verschiedenen Zellwandschichten zu bestimmen. Er wertete dazu UV-Mikrofotografien densitometrisch aus, die bei $280 \mathrm{~nm}$ aufgenommen wurden. In der folgenden Zeit wurde diese Methode von der Arbeitsgruppe um Goring noch verbessert und für eine Vielzahl quantitativer Ligninuntersuchungen in Holz eingesetzt (Scott et al., 1969, Fergus et al., 1969, Fergus und Goring, 1970). Fukazawa und Mitarbeiter modifizierten die Methode, indem sie die Densitometrie durch elektronische Bild-Analyse-Systeme ersetzten (Fukazawa et al., 1981).

Die UV-Mikroskopie wurde auch bereits eingesetzt, um den Ligningehalt in Thermomechanischem Faserstoff (TMP) zu bestimmen (Boutelje und Eriksson, 1984). Peng und Westermark (1997) kombinierten die Messung der Ligninabsorption im UVLicht bei $280 \mathrm{~nm}$ mit Messungen spezifisch markierten Coniferylalkohols und Coniferylaldehyds im sichtbaren Bereich (475 nm beziehungsweise $550 \mathrm{~nm}$ ), um auf diese Weise Anteile dieser reaktiveren Ligninbestandteile in Fichtenholz zu identifizieren. Der Einsatz der quantitativen UV-Mikroskopie ist jedoch begrenzt auf Lignin bekannter 
relativer Zusammensetzung aus den drei Grundbausteinen, da Coniferylalkohol, Sinapylalkohol und Cumarylalkohol jeweils leicht verschobene Absorptionsmaxima im Bereich um $280 \mathrm{~nm}$ besitzen (Fukazawa, 1992). Eine Ligninbestimmung in Laubholz oder in verschiedenen Zellwandschichten unbekannter Zusammensetzung in Nadelholz ist daher mittels dieser Methode nicht durchführbar.

\subsubsection{Interferenz-Mikroskopie}

Die quantitative Interferenz-Mikroskopie von Lignin in situ wurde von Boutelje (1972) eingeführt und wurde bisher ausschließlich von Donaldson eingesetzt (Donaldson, 1985a, Donaldson, 1986, Donaldson, 1991). Die Quantifizierung beruht auf dem Vergleich der Brechungsindizes zweier polarer Lichtstrahlen in gleicher Phase, die das ligninhaltige Präparat beziehungsweise ein Referenzmedium passieren, bevor sie wieder vereinigt werden. Die Interferenz-Mikroskopie beansprucht für sich, die einzige quantitative mikroskopische Technik zu sein, die den Ligningehalt unabhängig von Dickenschwankungen im Präparat und von einer absoluten gravimetrischen Ligninbestimmung angeben kann (Donaldson, 1992). Die Nachteile dieser Methode sind die geringe Auflösung des verwendeten Mikroskops und die aufwendige doppelte Messung eines Gewebeschnitts in zwei Referenzmedien. Ergebnisse von Ligningehalts-bestimmungen mittels Interferenz-Mikroskopie in Laubholz und in Holzwerkstoffen liegen nicht vor.

\subsubsection{Transmissions-Elektronen-Mikroskopie mit elektronendispersiver Röntgenmikroanalyse (TEM-EDXA)}

Die TEM-EDXA ist eine Methode, die zugleich morphologische Untersuchungen und Elementanalysen in sehr kleinen Ausschnitten des Präparates erlaubt. Die Auflösung eines TEM übertrifft diejenige von Licht- und UV-Mikroskop um das 2000fache beziehungsweise 1000fache. Zusätzlich zum TEM wird ein Röntgenstrahlungsdetektor benötigt, dessen Sensor in unmittelbarer Nähe des Präparates in Position gebracht wird. Das ElektronenBombardement von der Kathode des TEM bewirkt im Präparat eine Vielzahl von atomphysikalischen Reaktionen (Marshall, 1980). Elektronenoptisch dichte Bereiche des Präparates absorbieren und reflektieren auftreffende Elektronen. Transmittierte Elektronen erzeugen auf dem Fluoreszenzschirm oder dem Film das TEM-Bild des Präparates. Durch 
auftreffende Elektronen werden aber auch Sekundär-Elektronen aus der Hülle von Atomen im Präparat herausgeschlagen. Elektronen aus äußeren, energiereicheren Orbitalen füllen diese Lücken unter Abgabe ihrer überschüssigen Energie auf. Da Orbitale immer genau definierten Energieniveaus entsprechen, erfolgt diese Abgabe in Quanten, die exakt der Energiedifferenz der zwei beteiligten Orbitale entsprechen. Nachdem ein Silikondetektor die gequantelten Photonen aufgefangen hat, kann ein angeschlossener Computer aus diesen Signalen ein charakteristisches Emissionspektrum für jedes "getroffene" Element erstellen. Die Integration der Emissionsbanden liefert ein relatives Maß für die Konzentration des identifizierten Elementes am untersuchten Ort. Sind an einem Messpunkt mehrere Elemente vorhanden, so erscheinen ihre Emissionsbanden nebeneinander und teilweise auch sich überschneidend. Aufgrund der Detektoreigenschaften ist die Detektion in der Regel auf Elemente beschränkt, die mindestens das Atomgewicht von Natrium besitzen.

Die Konzentration der wichtigsten Nährelemente in unterschiedlichen Zellwandbereichen im Holz wurde bisher in wenigen Arbeiten mittels Röntgenmikroanalyse beschrieben (Saka und Goring, 1983, Saka und Mimori, 1994, Dünisch et al., 1996, Kuhn et al., 1997). Kohlenstoff, Wasserstoff und Sauerstoff sind die einzigen Elemente, aus denen Lignin, aber auch Cellulose und Hemicellulose bestehen. Da diese drei Elemente keinem der drei Grundbausteine des lignifizierten Gewebes zugeordnet werden können, ist eine solche Detektion nicht sinnvoll. Von den üblichen Detektoren wird die Röntgenemission der C-, H- und O-Atome aufgrund ihrer geringen Energiemenge nicht erkannt. Nach spezifischer Markierung mit einem Element höherer Ordnungszahl kann Lignin jedoch lokalisiert und quantifiziert werden. Der Pionier in der Röntgenmikroanalyse von Lignin ist S. Saka. Er veröffentlichte als erster Untersuchungen von Nadelholz und Zellstoff, in denen vor der Röntgenmikroanalyse in Gewebeproben Lignin mit Brom markiert worden war (Saka et al., 1978). In den folgenden Jahren wurde diese Methode von der Arbeitsgruppe um Saka in mehreren richtungsweisenden Untersuchungen angewendet, die einen großen Fortschritt bei der Aufklärung des Ligningehaltes in der Ultrastruktur von Laubholz, Nadelholz und Faserstoff ermöglichten (Saka et al., 1982, Saka und Thomas, 1982, Saka und Goring, 1988, Saka et al., 1988). Zwei weitere Arbeitsgruppen haben bisher die Methode der Bromierung von Lignin für die Röntgenmikroanalyse von Holz und Faserstoff übernommen (Otjen et al., 1988, Fengel et al., 1989). Ein Nachteil dieser Methode besteht in der nicht-stöchiometrischen Addition von Brom an Lignin. Bei der Bromierung verschiedener Zellwandfraktionen einer Holzart wurde eine geringere Reaktivität von 
p-Hydroxyphenylpropan-Lignin im Druckholz der Koniferen festgestellt (Westermark, 1985). Saka schlug deswegen einen Korrekturfaktor vor, der die unterschiedliche Reaktivität der Bausteine ausgleichen kann (Saka et al., 1982). Voraussetzung für die Anwendbarkeit der Bromierung ist dann aber immer noch die genaue Kenntnis der Zusammensetzung des Lignins aus den drei Bausteinen Coniferyl-, Sinapyl- und Cumarylalkohol. Für die Analyse von Laubholz erscheint die Bromierung daher weniger geeignet.

Westermark schlug alternativ die Merkurisierung des Lignins vor (Westermark et al., 1988, Eriksson et al., 1988). Die Merkurisierung ist in der Ligninchemie schon lange bekannt (Freudenberg, 1931). Unter schwach sauren Reaktionsbedingungen erfolgt durch Quecksilberacetat eine elektrophile Substitution am aromatischen Ring der Untereinheiten. Die Bindung zwischen Quecksilberacetat und dem aromatischen Ring ist kovalent und daher auch im Elektronenstrahl des TEM äußerst stabil. Für die Merkurisierung von Fichtenholz und Birkenholz in situ konnte eine stöchiometrische Addition von einem Mol Quecksilberacetat pro Mol C9-Untereinheiten unabhängig von deren weiteren Substituenten nachgewiesen werden (Westermark et al., 1988, Eriksson et al., 1988). Diese Methode empfiehlt sich daher zum quantitativen Nachweis von Zellwandlignin in Nadelholz, aber auch in Laubholz oder zum Nachweis von technischem Lignin unbekannter Substituierung.

\subsection{Ziel der Arbeit}

Aufgabe dieser Dissertation war die Veranschaulichung der Ligninverteilung in gewachsenem Gewebe und in neuartigen Verbundstoffen, die auf der Basis nachwachsender Rohstoffe hergestellt wurden. Unter Einsatz verschiedener licht- und elektronenmikroskopischer Techniken in Verbindung mit der Röntgenmikroanalyse galt es, Lignin in situ zu identifizieren und gleichzeitig zu quantifizieren. Aus dem Vergleich der natürlich gewachsenen Strukturen mit künstlichen Gefügen sollten Rückschlüsse auf die Funktion des Lignins in neuartigen Werkstoffen abgeleitet werden. Im einzelnen wurden folgende fünf Fragestellungen bearbeitet: 


\section{(1) Analyse der Ligninverteilung in gewachsenem Holz}

In zwei ökologisch und ökonomisch wichtigen Holzarten Mitteleuropas sollte die Ligninverteilung im Feinbau der verholzten Zellwand aufgeklärt werden. Gleichzeitig war dabei zu testen, ob die Merkurisierung des Zellwandlignins, die von Westermark und Mitarbeitern (1988) für die Röntgenmikroanalyse von Lignin eingeführt wurde, eine reproduzierbare Methode darstellt.

\section{(2) Biologische Delignifizierung durch Fäulepilze}

Im Frühstadium des Holzabbaues durch Fäulepilze kommt es zu einer Absenkung der mechanischen Stabilität. Untersuchungen der Ultrastruktur und der chemischen Zusammensetzung des pilzinfizierten Holzes sollten die Ursache dieser Materialschwächung herausfinden.

\section{(3) Lokalisierung von Mittellamellen-Lignin in der Leimfuge biotechnologischer Faserplatten}

Die biotechnologische Vorbehandlung von Faserrohstoff erlaubt durch Reaktivierung fasereigener Bindungskräfte die Herstellung von Faserplatten ohne Zugabe eines künstlichen Bindemittels. Hier sollte erstmalig die morphologische und chemische Zusammensetzung dieses neuen Gefüges beschrieben werden.

\section{(4) Lokalisierung von appliziertem Lignin als Bioleim in Spanplatten}

Bei der Zellstoffproduktion fallen große Mengen an technischem Lignin an. Als eine potentielle Verwendungsmöglichkeit dieses Sekundärrohstoffes wird sein Einsatz als enzymaktivierter Bioleim in Holzwerkstoffen getestet. Mikroskopische Analysen sollten Aufschluss über das Verhalten des Lignins auf der Spanoberfläche geben, um die Auftragungsart optimieren zu können.

\section{(5) Lokalisierung von appliziertem Lignin als Imprägnierung von Zellstoff}

Eine weitere Verwendungsmöglichkeit für technisches Lignin nach enzymatischer Aktivierung ist der Einsatz zur Imprägnierung biologisch abbaubarer Folien und Papiere. Die anatomische Struktur dieser neuen Werkstoffe ist gänzlich unbekannt. Die Verteilung des applizierten Lignins auf Filterpapier und Zellstoff-Vlies sollte hier erstmalig mit verschiedenen mikroskopischen Techniken veranschaulicht und quantifiziert werden. 


\section{MATERIAL UND METHODEN}

\subsection{Herkunft des Probenmaterials}

\subsubsection{Buchenholz und Kiefernholz}

Probehölzer aus dem Holz der Rotbuche (Fagus sylvatica) und der Waldkiefer (Pinus sylvestris) mit den Abmessungen 4,5 x 4,5 x 0,5 cm wurden vom Institut für Holz- und Papiertechnik der Technischen Universität Dresden zur Verfügung gestellt. Die Probehölzer wurden aus einem Buchenstamm und aus einem Kiefernstamm aus dem Elbsandsteingebirge mit einem Durchmesser von 30-35 cm zugeschnitten.

\subsubsection{Fichtenholz}

Fichtenholzproben wurde von C. Tomiczek von der Forstlichen Bundesversuchsanstalt Wien/Österreich übersendet. Die Proben stammten aus dem bodennahen Splintholz von Fichten der montanen Standorte Gleinalm (G) und Tamsweg (T) in der Steiermark, Österreich (800-1 600 müNN).

In diesen Beständen traten zu Beginn der 80er Jahre die Schadbilder Nadelvergilbung und Kronenverlichtung auf. Klimatische und edaphische Faktoren konnten als Verursacher dafür ausgeschlossen werden (Smidt und Leitner, 1991, Majer et al. 1989). Im bodennahen Splintholz wurde bei allen untersuchten Fichten, die im Kronenbereich die Schadbilder zeigten, ein Befall mit dem Erreger der Rotfäule Heterobasidion annosum nachgewiesen (C. Tomiczek, 1995 und persönliche Mitteilung ).

\subsubsection{Industriefasern und Bioleim-Faserplatten}

Freie Fasern aus thermomechanisch aufgeschlossenen Hackschnitzeln (80\% Fichte und Kiefer, 20\% Buche) wurden von der Firma Bestwood, Ribnitz-Damgarten bezogen. Aus diesen Fasern wurden ohne Zugabe von Bindemitteln Mitteldichte Faserplatten (MDF) hergestellt (Kharazipour et al., 1997). Die Besonderheit dieses Verfahrens (Deutsches 
Patent P 4305 411, 1993) beruht auf der Reaktivierung der Oberflächenkohäsion der freien Fasern durch Laccase (EC 1.10.3.2) oder Manganperoxidase (EC 1.11.1.7). Beide Enzyme, wurden aus Kulturen des Weißfäulepilzes Trametes versicolor isoliert und sind kommerziell erhältlich (NOVO-NORDISK, Bagsvaerdt, Dänemark).

Im Nassverfahren wurde Faserstoff in gepufferter Laccaselösung beziehungsweise in enzymfreier Pufferlösung inkubiert und anschließend $\mathrm{zu}$ MDF verpresst. Im Trockenverfahren wurde Faserstoff mit gepufferter Laccaselösung, gepufferter Peroxidaselösung beziehungsweise enzymfreier Pufferlösung besprüht, inkubiert und anschließend verpresst.

Proben von den drei Platten aus enzymatisch vorbehandeltem Fasermaterial und von den zwei Kontrollplatten aus nicht enzymatisch vorbehandeltem Fasermaterial wurden von A. Kharazipour für die röntgenmikroanalytische Untersuchung zur Verfügung gestellt.

\subsubsection{Lignifizierte Späne und Bioleim-Spanplatten}

Deckschichtspäne mit einer Dicke von 0,2-0,4 mm wurden von der Firma Pfleiderer, Arnsberg, bereitgestellt. In zwei parallelen Ansätzen wurden die Späne mit 10\% reinem Bioleim beziehungsweise mit 10\% Bioleim und 1\% Phenylmethan-Diisocyanat (PMDI) beleimt. Der Bioleim aus $80 \%$ Kraft-Lignin (Indulin AT, Westvaco, Raleigh, USA) und 20\% Ligninsulfonat (Wafex-122, Holmen, Karlsruhe) in wässriger Suspension war zuvor durch Inkubation mit pilzlicher Laccase reaktiviert worden (Kharazipour, 1996). Aus den beleimten Spänen wurden im Laborversuch zwei Spanplatten gepresst, die von A. Kharazipour für die Röntgenmikroanalyse zur Verfügung gestellt wurden.

\subsubsection{Lignifiziertes Filterpapier}

Laborübliches Filterpapier ( 2 x 3 cm, Ref. Nr. 334887, Schleicher und Schüll, Dassel) wurde von M. Schröter nach dem von ihm entwickelten Tauchverfahren (Schröter, 1998) mit Laccase-aktiviertem Ligninsulfonat (Calcium-Ligninsulfonat Wafex-122, Holmen, Karlsruhe) beschichtet. Nach einem Waschschritt mit 0,1 N NaOH blieb etwa die Hälfte des

gebundenen Lignins auf dem Filterpapier haften. Dem entsprach eine 
Gewichtszunahme des Filterpapiers durch Lignin um $10 \%$ des ursprünglichen Trockengewichtes. Als Kontrolle diente nicht-lignifiziertes Filterpapier.

\subsubsection{Lignifiziertes Sulfitzellstoff-Vlies}

Fichtenzellstoff aus dem Sulfitverfahren wurde von der Firma Philip Holzmann, Karlsruhe, geliefert. M. Schröter stellte nach seiner Methode (Schröter, 1998) aus dem Zellstoff Vliese her. Der Zellstoff wurde mit Ligninsulfonat (Calcium-Ligninsulfonat Wafex-122, Holmen, Karlsruhe) und gepufferter Laccase-Lösung für 6 h inkubiert. Nach der Inkubation wurde der Zellstoff abgenutscht. Das entstandene Vlies (Durchmesser $7 \mathrm{~cm}$ ) wurde mit einer Handwalze ausgedrückt und im Ofen $\left(100{ }^{\circ} \mathrm{C}\right)$ getrocknet. Nicht gebundenes Lignin wurde mit $0,1 \mathrm{~N} \mathrm{NaOH}$ abgewaschen. Zur Kontrolle wurde ein Vlies ohne Lignin-LaccaseVorbehandlung des Zellstoffs hergestellt.

\subsection{Inkubation von Probehölzern mit Weiß- und Braunfäulepilzen}

Zwischen dem Institut für Forstbotanik der Universität Göttingen, dem Institut für Holz- und Papiertechnik der Technischen Universität Dresden und der Faculty of Agriculture der Hebrew University Rehovot/Israel bestand eine Zusammenarbeit im Rahmen des DFG-Forschungsprojektes "Mechanismen der mykologischen Transformation von Holz für die Holzwerkstoffherstellung". Ziel dieses Forschungsprojektes war es, Veränderungen in der Beschaffenheit und Verarbeitbarkeit von Holz in der Frühphase des Abbaues durch Fäulepilze zu untersuchen.

In Göttingen wurden mikroskopische und chemische Analysen des infizierten Holzes durchgeführt und physiologische Parameter des Pilzwachstums gemessen. Die Ergebnisse dieser Untersuchungen wurden im Rahmen dieser Dissertation hier beschrieben und diskutiert. In Dresden wurden die holzmechanischen und werkstofftechnischen Eigenschaften des infizierten Holzes untersucht. Die Arbeitsgruppe der Faculty of Agriculture in Rehovot analysierte in einem eigens dafür 
entwickelten Verfahren die Veränderung der Aktivität pilzlicher Enzyme des Ligninstoffwechsels.

In Göttingen wurde zunächst ein Versuchssystem zur kontrollierten Infektion von Holz mit Fäulepilzen entwickelt und die Auswahl geeigneter Pilze (Screening) für einen gemeinsamen Versuch der drei Arbeitsgruppen getroffen. Die Inkubation mit Fäulepilzen innerhalb dieses Versuches wurde in Göttingen durchgeführt. Parallele Proben wurden nach der Ernte auch an die Arbeitsgruppen in Dresden und Rehovot weitergeleitet.

\subsubsection{Screening}

In einem Vorversuch mit Wiederholung wurden 31 Basidiomyceten aus der Stammkultursammlung des Instituts für Forstbotanik auf ihre holzabbauenden Eigenschaften getestet. Von den getesteten Pilzen erregen 19 Stämme Weißfäule und 12 Stämme Braunfäule (Tab.1). Als Auswahlkriterium wurde eine möglichst große Scherfestigkeitsabnahme infizierter Probehölzer nach drei Wochen Inkubation festgelegt. Die Scherfestigkeit ist ein proportionales Maß für den Energieaufwand bei der Zerfaserung der Hackschnitzel im Refiner (Wagenführ, 1988). Außerdem wurden

die Schnellwüchsigkeit der Pilze auf Malzagar und auf Probehölzern und der Gewichtsverlust der Probehölzer nach dreiwöchiger Inkubation gemessen.

\section{Anzucht}

Die Pilzkulturen wurden in Kulturschalen (Durchmesser $14 \mathrm{~cm}$, aus Polystyrol, Greiner) auf 2\% Agar (Bacto-Agar, Difco, Detroit, USA) mit 4\% Malzextrakt (Difco, Detroit, USA) angeimpft und bei $30{ }^{\circ} \mathrm{C}$ und gesättigter Luftfeuchtigkeit angezogen, bis das Mycel die gesamte Oberfläche überwachsen hatte. 
Tabelle 1

\section{Screening}

Es wurde der Befall von Buchen- und Kiefernprobehölzern durch 19 Weißfäulepilze und 12 Braunfäulepilze aus der Stammkultursammlung des Instituts für Forstbotanik getestet.
Nr. Name
1 Polyporus pinsitus
21 Pycnoporus sanguineus
48 Schizophyllum commune
76 Kuehneromyces mutabilis
174 Stereum hirsutum
511 Lentinula edodes
520 Stereum purpureum
521 Stereum sanguinolentum
6 Trametes versicolor 1
32 Fomes fomentarius
44 Ganoderma applanatum
141 Trametes hirsuta
522 Trametes versicolor IV
3 Merulius tremellosus
8 Pleurotus ostreatus
15 Bjerkandera adusta
101 Dichomitus squalens
121 Heterobasidion annosum
507 Phanerochaete chrysosporium

\section{Laetiporus sulphureus}
95 Piptoporus betulinus
166 Daedalea quercina
512 Gloeophyllum trabeum
513 Coniophora puteana
514 Serpula lacrymans
515 Gloeophyllum sepiarium
516 Coniophora arida
517 Poria vaporaria
518 Trametes serialis
519 Lentinus lepideus
523 Fomitopsis pinicola

Erstbeschreiber

Fr.:Fr.

(L.: Fr.) Murrill

Fr.: Fr.

(Schaeffer: Fr.) Singer

(Willd.:Fr.) S.F. Gray

(Berk.) Pegler

Pers.:Fr.

(Alb. \& Schw.: Fr.) Fr.

(L.:Fr.) Lloyd

(L.: Fr.) Fr.

(Pers.) Pat.

(Wulfen:Fr.)Lloyd

(L.:Fr.) Lloyd

Schrad.:Fr.

(Jacquin: Fr.), Kummer

(Willd.: Fr.) Karst.

(Karst.) Ried

(Fr.:Fr.) Bref.

Burdsall

\author{
Fäuleart \\ WF \\ WF \\ WF \\ WF \\ WF \\ WF \\ WF \\ WF sim \\ WF sim \\ WF sim/sel \\ WF sim \\ WF sim \\ WF sel \\ WF sel \\ WF sel \\ WF sel/sim \\ WF sel \\ WF sel
}

$\begin{array}{ll}\text { (Bull.: Fr.) Murrill } & \text { BF } \\ \text { (Bull.: Fr.) Karst.. } & \text { BF } \\ \text { L.: Fr. } & \text { BF } \\ \text { (Pers.: Fr.) Murril } & \text { BF } \\ \text { (Schum.: Fr.) Karst. } & \text { BF } \\ \text { (Wulf. ap. Jacq.: Fr.) Sch. } & \text { BF } \\ \text { (Wulf.: Fr.) P. Karst. } & \text { BF } \\ \text { (Fr.) P. Karst. } & \text { BF } \\ \text { (Pers.:Fr.) Cooke } & \text { BF } \\ \text { (Fr.:Fr.) Fr. } & \text { BF } \\ \text { (Fr.:Fr.) Fr. } & \text { BF } \\ \text { (Sw.: Fr.) P. Karst. } & \text { BF }\end{array}$

Legende:

Nr.: Nummer in der Stammkultursammlung des Instituts für Forstbotanik simWF: simultane Weißfäule selWF: selektive Weißfäule

BF: Braunfäule 
Probehölzer aus Buchen- und

Kiefernholz derselben Herkunft wie in

2.1 wurden in Wasser vorgequollen und anschließend autoklaviert. Danach besaßen die Probehölzer eine Holzfeuchte von 40-60\% bezogen auf das Trockengewicht. Vor dem Einbringen der Probehölzer in die Kulturschalen wurden sterilisierte Glasstäbchen als Abstandhalter auf das Mycel aufgelegt. Von jeder Pilzkultur wurden für jede Holzart zwei Kulturschalen mit jeweils vier Probehölzern pro Kulturschale bestückt. Die Inkubation erfolgte über 21 Tage bei $30{ }^{\circ} \mathrm{C}$ und gesättigter Luftfeuchtigkeit (Abb.3).

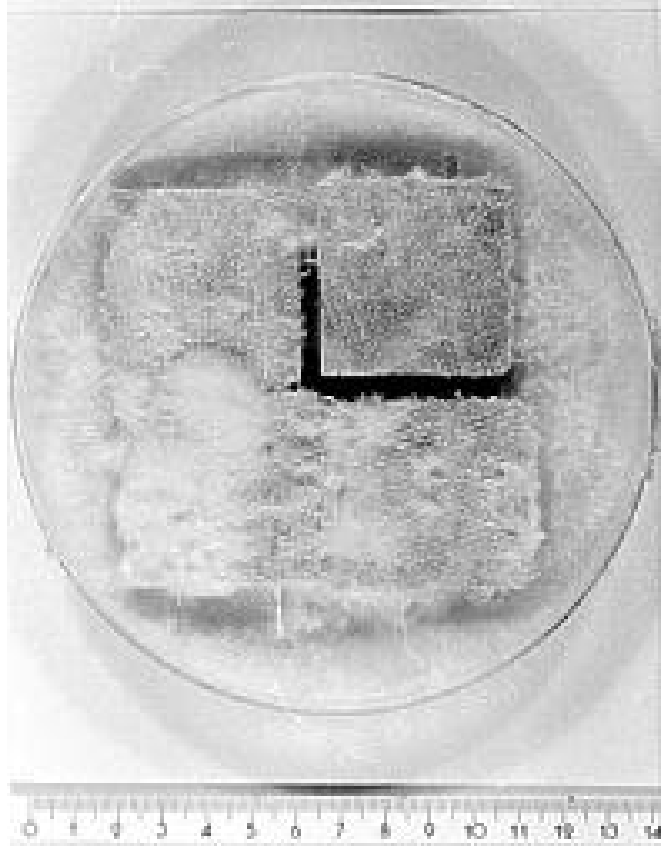

\section{Abbildung 3}

Kulturschale mit vier Probehölzern aus Kiefernholz über Malzagarkultur des Weißfäulepilzes Dichomitus squalens aus dem Screening (Skala in $\mathrm{cm}$ )

\section{Ernte und Transport}

Nach der Inkubation wurden die Probehölzer abgenommen, darrgetrocknet $\left(60{ }^{\circ} \mathrm{C}, 48 \mathrm{~h}\right)$, gewogen und zur Bestimmung der Scherfestigkeit nach Dresden versendet.

\subsubsection{Zeitlicher Verlauf der Infektion von Holz mit Fäulepilzen}

Die Pilze, die im Screening die größte Abnahme der Scherfestigkeit in Buchen- und Kiefernholz verursacht hatten (siehe 3.2), wurden in einem weiteren Versuch eingesetzt, um den zeitlichen Verlauf der Infektion in den ersten drei Wochen näher zu untersuchen. Die Inkubation wurde unter den Bedingungen wie im Screening (2.2.1) mit wenigen Änderungen durchgeführt. Die Probehölzer wurden anders als im Vorversuch nicht 
autoklaviert, sondern pasteurisiert $\left(3 \times 2 \mathrm{~h}, 65^{\circ} \mathrm{C}\right)$, um in Hinblick auf die Anwendbarkeit des Verfahrens in größerem Maßstab den Energieaufwand zu reduzieren. Während bei der Auswahl geeigneter Pilze auch Kiefernkernholz eingesetzt wurde, fand nun ausschließlich Splintholz Verwendung, da Inhaltsstoffe des Kernholzes eine fungizide Wirkung haben können. Dieser Effekt war wahrscheinlich für das inhomogene Befallsbild verantwortlich, das im Screening auf manchen Kiefernhölzern beobachtet wurde.

Für jeden Erntetag, jede Holzart und jeden Pilz wurden 24 Probehölzer angeimpft. Es wurden nach 5, 9, 13, 17 und 21 Tagen Probehölzer geerntet. Nach der Ernte wurden jeweils 10 Probehölzer darrgetrocknet, gewogen und an das Institut für Holz- und Papiertechnik nach Dresden versendet. Weitere 12 Probehölzer wurden in flüssigem Stickstoff tiefgefroren und in gefrorenem Zustand nach Israel transportiert. Die verbleibenden 2 Probehölzer jeder Behandlungsvariante wurden im Institut für Forstbotanik in Göttingen mikroskopisch, chemisch und physiologisch untersucht.

\subsection{Mikroskopie}

2.3.1 Transmissions-Elektronen-Mikroskopie (TEM) und Röntgenmikroanalyse (Electron Dispersive X-Ray Analysis, EDXA) von Holz und Holzwerkstoffen

\section{Spezifische Markierung des Lignins in situ}

Um Lignin mit der Röntgenmikroanalyse in Gewebeschnitten detektieren zu können, wurde es nach der Methode von Westermark und Mitarbeitern (1988) mit Quecksilber markiert. Dazu wurden aus Holz, pilzinfiziertem Holz und Holzwerkstoffen mit einer Rasierklinge Stifte mit den Maßen 1 x 1 x 5 mm zurechtgeschnitten. Jeweils $10 \mathrm{mg}$ dieses Materials wurden in $6 \mathrm{ml}$ Methanol (Merck, Darmstadt) mit $8 \mathrm{mg}$ Quecksilberacetat (HgAc, p.a., Fluka, Neu-Ulm) und $250 \mathrm{ml}$ Eisessig (Merck, Darmstadt) $8 \mathrm{~h}$ bei $95{ }^{\circ} \mathrm{C}$ inkubiert. Überschüssiges Quecksilber wurde durch Methanol-Soxhlet-Extraktion in mindestens 25 Zyklen entfernt.

\section{Einbettung}

Zur Einbettung wurde ein Methacrylat-Medium verwendet. Dieses Medium eignet sich aufgrund seiner geringen Viskosität besonders zur Infiltration von Holzproben 
(Dawes, 1988). Das Medium wurde stets frisch aus $1 \mathrm{~g}$ Dibenzoylperoxid (Fluka, NeuUlm),

$25 \mathrm{ml}$ Styrol (Merck, Darmstadt) und $25 \mathrm{ml}$ Butyl-Methacrylat (Fluka, Neu-Ulm) angemischt. Die merkurisierten Stifte wurden aus reinem Methanol über Zwischenschritte (1:3, 3:1, 2x 0:1, jeweils 24 h) in das Einbettungsmedium überführt. In Gelatinekapseln wurde das Medium bei $60^{\circ} \mathrm{C}$ in 7 Tagen ausgehärtet.

Bei der Präparation von Proben zur Röntgenmikroanalyse der natürlichen Ionengehalte musste jeder Kontakt mit hydrophilen Lösungsmitteln vermieden werden. Nach der Methode von Fritz (1989) wurden die Holzstifte daher über Nacht unter Druck in Diethylether (p.a., Merck, Darmstadt) gequollen. Ether wurde schrittweise durch Einbettungsmedium (1:3, 3:1, 2x 0:1, jeweils 24 h) ersetzt. Die Polymerisation des Einbettungsmediums erfolgte in Gelatinekapseln bei $60{ }^{\circ} \mathrm{C}$ in 7 Tagen.

Proben der Mitteldichten Faserplatten wurden nach der Merkurisierung von Methanol schrittweise in Spurr's Medium (1:3, 3:1, jeweils 12 h, 2x 0:1, jeweils 24 h) (Spurr, 1969) überführt. Dieses Medium wird aus vier teilweise sehr viskosen Komponenten angemischt. Eingewogen wurden 26 g Nonenylbernsteinsäureanhydrid (NSA, Serva, Heidelberg), $10 \mathrm{~g}$ Vinylcyclohexendioxid (VCD, Serva, Heidelberg), 4,5 g Polypropylenglykol-Diglycidylether (DER 736, Serva, Heidelberg) und 0,5 g Dimethylaminoethanol (DMAE, Serva, Heidelberg). Das Medium wurde in Aluminiumförmchen über Calciumchlorid (Merck, Darmstadt) als Trocknungsmittel bei $70{ }^{\circ} \mathrm{C}$ in $20 \mathrm{~h}$ ausgehärtet.

\section{Ultramikrotomie}

Glasmesser ( $45^{\circ}, 5 \mathrm{~mm}$ ) wurden aus Spezialglas (PKT 130, Leica, Wetzlar) an einem Messerbrecher (Knifemaker 7800, LKB, Bromma, Schweden) gebrochen. Kupfernetzchen (hexagonal, 100 mesh, 3,05 mm, Plano, Wetzlar) wurden vor ihrem Einsatz als Objektträger mit Formvar (Polyvinylformal 1595 E, Serva, Heidelberg) befilmt (Dawes, 1988) oder in Klebstoff-Lösung (Fritz, 1991) getaucht.

Von den eingebetteten Proben wurden mit Glasmessern oder mit einem Diamantmesser (Histo, $6 \mathrm{~mm}, 45^{\circ}$, DH 4560, Diatome, Biel, Schweiz) Semi-dünnschnitte $(1 \mu \mathrm{m})$ an einem Ultramikrotom (Ultracut E, Reichert-Jung) angefertigt. Merkurisierte Gewebeschnitte wurden mit formvarbeschichteten Kupfernetzchen von der Wasseroberfläche hinter der Messerkante abgefangen. Zur Ionenanalyse wurden die 
eingebetteten Proben trocken geschnitten und die Gewebeschnitte auf klebrigen Kupfernetzchen befestigt. Im Vakuum wurden die Gewebeschnitte mit Kohle bedampft (Mikro-Bedampfanlage, Balzers).

TEM

Die Gewebeschnitte wurden mit einem EM 420 (Philips, Niederlande) betrachtet. Es wurde ein low background holder PW 6597 (Philips, Niederlande) verwendet. Mikrofotos wurden mit der eingebauten Kamera auf 8,1 x $10 \mathrm{~cm}$ Negativ-Filmen (EM Ilford, Mobberley, GB) gemacht. Die Negativ-Filme wurden 4 min entwickelt (Entwickler Gevaline G7c, AGFA, Gevaert, Belgien), 2 min gewässert und 4 min fixiert (Superfix, Tetenal, Norderstedt).

\section{Die Identifizierung und Quantifizierung von Lignin mittels TEM-EDXA}

Zur Röntgenmikroanalyse wurde als Zusatz zum Transmissions-ElektronenMikroskop (EM 420, Philips, Eindhoven, Niederlande) ein angebauter Detektor (EDAX 4100, EDAX, Prairie View, USA) verwendet. Für Einzelmessungen und Messreihen wurden immer dieselben Geräteeinstellungen des TEM (Spannung 120 kV, Emission 5, Vergrößerung 6350fach, Durchmesser des Elektronenstrahls im Präparat $250 \mathrm{~nm}$ ) und des Detektors (Nähe und Winkel zum Präparat, Messdauer $30 \mathrm{~s}$ ) beibehalten. Bei der Analyse von merkurisierten Proben wurde das Röntgenemissionsspektrum von Quecksilber und Kupfer im Bereich von $0 \mathrm{keV}$ bis $16 \mathrm{keV}$ detektiert (Abb.4). Das $\mathrm{Cu}-\mathrm{K} \alpha$-Signal $(8,0 \mathrm{keV})$ und das $\mathrm{Cu}-\mathrm{K} \beta$-Signal $(8,9 \mathrm{keV})$ wurden durch Emission des Objektträgers verursacht, sie überschnitten sich jedoch nicht mit den Hg-M $\alpha-(2,2 \mathrm{keV}), \mathrm{Hg}-\mathrm{M} \beta-(2,3 \mathrm{keV}), \mathrm{Hg}-\mathrm{L} \alpha-(10,0 \mathrm{keV}), \mathrm{Hg}-\mathrm{L} \beta-$ $(11,8 \mathrm{keV})$ und $\mathrm{Hg}-\mathrm{L} \gamma-(13,8 \mathrm{keV})$ Signalen. Für die quantitative Auswertung wurde das $\mathrm{Hg}$-L $\alpha$-Signal herangezogen, weil in diesem Bereich des Spektrums das Hintergrundrauschen am geringsten war.

\section{Einzelmessung}

Der Durchschnittswert der Fläche des Hg-L $\alpha$-Signals einer Messung von $30 \mathrm{~s}$ wurde von der Systemsoftware (RT11 Operating System, EDAX, Prairie View, USA) integriert und in counts per second (cps) ausgegeben. Mikrofotos der untersuchten Bereiche dienten zur Dokumentation von Einzelmessungen. 


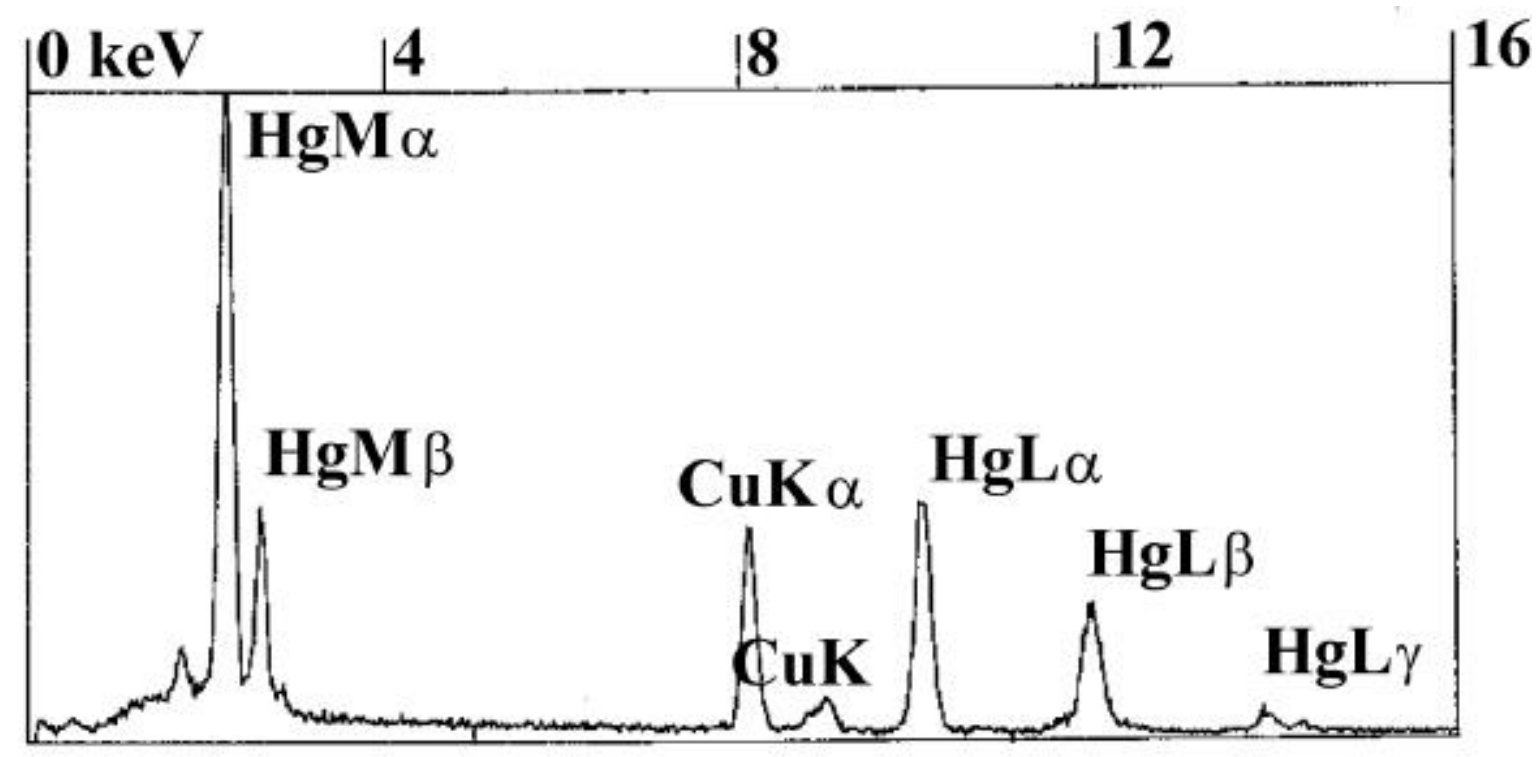

\begin{abstract}
Abbildung 4
Röntgenemissionsspektrum in Kiefernholz

In der Mittellamelle zwischen drei Tracheiden (Zellecke) wurden nach Anregung durch den

Elektronenstrahl des TEM die Cu-K-Emissionsbanden des kupfernen Objektträgers und die Hg-M- und HgL-Emissions-banden des merkurisierten Zellwandlignins detektiert. Das Hg-L $\alpha$-Signal wurde zur quantitativen Bestimmung des Lignins in situ ausgewertet.
\end{abstract}

\title{
Messreihen
}

Zum quantitativen Vergleich der Ligningehalte verschiedener morphologischer Regionen in Holz, in pilzinfiziertem Holz und in Faserplatten wurden in jedem Gewebe Referenzorte bestimmt, an denen die Hg-L $\alpha$-Röntgenemission gemessen wurde. Von jeder Behandlungsvariante und Kontrolle wurden vier individuelle Gewebeschnitte untersucht. In jedem Gewebeschnitt wurden fünf Messungen an gleichen Referenzorten gemacht. Die Summe der Hg-L $\alpha$-Peakflächen dieser fünf Messungen wurde von der Systemsoftware (RT11 Operating System, EDAX, Prairie View, USA) integriert und in counts per second (cps) ausgegeben. Die Berechnung der Summe aus den fünf Einzelmessungen führte zum Verlust der Information über die Abweichung vom Mittelwert der fünf Einzelmessungen in einem Schnitt. Dieser Verlust wurde akzeptiert, weil auf diese Weise die Rechengeschwindigkeit des prozessierenden Computers (Baujahr 1984) um den Faktor 5 beschleunigt wurde. Aus den Summenwerten der vier untersuchten Schnitte wurden der Mittelwert und die Standardabweichung für den Ligningehalt an den Referenzorten berechnet.

In Holz und in pilzinfizertem Holz wurde in jedem Schnitt zusätzlich an fünf Stellen im Einbettungsmedium neben dem Gewebe das Hintergrundrauschen im Fenster von 
5,3 keV bis 5,5 keV bestimmt. Der Summenwert der Signalstärke des Hintergrundrauschens in diesem Bereich diente als proportionales Maß für die jeweilige Schnittdicke (Roomans, 1980). Für jeden Schnitt konnte auf diese Weise ein Eichfaktor berechnet werden, mit dessen Hilfe der Summenwert des $\mathrm{Hg}-\mathrm{L} \alpha$-Signal für eine mittlere Standardschnittdicke korrigiert wurde.

In Spurr's Medium sind Spuren von Chlor enthalten, die als interner Standard zur Bestimmung der Schnittdicke ausgewertet werden können. Bei der Messung der merkurisierten Proben von Faserplatten wurde deswegen nicht das Hintergrundrauschen im Fenster von 5,3 bis 5,5 keV für die Ermittlung des Eichfaktors für die mittlere Standardschnittdicke herangezogen, sondern der Summenwert des Chlor-K-Signals im Einbettungsmedium bei 2,6 keV.

\section{TEM-EDXA Ionenmessung}

Elemente mit der Ordnungszahl 11 und größer wurden über die K-Hauptlinien ihres Röntgenemissionsspektrums identifiziert. Die Signalstärke der Röntgenemission von $\mathrm{Mg}, \mathrm{K}, \mathrm{Ca}$ und $\mathrm{Mn}$ wurde nach der für das benutzte TEM-EDXA-System veröffentlichten Eichung (Fritz und Jentschke, 1994, nach Cliff und Lorimer, 1975) in molare Konzentrationen im Gewebe umgerechnet. Die Eichung berücksichtigte die jeweilige Schnittdicke durch Messung des Hintergrundrauschens in gewebefreiem Einbettungsmedium im Fenster von 5,3 keV bis 5,5 keV. In jedem Schnitt wurde die durchschnittliche Elementkonzentration an gleichen Referenzorten aus fünf Einzelmessungen bestimmt. Angegeben sind jeweils der Mittelwert und die Standardabweichung aus der durchschnittlichen Elementkonzentration in vier individuellen Schnitten.

\subsubsection{Lichtmikroskopie (LM)}

Für die Lichtmikroskopie wurden mit einem Stahlmesser (C-Messer, $18 \mathrm{~cm}$, Leica, Nussloch) Gefriermikrotomschnitte $(25 \mu \mathrm{m})$ frischer Proben oder mit einem Glasmesser Semidünnschnitte $(1 \mu \mathrm{m})$ eingebetteter Proben angefertigt. Die Mikrotomschnitte wurden mit Toluidinblau $(0,1 \%$ in $0,2 \mathrm{M}$ Phosphatpuffer, $\mathrm{pH} 7$; Toluidinblau von Merck, Darmstadt) angefärbt und im Lichtmikroskop (Zeiss) betrachtet. Mikrotomschnitte wurden mit einer angebauten 35mm-Kamera mit 
Belichtungsautomatik (MC63) auf S/W-Filmen (AGFA PanX 25, AGFA, Gevaert, Belgien) dokumentiert.

\subsubsection{Raster-Elektronen-Mikroskopie (Scanning Electron Microscopy, SEM)}

Spanplattenproben wurden mit einer verkanteten Rasierklinge aufgebrochen. Filterpapier und Sulfitzellstoff-Vlies wurden mit einer Rasierklinge quergeschnitten oder nach Tieffrieren in flüssigem Stickstoff gebrochen. Alle untersuchten Holzwerkstoffe wurden bei $50{ }^{\circ} \mathrm{C} 24 \mathrm{~h}$ getrocknet, auf Objektträger geklebt und mit Gold beschichtet (SC 500, Emscope Lab., Ashford, GB). Die Betrachtung der Proben erfolgte mittels eines SEM 515 (Philips, Eindhoven, Niederlande). SEM-Mikrofotos wurden mit einer angebauten 35mm-Kamera mit Farb-Diapositiv-Filmen (Ektachrome 100HC, Kodak) aufgenommen. Die mittlere Oberflächenbedeckung von beleimten Spänen wurde mit WinRhizo-Software 3.6d (Regent Instrument Inc., Quebec, Kanada) quantifiziert. Es wurden dazu 8 Flächen von 200 x $300 \mu \mathrm{m}$ ausgewertet.

\subsection{Analyse chemischer, mechanischer und physiologischer Parameter pilzinfizierter Probehölzer}

Von Probehölzern, die der kontrollierten Infektion ausgewählter Fäulepilze ausgesetzt waren (vgl. 2.2), wurden der Ligningehalt, die Scherfestigkeit und die $\mathrm{CO}_{2^{-}}$und Wärmeproduktion bestimmt.

\subsubsection{Klason-Lignin-Bestimmung}

Es wurde das säureunlösliche Lignin (Klason-Lignin) der Probehölzer nach der Methode von Effland (1977) bestimmt. Diese Methode ist speziell für kleine Mengen Lignocellulose geeignet. Probehölzer wurden mit einer Zange vorzerkleinert und in einer Schwingmühle (Typ MM2, Retsch) feingemahlen. Anschließend wurde das Holzmehl gesiebt (Maschenweite 0,85 mm). Zur Entfernung störender Holzinhaltsstoffe folgten eine Soxhlet-Extraktion mit Ethanol:Cyclohexan 1:1 für 60 min und Waschschritte mit Ethanol und Aceton. 


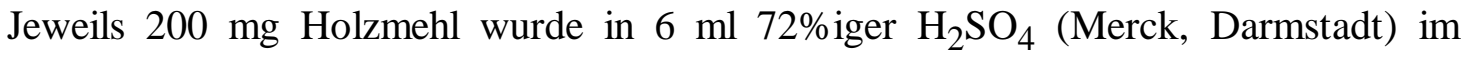
Wasserbad bei $30{ }^{\circ} \mathrm{C}$ für 60 min unter Schütteln hydrolysiert. In parallelen Proben des Holzmehls $(2 \times 50 \mathrm{mg})$ wurde die relative Holzfeuchte zum Zeitpunkt der Einwaage bestimmt. Mit Hilfe der relativen Holzfeuchte wurde das Trockengewicht des Holzmehls berechnet, das für die Hydrolyse eingewogen worden war. Anschließend wurde der Reaktionsansatz mit $84 \mathrm{ml}$ doppelt destilliertem Wasser verdünnt, so dass eine 2,4\%ge $\mathrm{H}_{2} \mathrm{SO}_{4}$-Konzentration eingestellt war. Zur vollständigen Hydrolyse wurden die Ansätze autoklaviert $\left(120{ }^{\circ} \mathrm{C}, 60 \mathrm{~min}\right)$. Das Hydrolysat wurde in Glasfiltertiegeln (50 ml, 40 mm Durchmesser, Porösität 3, Duran, Schott, Mainz), die mit einem zusätzlichen Glasfaserfilter (GF 92, Schleicher und Schuell, Dassel) ausgelegt waren, abgenutscht und fünfmal mit kochendem Wasser ausgewaschen. Die Glasfiltertiegel wurden bei $100{ }^{\circ} \mathrm{C} 24 \mathrm{~h}$ getrocknet und in Exsikkatoren abgekühlt. Das Gewicht des auf dem Filter zurückgehaltenen Lignins wurde auf einer Analysenwaage auf $0,0 \mathrm{mg}$ genau bestimmt. Das Gewicht des Lignins dividiert durch das Trockengewicht des eingesetzten Holzmehls ergab den Ligningehalt. Von jedem Ansatz wurden Doppelbestimmungen durchgeführt, von denen der Mittelwert angegeben wurde.

\subsubsection{Gewichtsverlustbestimmung}

Als ein Parameter des Holzabbaues durch Fäulepilze wurde der Trockengewichtsverlust jedes inkubierten Probeholzes berechnet. Das Anfangstrockengewicht der Probehölzer wurde indirekt bestimmt, um ein Darrtrocknen der Probehölzer und damit verbundene Verhornungserscheinungen zu vermeiden. Alle Probehölzer wurden vor dem Quellen gewogen (lutro). Je Holzart wurden 10 Probehölzer darrgetrocknet (atro) und die mittlere Holzfeuchte der Charge berechnet. Durch Abzug der mittleren Holzfeuchte wurde auf das theoretische Anfangstrockengewicht $\left(\mathrm{ATG}_{\mathrm{t}}\right)$ jedes Probeholzes zurückgerechnet. Die Differenz des theoretischen Anfangstrockengewichtes und des Endtrockengewichtes (ETG) nach der Inkubation (atro) bezogen auf das theoretische Anfangstrockengewicht ergab den Gewichtsverlust (GV):

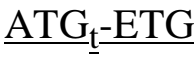

$\mathrm{ATG}_{\mathrm{t}} \quad \mathrm{x} 100 \%=\mathrm{GV}$ 


\subsubsection{Scherfestigkeitsbestimmung}

Die Scherfestigkeit der Probehölzer wurde mit einer Prüfmaschine nach Wagenführ (1988) von Dipl.-Ing. H. Unbehaun und Dipl.-Ing. M. Wolff am Institut für Holz- und Papiertechnik in Dresden gemessen. Die Messungen erfolgten in einer ZwickUniversalprüfmaschine, in die ein spezielles Werkzeug integriert wurde, bei dem ein kreisförmiger Stempel die Prüfkraft senkrecht zur Hirnfläche des Probeholzes aufbringt. Wegen der gleichwertigen Einbeziehung von Radial- und Tangentialbruch berücksichtigt diese Messmethode in besonderer Weise die Anisotropie des Holzes. Im

Screening (2.2.1) wurde die Scherfestigkeit von 8 Buchen- und Kiefernprobehölzern je Behandlungsvariante bestimmt. Im folgenden Experiment, das den zeitlichen Verlauf der Pilzinfektion untersuchte (2.2.2), wurde die Scherfestigkeit von jeweils 10 Probehölzern pro Ansatz und Erntetag gemessen. Angegeben wurden der Mittelwert und die Standardabweichung der parallelen Messungen.

\subsection{4 $\mathrm{CO}_{2}$-Produktion}

Pilzinfiziertes Probeholz (100-200 mg Frischgewicht) wurde in gasdichten Reagenzgläsern bei $30{ }^{\circ} \mathrm{C} 24 \mathrm{~h}$ inkubiert. Unter gleichzeitiger Verdrängung durch Wasser wurde eine Gasprobe von $20 \mathrm{ml}$ abgenommen. Davon wurden jeweils $10 \mathrm{ml}$ in den Gaschromatographen ( HP 5890 Series II mit HP 3396A Integrator, Hewlett Packard, Avondale, USA) injiziert. Mittels eines Wärmeleitfähigkeitsdetektors (TCD) wurde die prozentuale Zusammensetzung der Gasprobe aus $\mathrm{N}_{2}, \mathrm{O}_{2}$ und $\mathrm{CO}_{2}$ analysiert. Die $\mathrm{CO}_{2}$-Menge, die während $24 \mathrm{~h}$ Inkubation freigesetzt wurde, wurde umgerechnet in die $\mathrm{CO}_{2}$-Produktion in Mikromol pro Gramm Trockengewicht des inkubierten Holzes pro Stunde. Von jedem Ansatz wurden Doppelbestimmungen durchgeführt, deren Mittelwert angegeben wurde. 


\subsubsection{Wärmeproduktion}

Die Wärmeproduktion von pilzinfiziertem Holz wurde mit einem Mikrokalorimeter (Thermal Activity Monitor 2277, Thermometric, Schweden) gemessen. Pilzinfiziertes Probeholz (50-100 mg Frischgewicht) wurde in gasdichten Messfläschchen ins Kalorimeter eingebracht. Nach fünfzehnminütiger Äquilibrierung bei $25{ }^{\circ} \mathrm{C}$ wurde die Probe in die Messposition vorgerückt. Als Messwert diente der Plateauwert, der sich nach 3 h einstellte. Die Messung wurde gegen nicht-infiziertes Holz im zweiten Messkanal geeicht. Die Wärmemenge wurde auf das Trockengewicht des eingesetzten Holzes bezogen. Von jedem Ansatz wurden Doppelbestimmungen durchgeführt, deren Mittelwert angegeben wurde. 


\section{ERGEBNISSE}

\subsection{Lignin- und Elementverteilung in gewachsenem Holz}

Der relative Ligningehalt und die Konzentrationen der häufigsten Elemente in verschiedenen Zellwandschichten von Holzfasern der Rotbuche (Fagus sylvatica) und von Tracheiden der Waldkiefer (Pinus sylvestris) wurden in der vorliegenden Arbeit erstmalig mit Hilfe der Röntgenmikroanalyse in situ gemessen.

\subsubsection{Ligninverteilung in Buchenholz}

Die wichtigsten Strukturelemente im Buchenholz sind die Holzfaserzellen (Abb.5a). Sie repräsentieren mehr Zellwandmaterial als die Gefäße, die Holzstrahl-Parenchymzellen und die Längsparenchymzellen. Messungen der Röntgenemission von merkurisiertem Lignin in Gewebequerschnitten zeigten, dass der höchste kleinräumige Ligningehalt in der Mittellamelle zwischen mindestens drei Holzfasern, im folgenden Zellecke genannt, lokalisiert war (Abb.5b). In der zusammengesetzten Mittellamelle, die aus Resten der Primärwand und der lignifizierten Mittellamelle besteht, wurde ein um etwa ein Drittel kleineres Signal gemessen. Das Röntgenemissions-Profil der Sekundärwand zeigte eine deutliche Abstufung des Ligningehaltes von der Mitellamelle zum Lumen. Während in der zuerst gebildeten S1-Schicht noch ein mittlerer Wert im Vergleich zur Mittellamelle detektiert wurde, wiesen die S2-Schichten, die den größten Anteil an der Sekundärwand ausmachen, gleichbleibend niedrige Werte auf. Das Hg-Lignin-Signal der Tertiärwand, die die Holzfaser zum Lumen hin abschließt, erreichte ähnliche Werte wie in der Sekundärwand. Die sehr dünne und kaum kontrastierte Tertiärwand der Buchenholzfasern war im elektonenmikroskopischen Bild schwierig einzugrenzen. Für eine Messreihe wurde sie als Referenzort deswegen nicht herangezogen, sondern nur die Zellecke (C), die zusammengesetzte Mittellamelle (M) und eine zentrale Position in der S2-Schicht (S). Ein Vergleich der Mittelwerte der Hg-Röntgenemission ergab eine deutliche Abstufung der relativen Ligningehalte in den drei Zellwandbereichen C:M:S von 3,5 : 2,5 : 1 (Abb.6). Eine solche Abstufung der Ligningehalte war bereits in Faserzellen der Birke in ähnlicher Größenordnung mit verschiedenen Methoden nachgewiesen worden (Tab.2). 


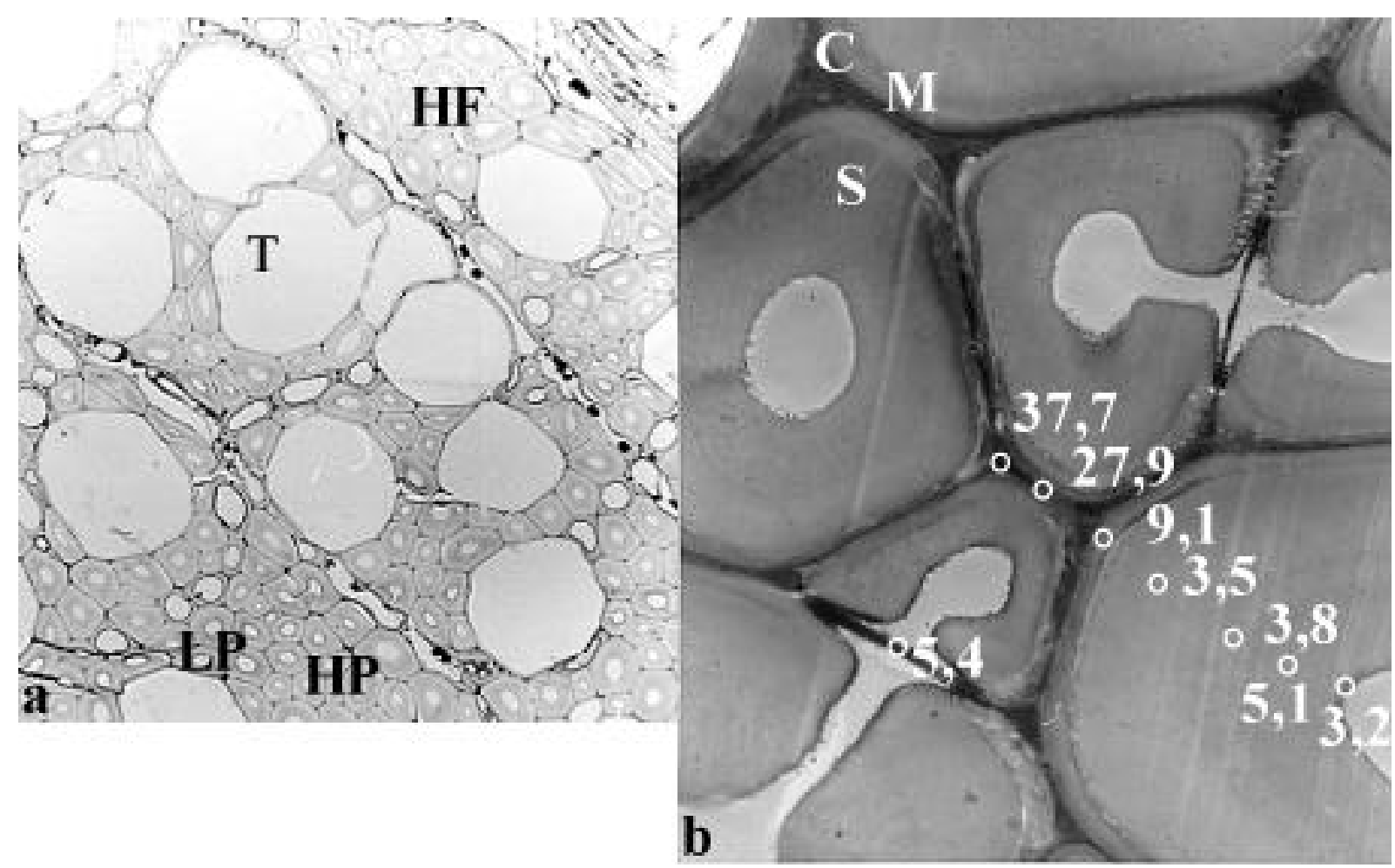

Abbildung 5

Buchenholz im Querschnitt

a) Lichtmikroskopische Übersicht

Buchenholz besteht aus Holzfaserzellen (HF), Gefäßen (T), Holzstrahl-Parenchymzellen (HP) und Längsparenchymzellen (LP).

b) Röntgenmikroanalyse des merkurisierten Lignins in der Zellwand von Holzfaserzellen

Die Zahlen geben das Hg-Lignin-Signal der Zellecke, der zusammengesetzten Mittellamelle, der S1-Wand, dreier Positionen der S2-Wand, der Tertiärwand und des Torus an. Die Buchstaben bezeichnen die Referenzorte Zellecke (C), Mittellamelle (M) und Sekundärwand (S), die in einer Messreihe in mehreren Schnitten untersucht wurden

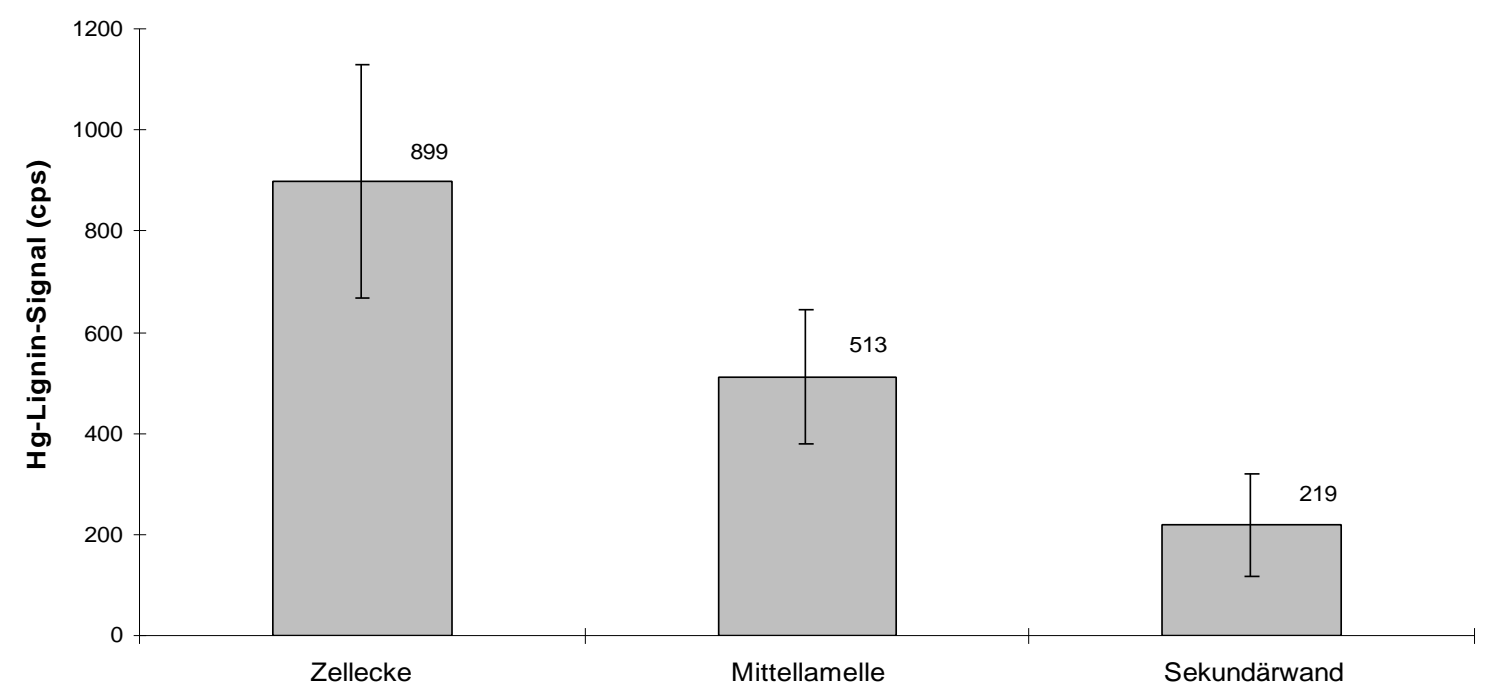

\section{Abbildung 6}

Röntgenmikroanalyse des Ligningehaltes an drei Referenzorten in der Zellwand von Holzfaserzellen der Buche

Angegeben ist der Mittelwert von jeweils 20 Messungen. 
Tabelle 2

Ligninverhältnis in Zellecke (C) und Sekundärwand (S) in Laubholz-Faserzellen nach verschiedenen quantitativen mikroskopischen Analysemethoden

\begin{tabular}{lllc} 
Laubholzart & Methode & Autor & Ligninverhältnis C:S \\
\hline Betula papyrifera & UV-Mikroskopie & Fergus und Goring, 1970 & 4,5 \\
Betula papyrifera & Br-EDXA & Saka et al., 1983 & 3,7 \\
Betula papyrifera & Br-EDXA & Otjen und Blanchette, 1988 & 1,8 \\
Betula verrucosa & Hg-EDXA & Eriksson et al., 1988 & 3,1 \\
Fagus sylvatica & Hg-EDXA & diese Arbeit & 3,5
\end{tabular}

\subsubsection{Elementkonzentrationen in Buchenholz}

An den Referenzorten C, M, S wurde außerdem die Röntgenemission der natürlich enthaltenen Elemente in nicht-merkurisiertem Buchenholz gemessen und in molare Konzentrationen umgerechnet (Abb.7). Erfasst wurden dabei aufgrund der Detektoreigenschaften nur Elemente mit dem Atomgewicht von Natrium und größer. Als häufigstes Element wurde in der Zellecke Calcium nachgewiesen, gefolgt von Kalium, Magnesium und Mangan. Außerdem ließen sich Spuren von Natrium, Aluminium, Phosphor, Schwefel, Chlor und Eisen detektieren (Daten nicht gezeigt).

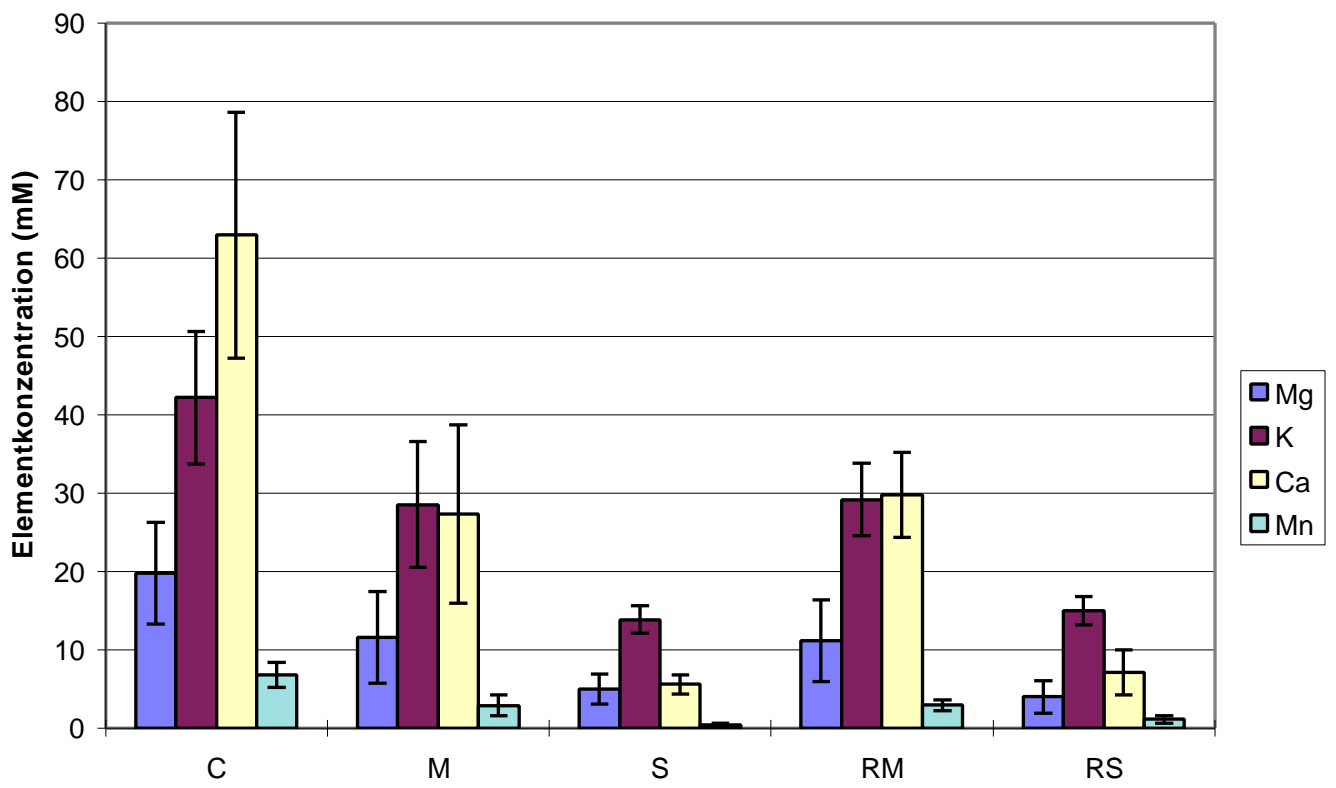

\section{Abbildung 7}

Röntgenmikroanalyse der Elementkonzentrationen von Magnesium, Kalium, Calcium und Mangan in der Zellecke (C), der Mittellamelle (M) und der Sekundärwand (S) von Holzfaserzellen, in der Mittellamelle zwischen Holzfaserzellen und Holzstrahl-Parenchymzellen (RM) und in der Sekundärwand von HolzstrahlParenchymzellen (RS) 
In der zusammengesetzten Mittellamelle wurden Calcium und Kalium in etwa gleicher Menge vor Magnesium und Mangan gemessen, während in der Sekundärwand Kalium alle anderen Elemente an Häufigkeit übertraf. Im Vergleich der verschiedenen Zellwandbereiche ließ sich eine ähnliche Abstufung der Elementgehalte wie zuvor beim Ligningehalt von der Zellecke über die Mittellamelle zur Sekundärwand feststellen.

Die Zellwände des Holzstrahl-Parenchyms zeigten in der Röntgenmikroanalyse die gleiche Zusammensetzung aus den vier häufigsten Elementen sowohl in der Mittellamelle zur benachbarten Faserzelle als auch in der Sekundärwand.

\subsubsection{Ligninverteilung in Kiefernholz}

Im Holz der Kiefer bestimmen Tracheiden das Bild eines Gewebequerschnittes (Abb.8a). An den drei Referenzorten Zellecke (C), zusammengesetzte Mittellamelle (M) und Sekundärwand (S) (Abb.8b) wurde die Ligninverteilung mittels Röntgenmikroanalyse bestimmt. Die höchsten lokalen Ligningehalte, die als Röntgenemission des merkurisierten Zellwandlignins in situ gemessen wurden, wurden in der Zellecke zwischen mindestens drei Tracheiden nachgewiesen (Abb.9). Die in der Mittellamelle erreichten Werte waren etwas mehr als halb so groß, während sie in der Sekundärwand nur etwa ein Drittel der Werte der Zellecke erreichten. Diese Abstufung der Ligningehalte entsprach einem Verhältnis C:M:S von $3: 1,7: 1$. Die Anreicherung von Lignin in der Mittellamelle von Tracheiden von Pinus sylvestris folgte damit einem Muster, das schon bei mehreren anderen Nadelhölzern mit verschiedenen Methoden beobachtet worden war (Tab.3).

Tabelle 3

Ligninverhältnis in Zellecke (C) und Sekundärwand (S) in Nadelholztracheiden nach verschiedenen quantitativen mikroskopischen Analysemethoden

\begin{tabular}{lllc} 
Nadelholzart & Methode & Autor & Ligninverhältnis C:S \\
\hline Pinus radiata & I-Mikroskopie & Donaldson, 1985b & 4,0 \\
Picea nigra & UV-Mikroskopie & Fergus et al., 1969 & 4,1 \\
Pseudotsuga menziesii & UV-Mikroskopie & Wood, Goring, 1971 & 3,7 \\
Pseudotsuga menziesii & Br-EDXA & Saka et al., 1981 & 2,1 \\
Pinus taeda & Br-EDXA & Saka et al., 1982 & 2,1 \\
Picea abies & Hg-EDXA & Westermark et al., 1988 & 2,5 \\
Pinus sylvestris & Hg-EDXA & diese Arbeit & 3,0
\end{tabular}



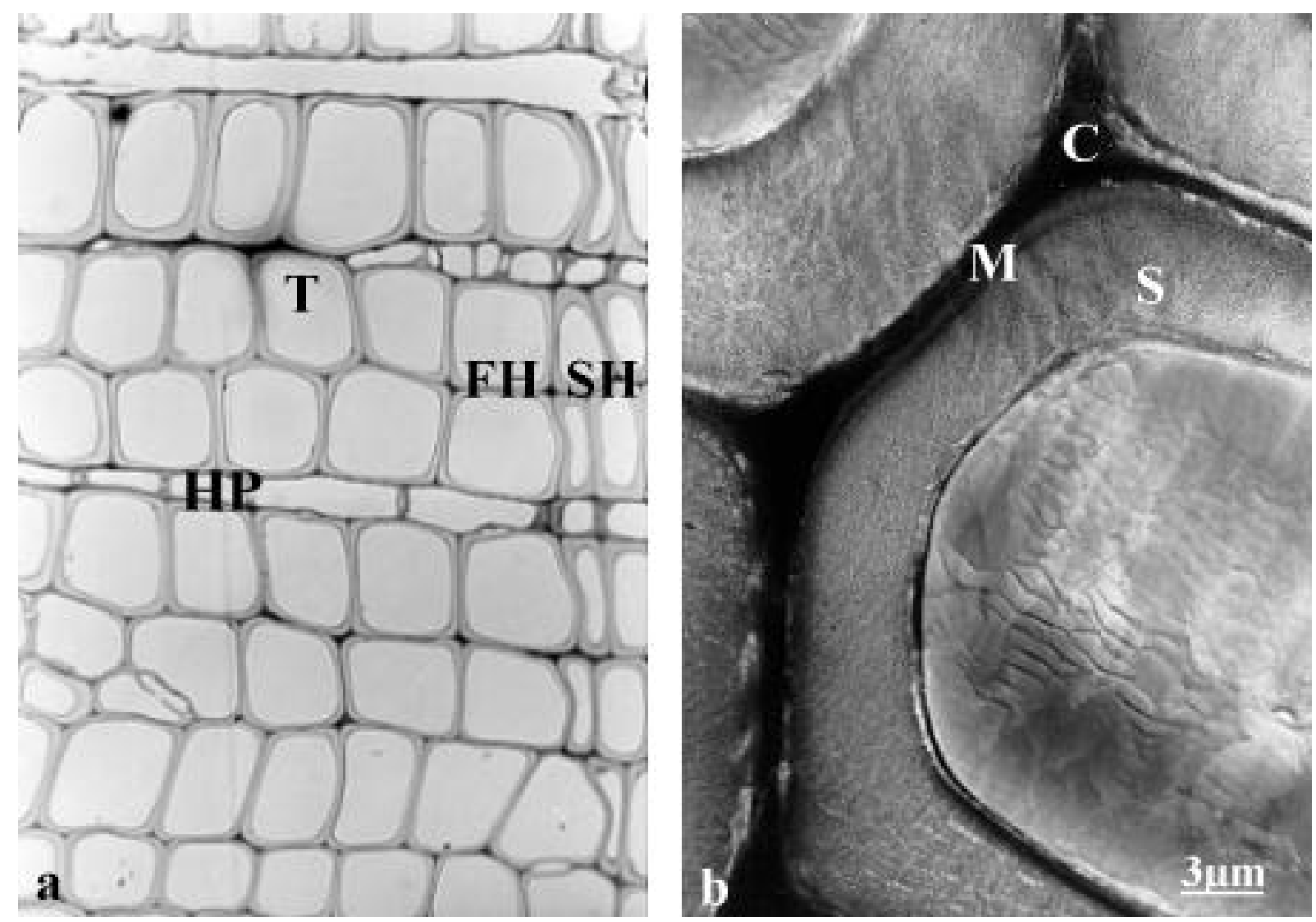

\section{Abbildung 8}

Kiefernholz im Querschnitt

a) Lichtmikroskopische Übersicht

Tracheiden (T) und Holzstrahl-Parenchymzellen (HP) bilden das dünnwandige Frühholz (FH) und dickwandige Spätholz (SH).

b) Mikrofoto der Referenzorte für die Röntgenmikroanalyse

In der Zellecke (C), der zusammengesetzten Mittellamelle (M) und in der Sekundärwand (S) wurde der Ligningehalt in einer Messreihe untersucht.

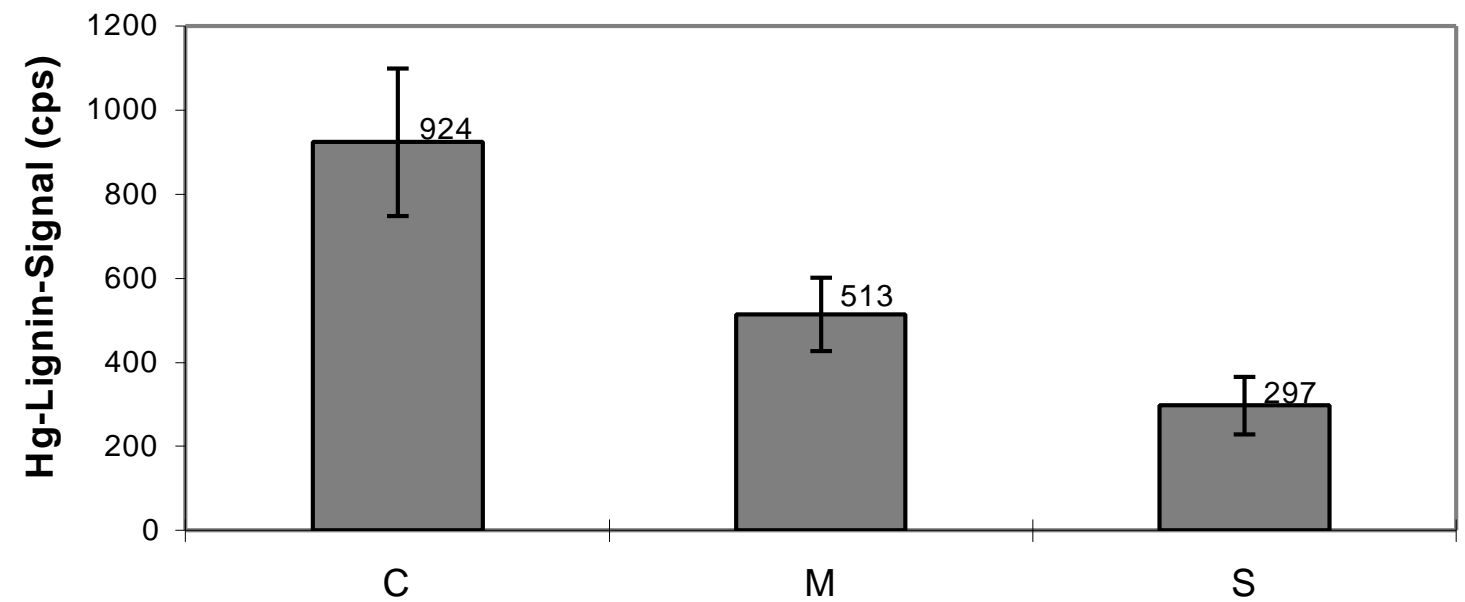

Abbildung 9

Röntgenmikroanalyse des Ligningehaltes an drei Referenzorten in der Zellwand von Kieferntracheiden Angegeben ist der Mittelwert von jeweils 20 Messungen. 


\subsubsection{Elementkonzentrationen in Kiefernholz}

Die Analyse der Elementzusammensetzung in Kiefernholz wies Calcium als häufigstes Element in der stark lignifizierten Zellecke und in der zusammengesetzten Mittellamelle nach (Abb.10). Außerdem wurden quantifizierbare Mengen von Magnesium, Kalium und Mangan (Abb.10) und Spuren von Natrium, Aluminium, Phosphor, Schwefel, Chlor und Eisen (Daten nicht gezeigt) detektiert. Die Abstufung der Calcium-, Magnesium- und Mangankonzentration an den drei Referenzorten Zellecke, Mittellamelle und Sekundärwand glich in auffälliger Weise der Abstufung, die zuvor für die Ligningehalte beobachtet worden war (Abb.9). Die Abstufung der Kaliumkonzentration zwischen den untersuchten Zellwandbereichen war weniger ausgeprägt.

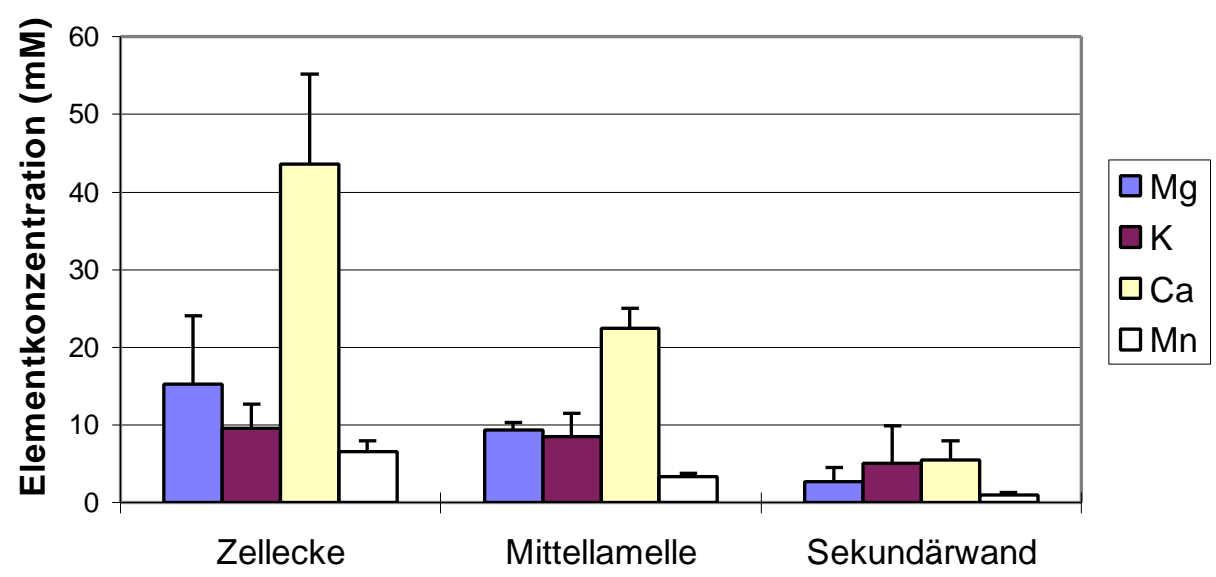

\section{Abbildung 10}

Röntgenmikroanalyse der Elementkonzentrationen von Magnesium, Kalium, Calcium und Mangan in der Zellecke, der Mittellamelle und in der Sekundärwand von Kieferntracheiden 


\subsection{Lignin in pilzinfiziertem Holz}

Standardisierte Probehölzer aus Buchen- und Kiefernholz wurden im Laborversuch unter kontrollierten Bedingungen dem Abbau durch Weiß- und Braunfäulepilze ausgesetzt. Diese Experimente waren eingebunden in ein gemeinsames Forschungsprojekt der Technischen Universität Dresden, der Hebrew University Rehovot/Israel und der Universität Göttingen (siehe Material und Methoden 2.2).

Zunächst wurden in zwei Screenings für Buchen- und Kiefernholz Pilzstämme isoliert, die bei unterschiedlicher Verwertung des Lignins während des Zellwandabbaues eine Reduktion der mechanischen Festigkeit der Probehölzer verursachten. Im anschließenden Experiment wurden mehrere mikroskopische, chemische und physiologische Parameter des Zellwandabbaues in den ersten drei Wochen der kontrollierten Infektion untersucht.

Um die Ergebnisse aus diesem Labor-Experiment auf ihre biologische Relevanz zu überprüfen, wurden mit der Röntgenmikroanalyse Holzproben von Fichten untersucht, die am natürlichen Standort über unbestimmte Zeit dem Erreger der Rotfäule (Heterobasidion annosum) ausgesetzt waren.

\subsubsection{Buchenholz nach kontrollierter Infektion mit Fäulepilzen}

Im Screening wurden 31 Pilzstämme auf ihre Fähigkeit getestet, die mechanische Stabilität von Buchenholz in nur dreiwöchiger Inkubation zu reduzieren. Die Inkubation mit dem Weißfäulepilz Trametes hirsuta verursachte in Buchen-Probehölzern eine Absenkung der Scherfestigkeit um über $50 \%$ bei einem Gewichtsverlust von $6 \%$ der Trockenmasse (Abb.11). Da Industrierestholz für eine langfristig angestrebte biotechnologische Anwendung dieses Verfahrens als preiswerte Rohstoffquelle für die Holzwerkstoffindustrie zur Verfügung steht, kann dieser Ausbeuteverlust akzeptiert werden. Die Möglichkeit einer drastischen Reduktion der Energiekosten beim Faseraufschluss machte T. hirsuta demzufolge sehr interessant für weitere Experimente.

Während einer zweiten dreiwöchigen Inkubation wurden nun alle fünf Tage Probehölzer geerntet, um die Vorgänge, die für die Absenkung der Scherfestigkeit in der Frühphase der Infektion verantwortlich sind, zu untersuchen. Die Röntgenmikroanalyse wurde hierbei gezielt eingesetzt, um einen Zusammenhang zwischen mechanischer Stabilität und Ligningehalt nachzuweisen. 
Dem simultan Lignin und Cellulose abbauenden Weißfäulepilz T. hisuta wurden in diesem Experiment zum Vergleich der Abbaustrategien außerdem der selektiv Lignin abbauende Weißfäulepilz $M$. tremellosus und der Braunfäulepilz $P$. vaporaria zur Seite gestellt. $P$. vaporaria hatte sich im Screening durch eine Absenkung der Scherfestigkeit von Buchenholz um fast 50\% ausgezeichnet, während $M$. tremellosus sich von den anderen selektiven Weißfäulepilzen durch schnelleres und üppigeres Wachstum auf den Probehölzern abhob.

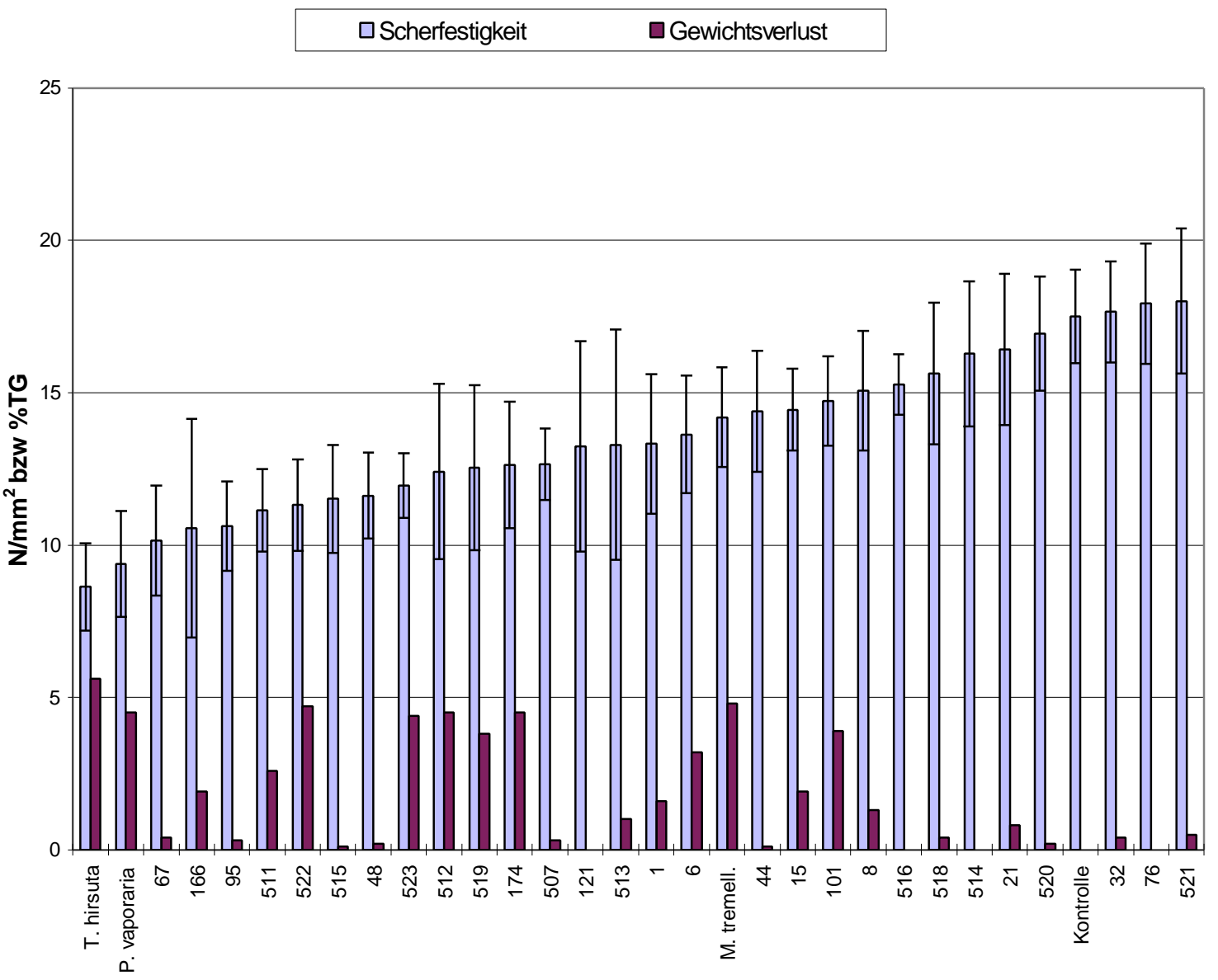

\section{Abbildung 11}

Scherfestigkeit und Gewichtsverlust von Buchen-Probehölzern bei Pilzbefall

In einem Screening-Experiment wurden 31 Weißfäule- und Braunfäulepilze darauf getestet, Scherfestigkeit und Gewicht von Buchen-Probehölzern in drei Wochen zu reduzieren. Die Namen der Pilze, die für weitere Experimente ausgewählt wurden sind angegeben. Die Namen der übrigen Kulturen sind in Tabelle 1 aufgelistet. Die Scherfestigkeit von jeweils 8 Probehölzern wurde von H. Unbehaun, TU Dresden gemessen.

\section{Lichtmikroskopie}

Bei der lichtmikroskopischen Betrachtung von Querschnitten von Buchenholz, welches drei Wochen mit den drei ausgewählten Fäulepilzen inkubiert worden war, ließen sich keine Anzeichen eines fortschreitenden Zellwandabbaues auffinden (Abb.12a-d). Nach 

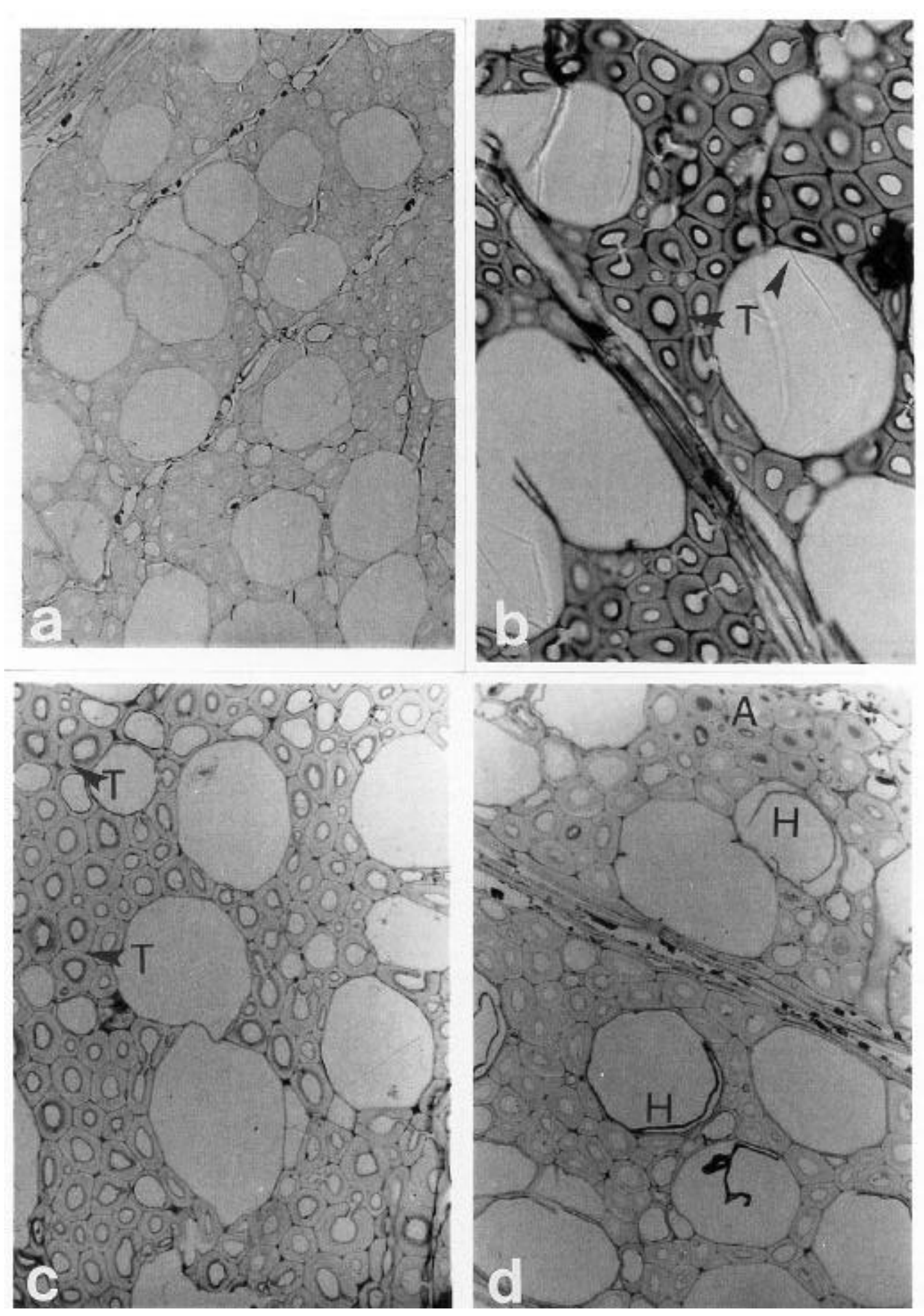

\section{Abbildung 12}

Buchenholz nach dreiwöchiger Inkubation mit Fäulepilzen

a) Kontrolle

b) Simultane Weißfäule durch $T$. hirsuta

c) selektive Weißfäule durch $M$. tremellosus

d) Braunfäule durch $P$. vaporaria

Nach Infektion mit Weißfäulepilzen werden Toluidinblau-Färbungsmuster (T) in der Sekundärwand von Holzfaserzellen beobachtet. Im Frühstdium von Braunfäule erscheinen Ablagerungen (A) im Lumen von Holzfaserzellen und Längsparenchymzellen und Häutchen $(\mathrm{H})$ im Lumen von Gefäßen. 
simultaner und selektiver Weißfäule wurde jedoch in der Sekundärwand vieler Holzfasern eine verstärkte Reaktion auf den Farbstoff Toluidinblau vom Lumen her beobachtet (Abb.12b,c). In Braunfäule-infiziertem Buchenholz wiesen kollabierte Häutchen in den Gefäßen und stark lichtbrechende Ablagerungen im Lumen der Holzfaserzellen, der Längsparenchymzellen und der Holzstrahl-Parenchymzellen auf pilzliches Wachstum im Holz hin (Abb.12d).

\section{Hg-TEM-EDXA}

Die Röntgenmikroanalyse des merkurisierten Zellwandlignins an den Referenzorten Zellecke (C), zusammengesetzte Mittellamelle (M) und Sekundärwand (S) von Holzfasern wies bei allen pilzinfizierten Proben die gleiche Ligninverteilung nach, die auch in der nichtinfizierten Kontrolle gemessen wurde (Abb.13). Das Verhältnis der relativen Ligningehalte C:M:S war bei allen vier Messreihen etwa 3,5 : 2,5 : 1 und auch die absoluten Werte waren an jedem Referenzort sehr ähnlich wie in Kontrollen. Frühere Stadien der Infektion wurden deswegen nicht licht- und elektronenmikroskopisch untersucht.

\section{$\square$ Zellecke $\quad \square$ Mittellamelle $\square$ Sekundärwand}

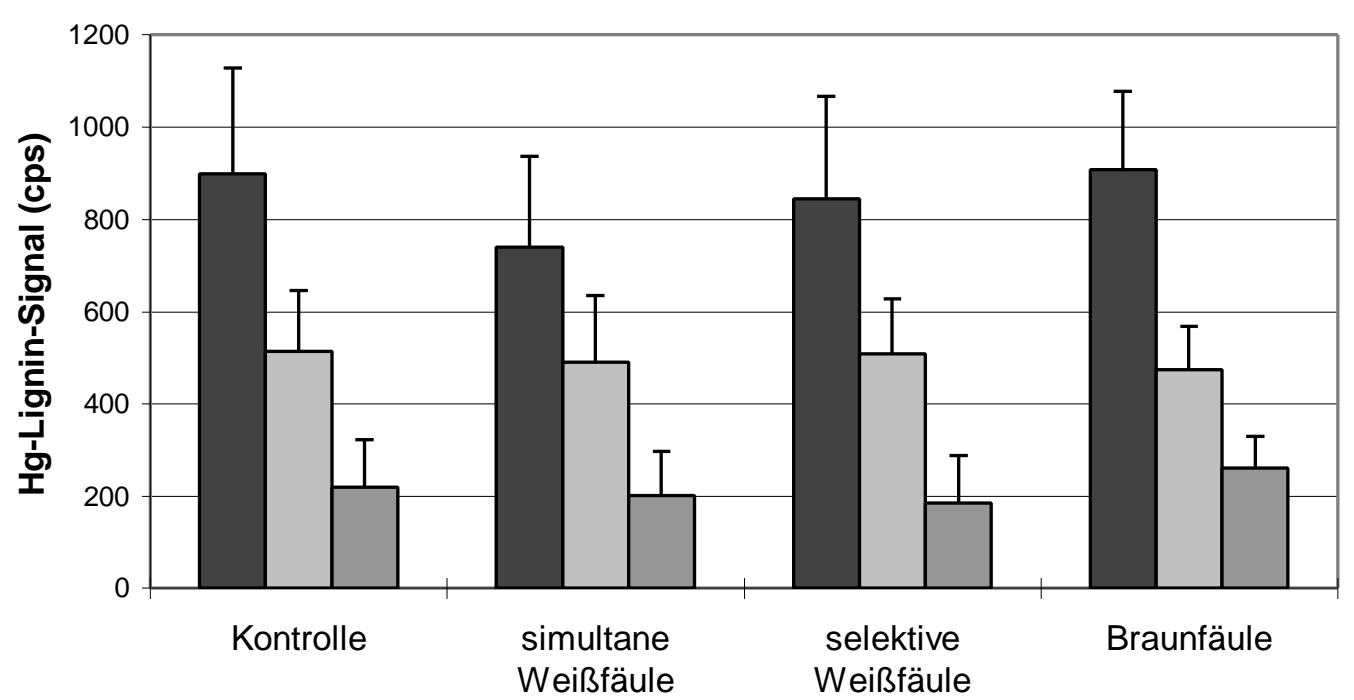

\section{Abbildung 13}

Röntgenmikroanalyse des Ligningehaltes an drei Referenzorten in der Zellwand von Holzfaserzellen der Buche nach dreiwöchiger Inkubation mit T. hirsuta (simultane Weißfäule) M. tremellosus (selektive Weißfäule) und P. vaporaria (Braunfäule) 
Chemische, mechanische und physiologische Parameter infizierter Probehölzer

Die Veränderungen des Ligningehaltes, der Scherfestigkeit, des Gewichtsverlusts, der $\mathrm{CO}_{2^{-}}$ und der Wärmeproduktion der pilzinfizierten Buchen-Probehölzer wurden jedoch auch während der dreiwöchigen Inkubation bestimmt. Dazu wurden vom fünften Tag nach der Infektion jeweils im Abstand von vier Tagen Probehölzer geerntet. Im zeitlichen Verlauf blieb der relative Anteil des Lignins am Gesamtgewicht der Probehölzer bei simultaner Weißfäule und bei Braunfäule konstant (Abb.14). Bei selektiver Weißfäule sank der relative Ligningehalt hingegen von $23 \%$ auf $17 \%$ ab. Simultane Weißfäule durch T. hirsuta verursachte schon innerhalb der ersten zehn Tage eine deutliche Abnahme der Scherfestigkeit, ohne Auswirkungen auf das Gewicht der Probehölzer zu haben (Abb.15). Ein Gewichtsverlust war erst in den folgenden Tagen messbar, während die Scherfestigkeit nicht weiter reduziert wurde. Einen sehr ähnlichen Infektionsverlauf zeigte Braunfäule durch P. vaporaria. Auch hier kam es ohne Gewichtsverlust zu einer deutlichen Abnahme der Scherfestigkeit in den ersten zehn Tagen (Abb.17). Allerdings ist dieses Phänomen hier weniger deutlich, da $P$. vaporaria sehr sensibel auf eingetretene Schimmelpilzinfektionen reagierte. In den Kulturschalen, die an den Tagen 13, 17 und 21 geerntet wurden, brach die Infektion früher aus, so dass ein Scherfestigkeits- oder Gewichtsverlust nicht mehr beobachtet werden konnte. Selektive Weißfäule durch $M$. tremellosus führte wie auch schon in den Vorversuchen zu keiner deutlichen Abnahme der Scherfestigkeit und zu einem Gewichtsverlust von etwa 4,5\% (Abb.16).
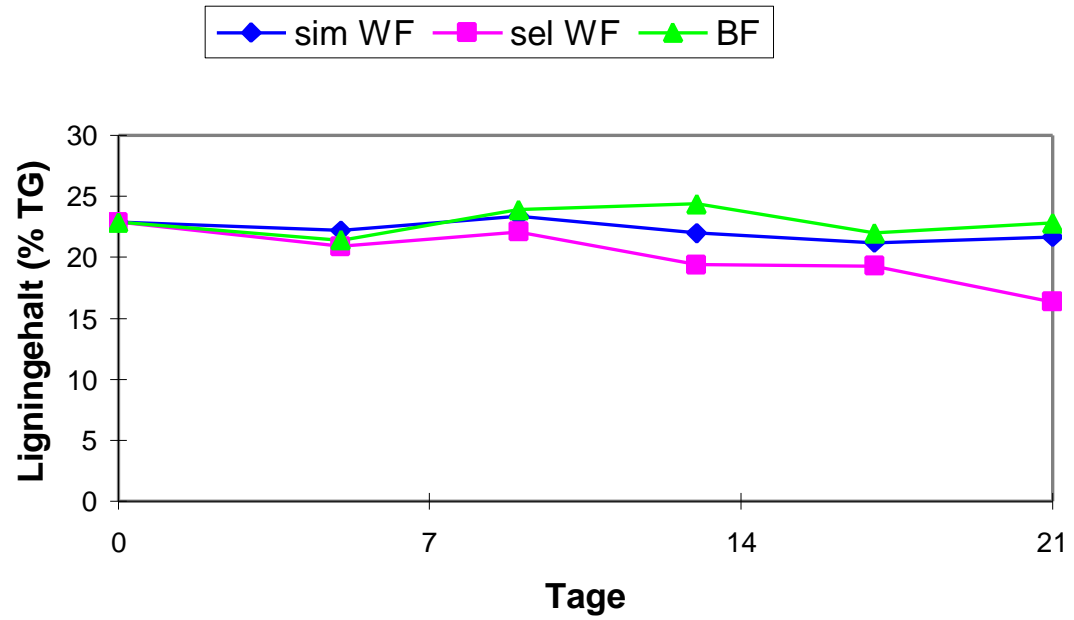
Abbildung 14
Klason-Ligningehalt von Buchenholz während dreiwöchiger Inkubation mit Weißfäule- und Braunfäulepilzen 


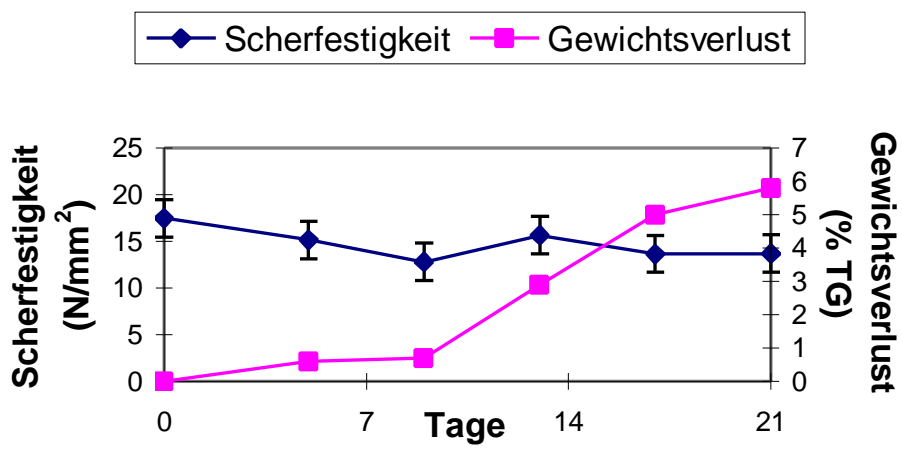

Abbildung 15

Scherfestigkeit und Gewichtsverlust von Buchen-Probenhölzern während dreiwöchiger Inkubation mit dem Erreger simultaner Weißfäule $T$. hirsuta

\section{Abbildung 16}

Scherfestigkeit und Gewichtsverlust von Buchen-Probehölzern

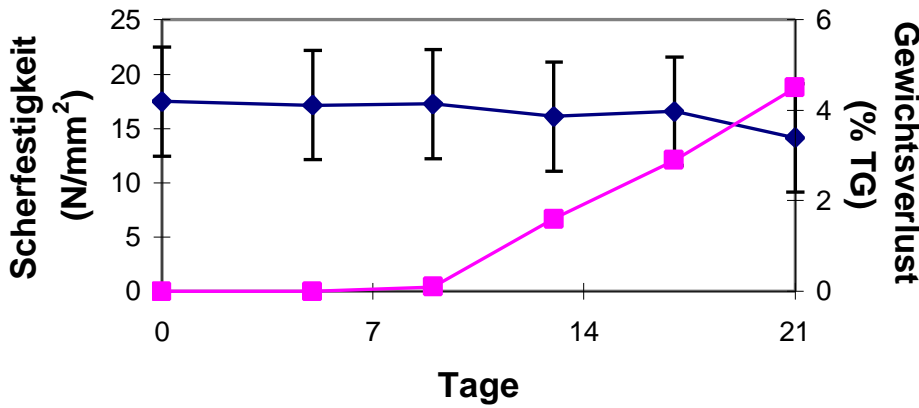
während dreiwöchiger Inkubation mit dem Erreger selektiver Weißfäule $M$. tremellosus

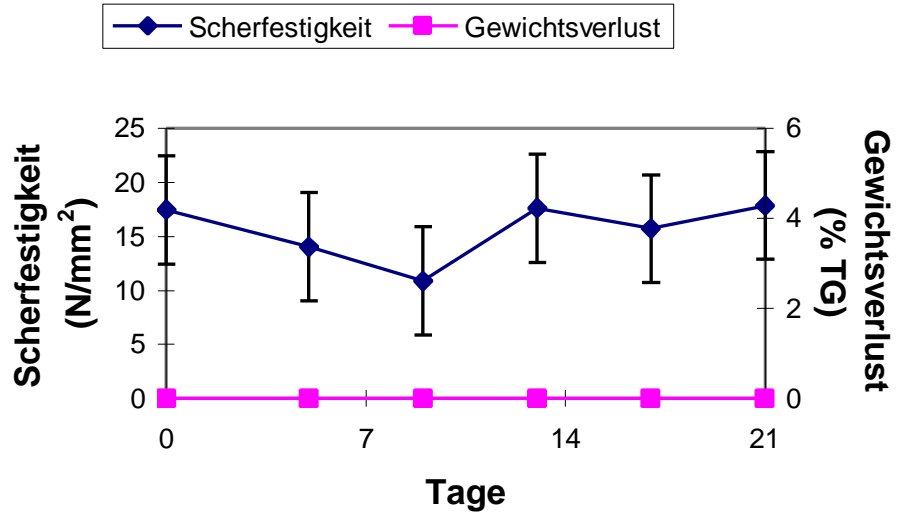

Abbildung 17

Scherfestigkeit und Gewichtsverlust von Buchen-Probehölzern während dreiwöchiger Inkubation mit dem Braunfäuleerreger $G$. trabeum

Die dissimilatorische $\mathrm{CO}_{2-}$ und Wärmeproduktion mikrobieller Organismen in totem organischem Substrat gilt allgemein als ein relatives Maß für die Biomasseproduktion und das Wachstum dieser Organismen (Beck et al., 1995, Heilmann, 1995). Da pilzliches Mycel nicht vollständig aus infiziertem Holz isoliert werden kann, wurde auf diese schnelle Methode zurückgegriffen, um die physiologische Aktivität der Fäulepilze in der Frühphase der Infektion von Holz zu erfassen. Die $\mathrm{CO}_{2}$ und Wärmeproduktion der pilzinfizierten 
Probehölzer zeigten vom ersten Messtag an eine parallele Entwicklung, was die Zuverlässigkeit dieser Methoden unterstreicht (Abb.18, Abb.19). Am fünften Tag nach Inkubationsbeginn hatten alle drei Pilze das Buchenholz schon soweit infiziert, dass eine geringe $\mathrm{CO}_{2}$ - und Wärmeproduktion festgestellt werden konnte. Im weiteren Verlauf zeigten diese Parameter bei Probehölzern, die mit T. hirsuta infiziert waren, einen steileren Anstieg als bei den anderen beiden Varianten. Erst am Ende der Inkubation, als die Produktionsraten von $T$. hirsuta wieder etwas absanken, erreichten alle drei Varianten ähnlich hohe Werte. Schimmelpilze, die bei der Vorbereitung der Probehölzer in diesem Experiment nicht vollständig abgetötet wurden, keimten in der Endphase der Inkubation aus und trugen in unbekanntem Maße zu der gemessenen $\mathrm{CO}_{2}$ - und Wärmemenge bei.

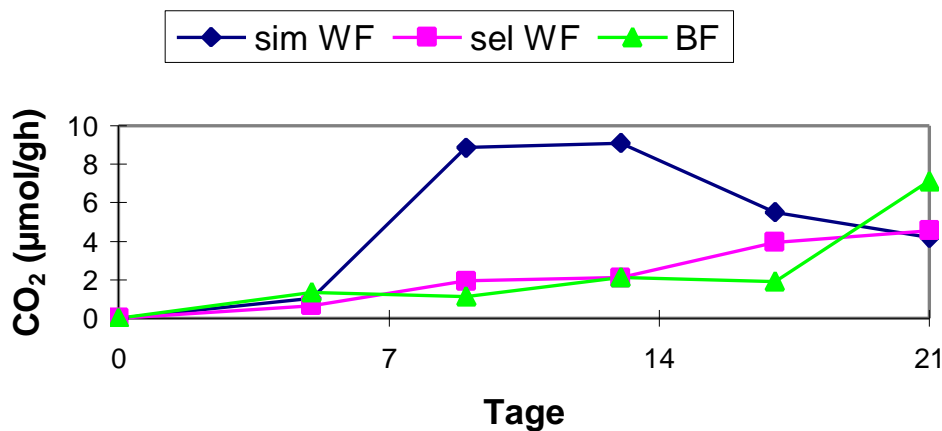

\section{Abbildung 18}

$\mathrm{CO}_{2}$-Produktion von infiziertem Buchenholz

\section{$\multimap \operatorname{sim} W F \rightarrow$ sel WF $\leftarrow$ BF}

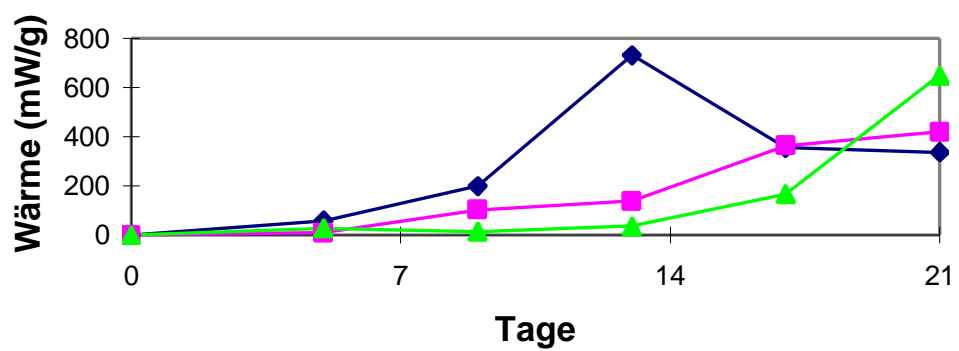

\section{Abbildung 19}

Wärmeproduktion von infiziertem Buchenholz

Zusammenfassend konnte festgestellt werden, dass die Abnahme der Scherfestigkeit von Buchenholz, die im Frühstadium der Infektion mit Fäulepilzen beobachtet worden war, nicht an einen selektiven Ligninabbau oder einen gleichmäßigen Masseverlust der Zellwand gebunden war. 


\subsubsection{Kiefernholz nach kontrollierter Infektion mit Fäulepilzen}

In einem Screening wurde derjenige Fäulepilz isoliert, der nach dreiwöchiger Inkubation von Kiefern-Probehölzern deren Scherfestigkeit am deutlichsten absenken konnte. Unter den getesteten 31 Pilzstämmen verursachten fünf Braunfäulepilze eine Scherfestigkeitsabnahme der Probehölzer um mehr als 16\% (Abb.20). Nach Abbau durch Lentinus lepideus und Gloeophyllum trabeum war die Scherfestigkeit im Vergleich zum Kontrollwert nur noch annähernd halb so groß. Außerdem hatten diese beiden Pilze über $9 \%$ der Trockenmasse der Probehölzer bis dahin abgebaut. L. lepideus erwies sich in halbsterilen Fermentationen als konkurrenzschwach gegenüber Schimmelpilzen. Mit Blick auf die technische Anwendbarkeit des Verfahrens wurde daher für das nächste halbsterile Experiment $G$. trabeum bevorzugt. Um auch simultanen und selektiven Weißfäuleabbau zu untersuchen, wurden außerdem Trametes versicolor IV beziehungsweise Merulius tremellosus ausgewählt.

Im nächsten Experiment wurden Kiefern-Probehölzer drei Wochen dem Abbau durch $T$. versicolor, M. tremellosus und G. trabeum ausgesetzt, wobei nun alle 4 Tage Proben geerntet wurden.

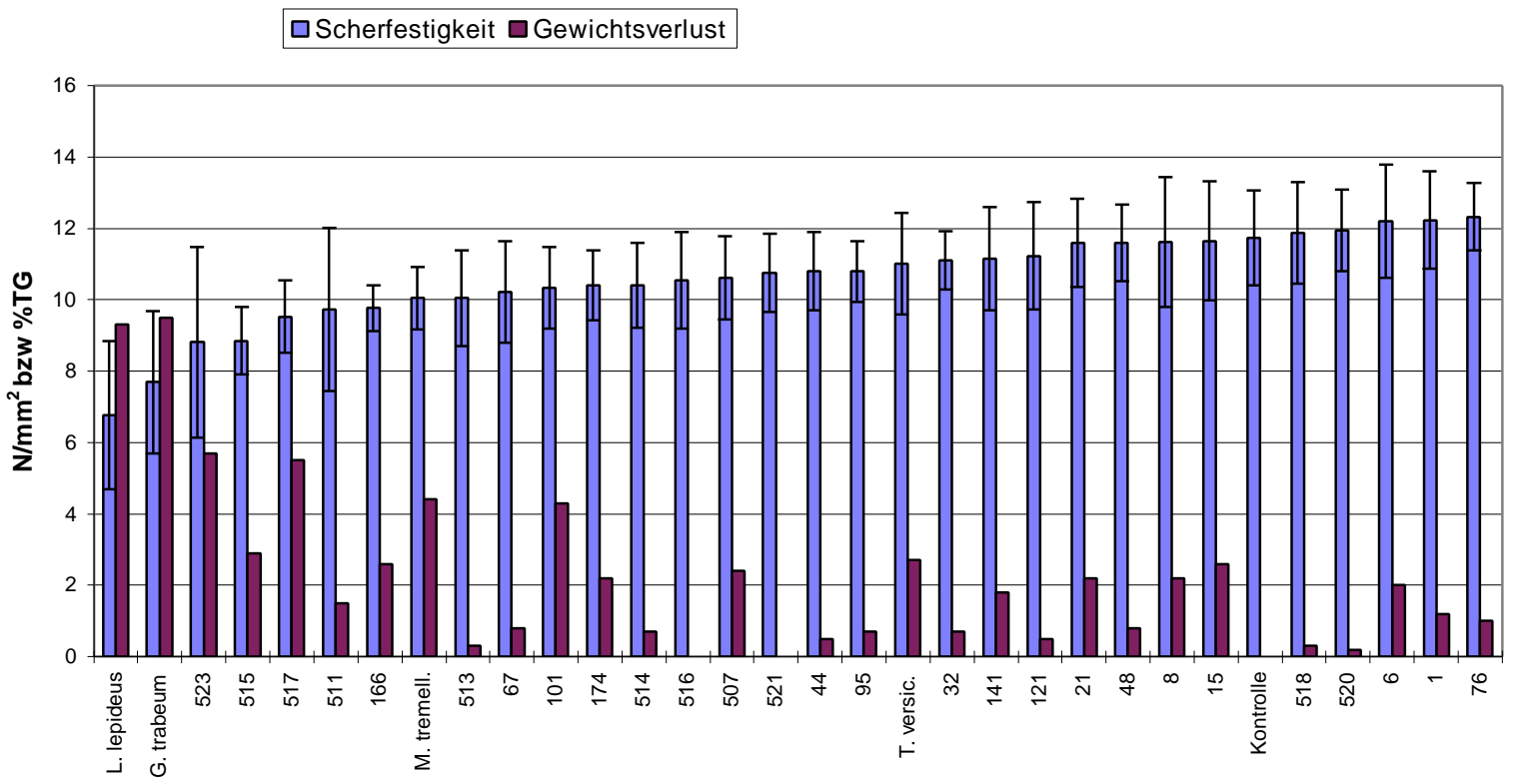

\section{Abbildung 20}

Scherfestigkeit und Gewichtsverlust von Kiefern-Probehölzern

In einem Screening-Experiment wurden 31 Weißfäule- und Braunfäulepilze darauf getestet, Scherfestigkeit und Gewicht von Kiefern-Probehölzern in drei Wochen zu reduzieren. Die Namen der Pilze, die für weitere Experimente ausgewählt wurden sind angegeben. Die Namen der übrigen Kulturen sind in Tabelle 1 aufgelistet. Die Scherfestigkeit von jeweils 8 Probehölzern wurde von H. Unbehaun, TU Dresden gemessen. 

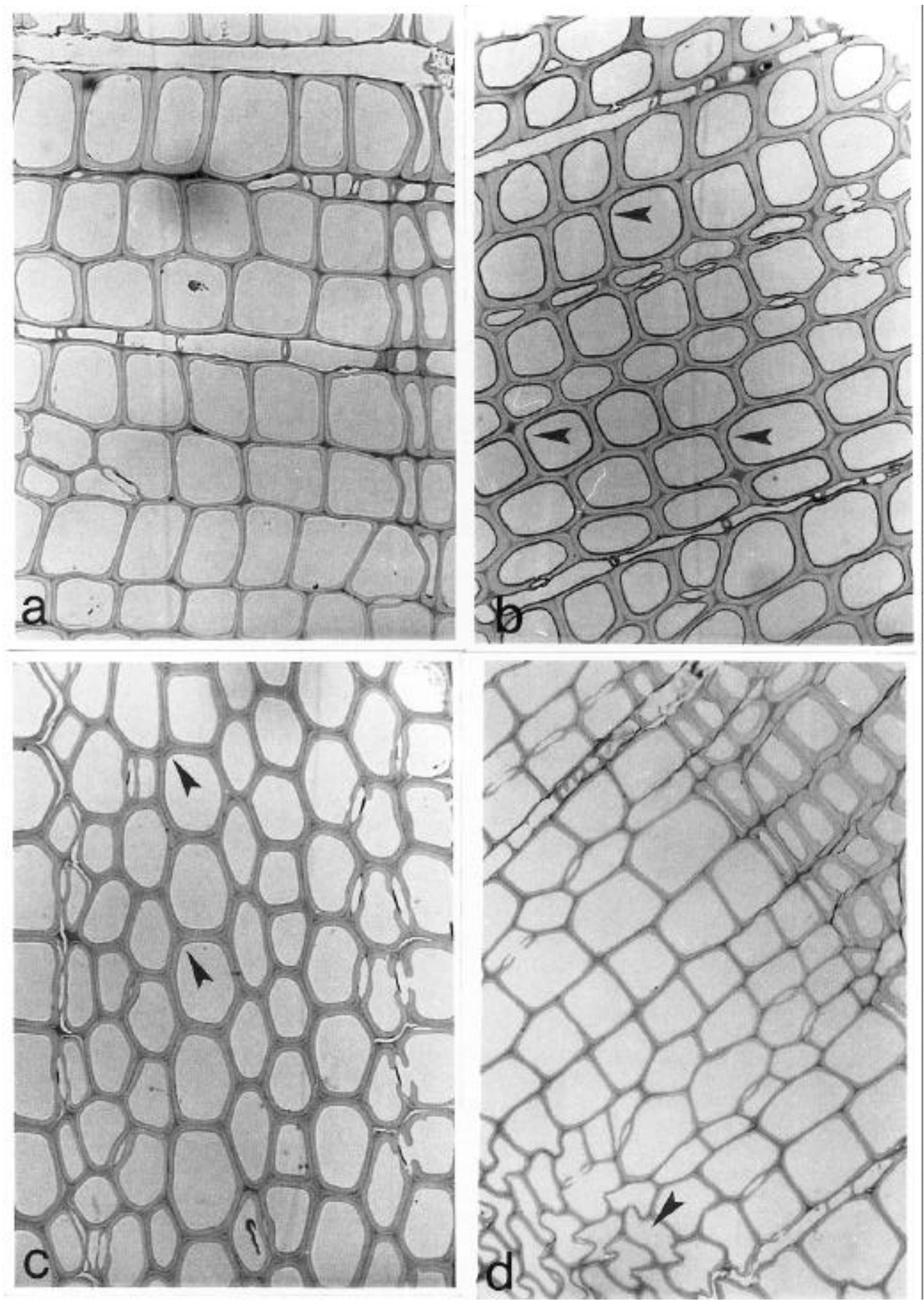

\section{Abbildung 21}

Kiefernholz nach dreiwöchiger Inkubation mit Fäulepilzen

a) Kontrolle

b) simultane Weißfäule durch $T$. versicolor

Der Pfeil weist auf eine dunkle Ablagerung auf der Tertiärwand.

c) selektive Weißfäule durch M. tremellosus

Der Pfeil weist auf angefärbte Schatten in der Sekundärwand nahe der Zellecke

d) Braunfäule durch G. trabeum

Der Pfeil weist auf kollabiertes Frühholz. 


\section{Lichtmikroskopie}

Kiefernholz, das nach Ablauf der dreiwöchigen Inkubation geerntet worden war, wurde lichtmikroskopisch auf Zellwandabbau untersucht. In Probehölzern, die mit dem Erreger simultaner Weißfäule infiziert waren, wurde in den Tracheiden nach Anfärbung mit Toluidinblau eine stark lichtbrechende Ablagerung auf der Lumenseite der Tertiärwand nachgewiesen (Abb.21b). Die Sekundärwand mancher Tracheiden war unregelmäßig ausgedünnt, während die Zellecken und Mittellamellen insgesamt unverändert erschienen. Bei selektivem Weißfäulebefall wurden in der Sekundärwand der Tracheiden im Bereich der Zellecke durch Anfärbung mit Toluidinblau dunkle Schatten sichtbar (Abb.21c). Tracheiden, die mit dem Braunfäuleerreger G. trabeum infiziert waren, wiesen im Querschnitt ungleichmäßig dicke Sekundärwände und auf der Lumenseite der Tertiärwand eine dunkle Ablagerung auf (Abb.21d). Nur an wenigen Stellen im dünnwandigen Frühholz waren die Zellwände jedoch so stark angegriffen, dass sie spätestens bei der Präparation für die Mikroskopie kollabierten.

\section{Hg-TEM-EDXA}

Die Röntgenmikroanalyse des merkurisierten Lignins an den drei Referenzorten Zellecke (C), Mittellamelle (M) und Sekundärwand (S) konnte keine Delignifizierung des Kiefernholzes durch die ausgewählten Fäulepilze nach dreiwöchiger Inkubation nachweisen (Abb.22). Weder im Vergleich der absoluten Werte mit Kontrollwerten noch in der Abstufung der Ligningehalte zwischen den untersuchten Geweben wurde ein Zellwandabbau durch Fäulepilze deutlich.

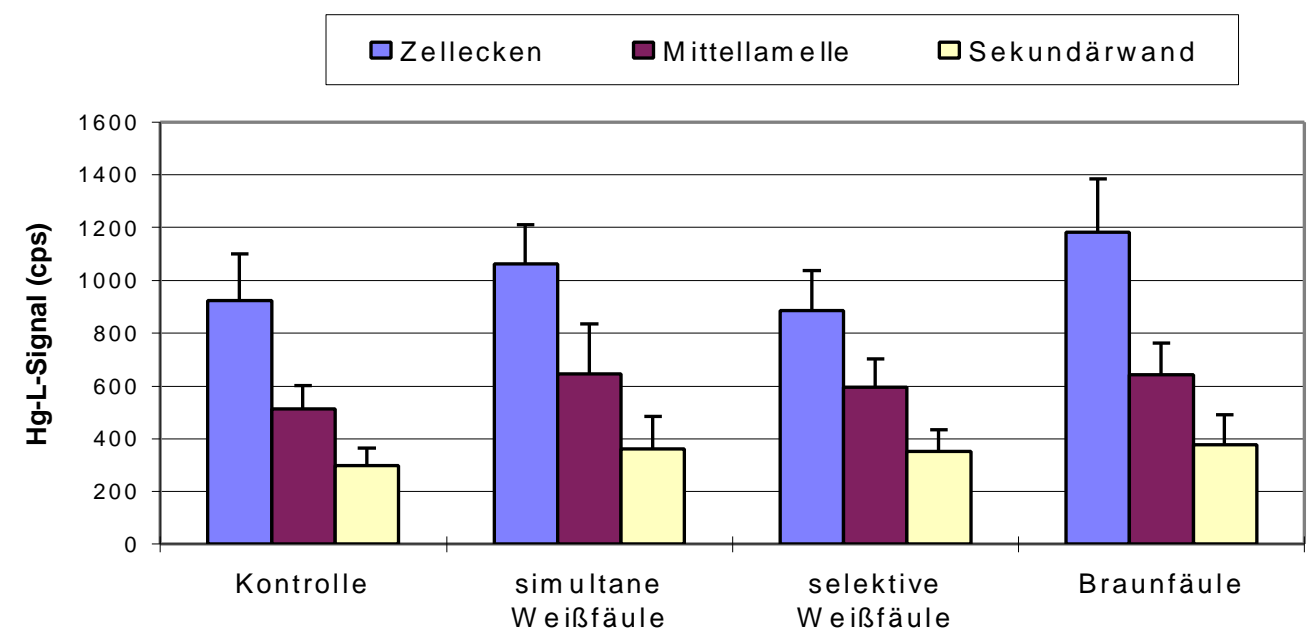

Abbildung 22

Röntgenmikroanalyse des Ligningehaltes an drei Referenzorten in der Zellwand von Kieferntracheiden nach dreiwöchiger Inkubation mit Fäulepilzen 


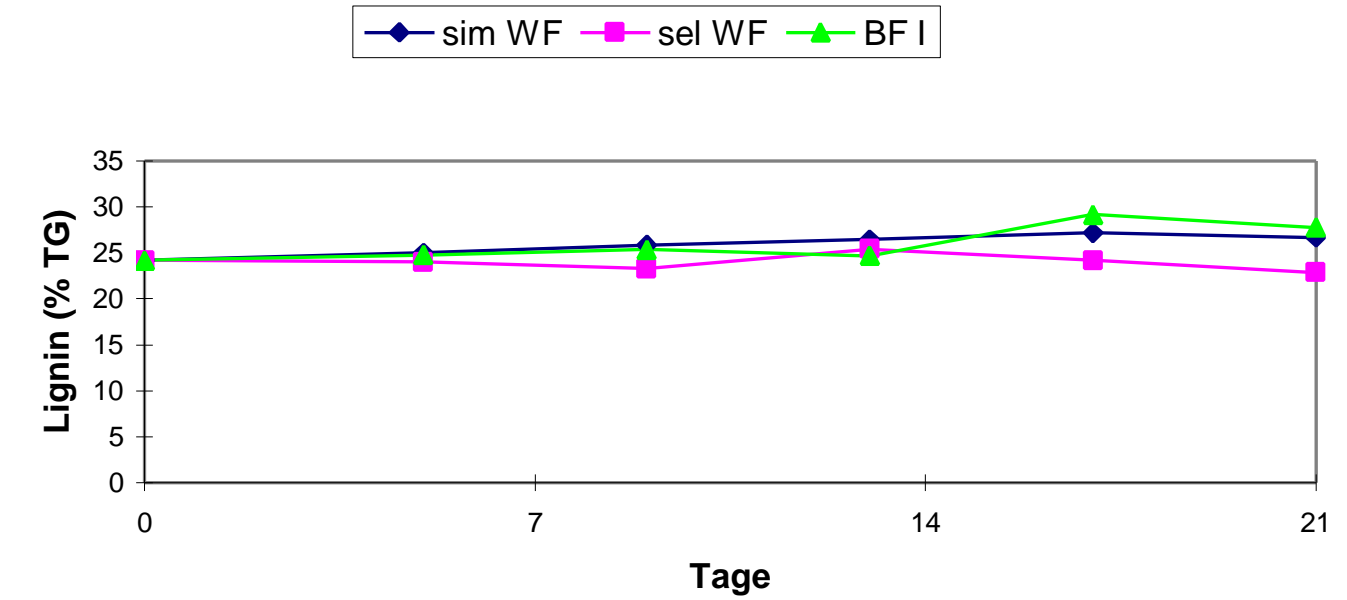

\begin{abstract}
Abbildung 23
Klason-Ligningehalt von Kiefernholz während dreiwöchiger Inkubation mit Weißfäule- und Braunfäulepilzen
\end{abstract}

\title{
Chemische, mechanische und physiologische Parameter infizierter Probehölzer
}

Ebenso blieb der relative Ligningehalt der Probehölzer bezogen auf das Trockengewicht von der Anwesenheit der Pilze unbeeinflusst (Abb.23). Lediglich bei selektiver Weißfäule durch M. tremellosus war eine Tendenz zu bevorzugtem Ligninabbau zu erkennen.

Dass Braunfäule in Kiefernholz aber dennoch schon innerhalb der ersten drei Wochen nach der Infektion zu einer massiven Veränderung der Zellwandeigenschaften führte, zeigte die Untersuchung des Gewichtsverlustes und der Scherfestigkeit der Probehölzer nach Befall mit G. trabeum. Bereits ab dem 13. Tag nach der Infektion war ein stetig wachsender Gewichtsverlust $\mathrm{zu}$ beobachten, und $\mathrm{ab}$ dem 17. Tag wurde eine Abnahme der Scherfestigkeit deutlich (Abb.26). Am Ende der Inkubation war die mechanische Stabilität der Probehölzer um etwa 25\% erniedrigt und das Trockengewicht um $4 \%$ gesunken. Im Screening waren aber zuvor mehr als doppelt so große Abnahmen dieser Messwerte nach Abbau durch $G$. trabeum gemessen worden. Dort verhinderte ein vorangegangenes Autoklavieren der Probehölzer eine Ausbreitung von Schimmelpilzen. Für das Folgeexperiment wurden die Probehölzer nur pasteurisiert. Die nach etwa zehn Tagen in mehreren Kulturschalen ausbrechende Schimmelpilzinfektion reduzierte die Aggresivität des Braunfäulepilzes wahrscheinlich in solchem Maße, dass diese Werte nicht wieder erreicht werden konnten. 


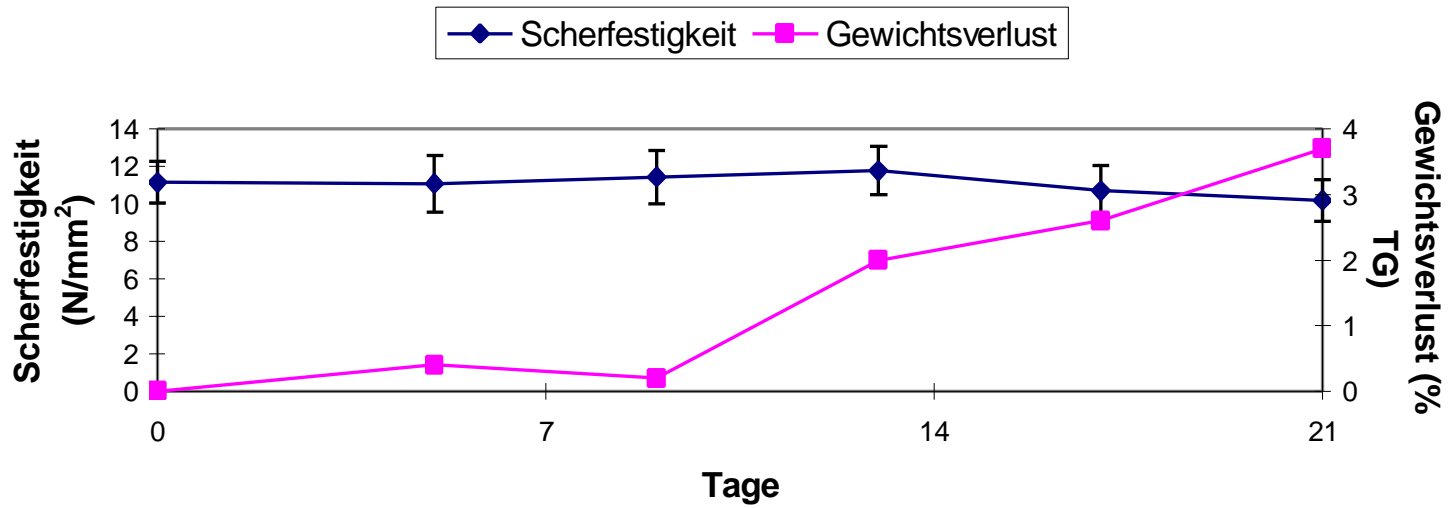

\section{Abbildung 24}

Scherfestigkeit und Gewichtsverlust von Kiefern-Probehölzern während dreiwöchiger Inkubation mit T. versicolor (simultane Weißfäule)

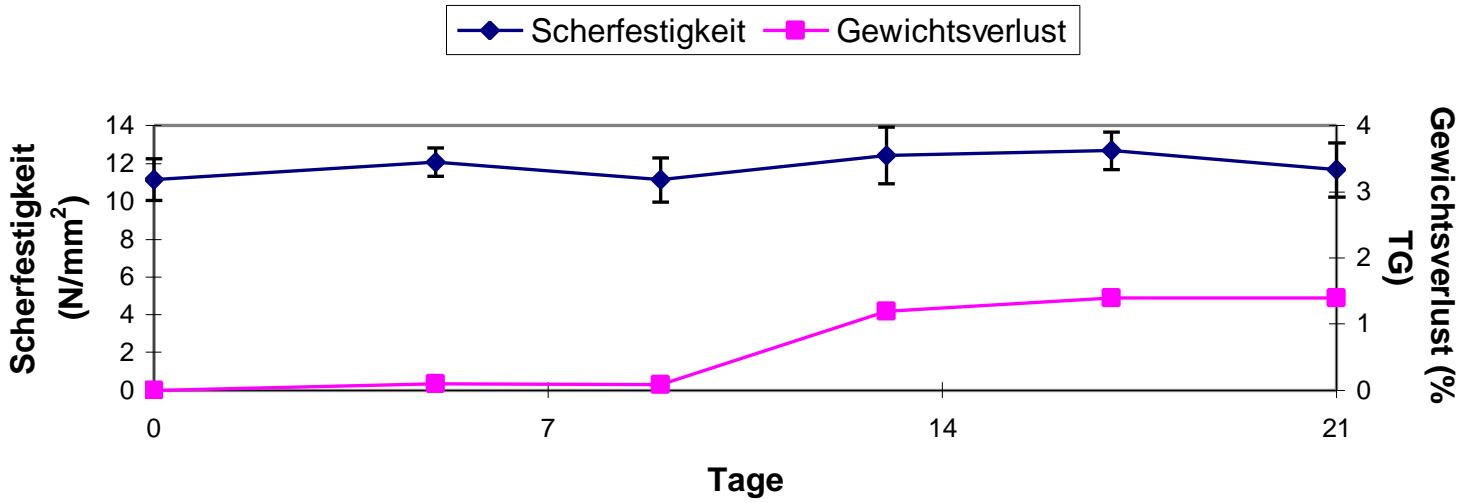

Abbildung 25

Scherfestigkeit und Gewichtsverlust von Kiefern-Probehölzern während dreiwöchiger Inkubation mit M. tremellosus (selektive Weißfäule)

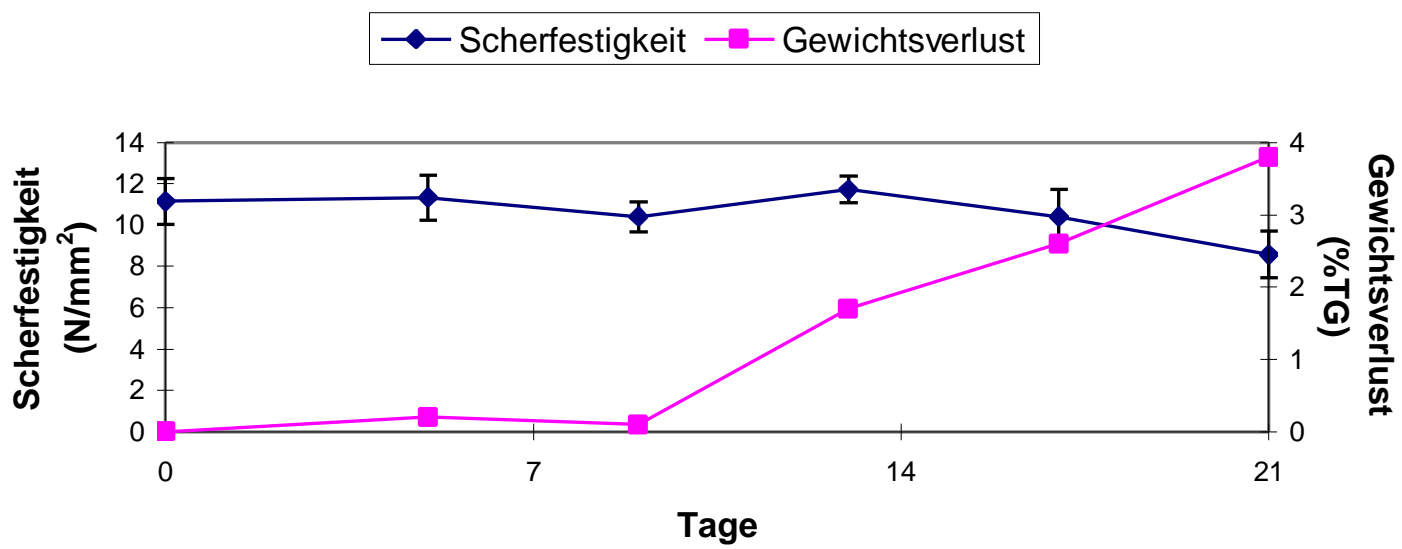

Abbildung 26

Scherfestigkeit und Gewichtsverlust von Kiefern-Probehölzern während dreiwöchiger Inkubation mit G. trabeum (Braunfäule) 
Der Befall von Kiefernholz mit den Weißfäulepilzen T. versicolor und M. tremellosus hatte wie auch schon im Screening keinen Einfluss auf die Scherfestigkeit in den ersten drei Wochen nach der Infektion (Abb.24, Abb.25). Das Trockengewicht der Probehölzer nahm infolge des Zellwandabbaues dagegen schon ab dem 13. Tag nach Inkubationsbeginn messbar ab.

Als ein indirektes $\mathrm{Ma}$ für die Pilzbiomasse-Produktion wurden die $\mathrm{CO}_{2^{-}}$und die Wärmefreisetzung der infizierten Probehölzer bestimmt. Die Messung beider Parameter wies auf einen kontinuierlichen Anstieg der pilzlichen Dissimilation und des Mycelwachstums im befallenen Holz vom Beginn bis zum Ende der Inkubation hin (Abb.27, Abb.28). Die Spitzenwerte der $\mathrm{CO}_{2^{-}}$und Wärmeproduktion wurden bei Kiefernholz gemessen, das mit dem Braunfäuleerreger G. trabeum infiziert war.
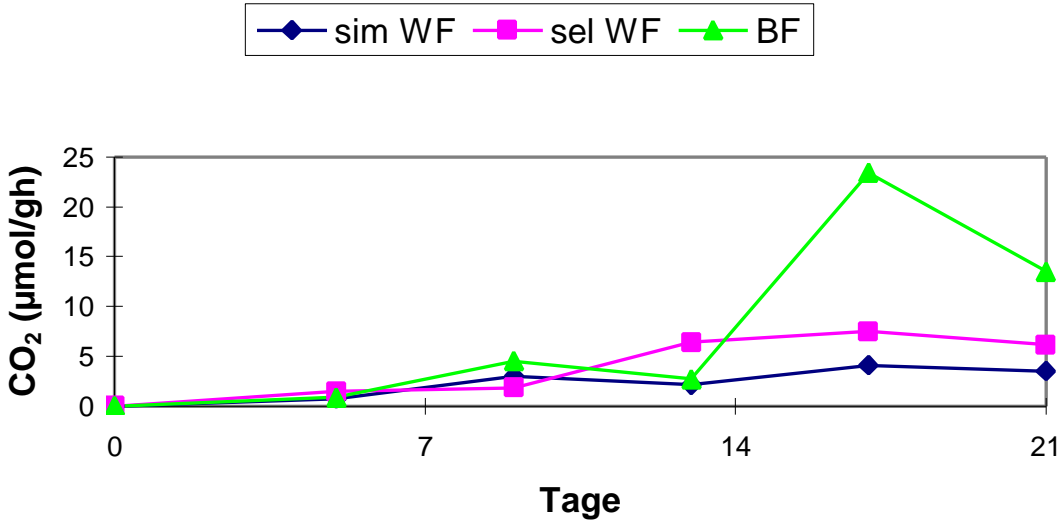

Abbildung 27

$\mathrm{CO}_{2}$-Produktion von infiziertem Kiefernholz
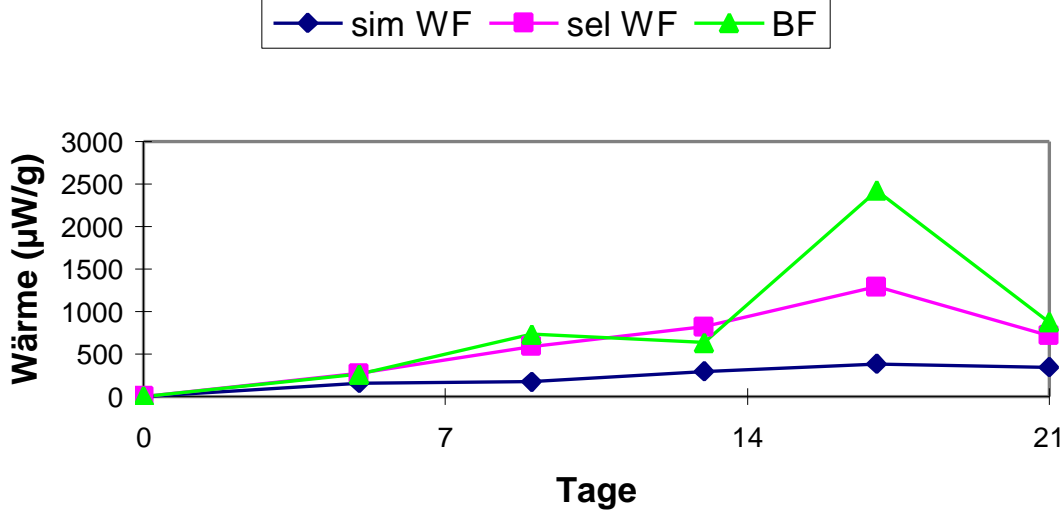

Abbildung 28

Wärmeproduktion von infiziertem Kiefernholz 


\section{TEM-EDXA der Zellwandelemente}

In nicht-merkurisiertem Kiefernholz wurde die Elementzusammensetzung der Tracheidenzellwände nach Fäulebefall mittels Röntgenmikroanalyse bestimmt. Zur besseren Übersicht wurde die Untersuchung auf die vier häufigsten gemessenen Elemente Magnesium, Kalium, Calcium und Mangan begrenzt.

Simultaner Weißfäulebefall durch T. versicolor verursachte in drei Wochen einen Rückgang der Konzentrationen der vier häufigsten Elemente in der Zellecke um etwa die Hälfte und von Calcium und Mangan in den Mittellamellen um etwa ein Drittel (Abb.29a,b). Die Röntgenmikroanalyse einer hier beobachteten elektronenoptisch dunklen Ablagerung auf der Lumenseite der Tertiärwand der Tracheiden gab einen Hinweis über den Verbleib der Zellwandelemente: Die Ablagerung bestand aus einer lokalen Akkumulation von Magnesium, Kalium, Calcium und Mangan.

Nach dreiwöchiger Inkubaton mit M. tremellosus, einem Erreger selektiver Weißfäule, wurden in allen untersuchten Zellwandbereichen nur noch etwa halb so große Magnesium-, Calcium- und Mangan-Konzentrationen gemessen wie zuvor, während die proportionale Abstufung der Konzentrationen zwischen den Zellwandbereichen erhalten blieb (Abb.29c). Die Kaliumkonzentration war nach dem Fäulebefall nur in der Zellecke reduziert.

Eine solche dunkle Ablagerung fand sich ebenso nach dreiwöchigem Braunfäulebefall durch G. trabeum am Rande des Lumens der Tracheiden. Auch hier konnte die Röntgenmikroanalyse eine Akkumulation derjenigen Elemente nachweisen, die während des Braunfäulebefalles aus tieferen Zellwandschichten herausgelöst worden waren (Abb.29d). Die Zellecken der Tracheiden wiesen im Vergleich zu den Mittellamellen und den Sekundärwänden überproportional große Verluste auf. Die in Kontrollen beobachtete Abstufung der Elementkonzentrationen zwischen den Referenzorten blieb hier deswegen nicht erhalten. 


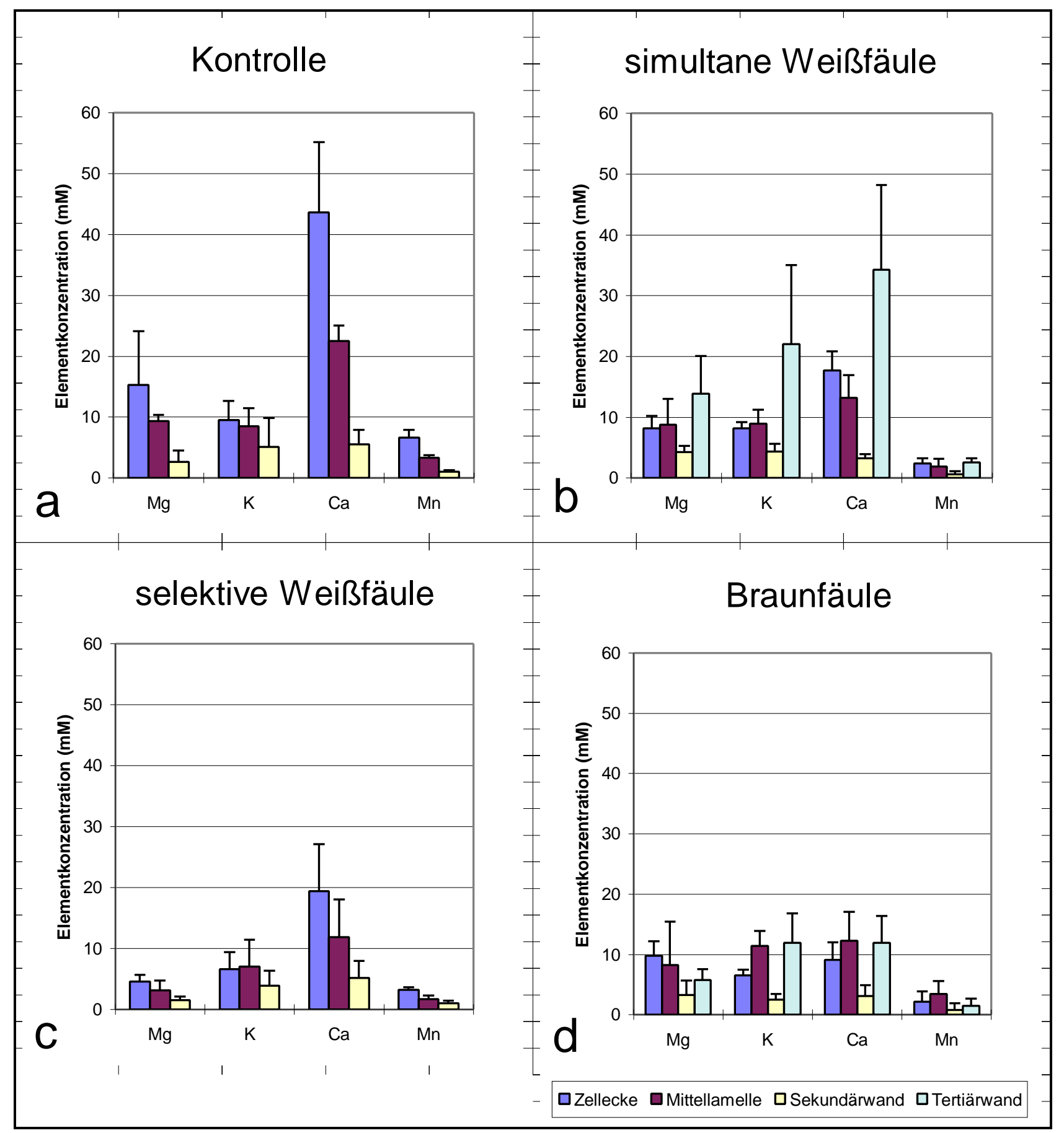

\section{Abbildung 29}

Röntgenmikroanalyse der Konzentrationen von Magnesium, Kalium, Calcium und Mangan an den Referenzorten Zellecke, Mittellamelle, Sekundärwand und Tertiärwandauflage in Kieferntracheiden nach Inkubation mit Fäulepilzen
a) Kontrolle
b) Simultane Weißfäule durch $T$. versicolor
c) Selektive Weißfäule durch M. tremellosus
d) Braunfäule durch G. trabeum 
Die Beobachtungen in der Frühphase des Befalls von Kiefernholz durch Fäulepilze lassen sich folgendermaßen zusammenfassen: Kiefernholz, das drei Wochen mit verschiedenen Fäulepilzen inkubiert worden war, wies nur geringe Anzeichen eines beginnenden Zellwandabbaues auf. Braunfäule verursachte im Vergleich die größten mikroskopisch feststellbaren Schäden in der Sekundärwand. Es hatte hier, wie auch bei simultaner und selektiver Weißfäule, jedoch noch kein flächendeckend an mehreren Referenzorten messbarer Ligninabbau stattgefunden. Parallel zu einer Absenkung der Scherfestigkeit des Kiefernholzes in dieser frühen Phase der Infektion wurde die massive Entfernung zweiwertiger Ionen aus allen Schichten der Tracheidenzellwand und deren Akkumulation auf der Lumenseite der Tertiärwand beobachtet. 


\subsubsection{Rotfaules Fichtenholz aus dem Freiland}

In Fichten, die an montanen Standorten die Schadsymptome Nadelvergilbung und Kronenverlichtung zeigten, wurde im Wurzelholz und im bodennahen Splintholz eine Infektion mit dem Erreger der Rotfäule Heterobasidion annosum nachgewiesen. Analysen des Aschegehaltes des pilzinfizierten Holzes wiesen auf eine drastische Veränderung der Elementkonzentrationen bei Pilzbefall hin (Tab.4).

In Göttingen wurden Proben des rotfaulen Fichtenholzes mikroskopisch und röntgenmikroanalytisch untersucht, um die auffälligen Ionen im befallenen Gewebe zu lokalisieren. In Querschnitten des befallenen Fichtenholzes wurden massive Ablagerungen einer stark lichtbrechenden amorphen Matrix im Lumen der Tracheiden beobachtet (Abb.30a-d). Bei stärkerer Vergrößerung im elektronenmikroskopischen Bild konnte gezeigt werden, dass in fast allen Tracheiden eine elektronendichte Schicht vom Lumen auf die Tertiärwand aufgelagert war (Abb.31b). Vor allem in Spätholztracheiden war das gesamte Lumen mit der amorphen Matrix ausgefüllt (Abb.31c). Neben den Ablagerungen wurden oft runde, hohle Strukturen beobachtet, die als Hyphenquerschnitte angesprochen wurden (Abb.31d). Die Mittellamelle in den Zellecken und zwischen zwei Tracheiden zeigte keine Veränderung, während die Sekundärwand an wenigen Stellen teilweise abgebaut war. 

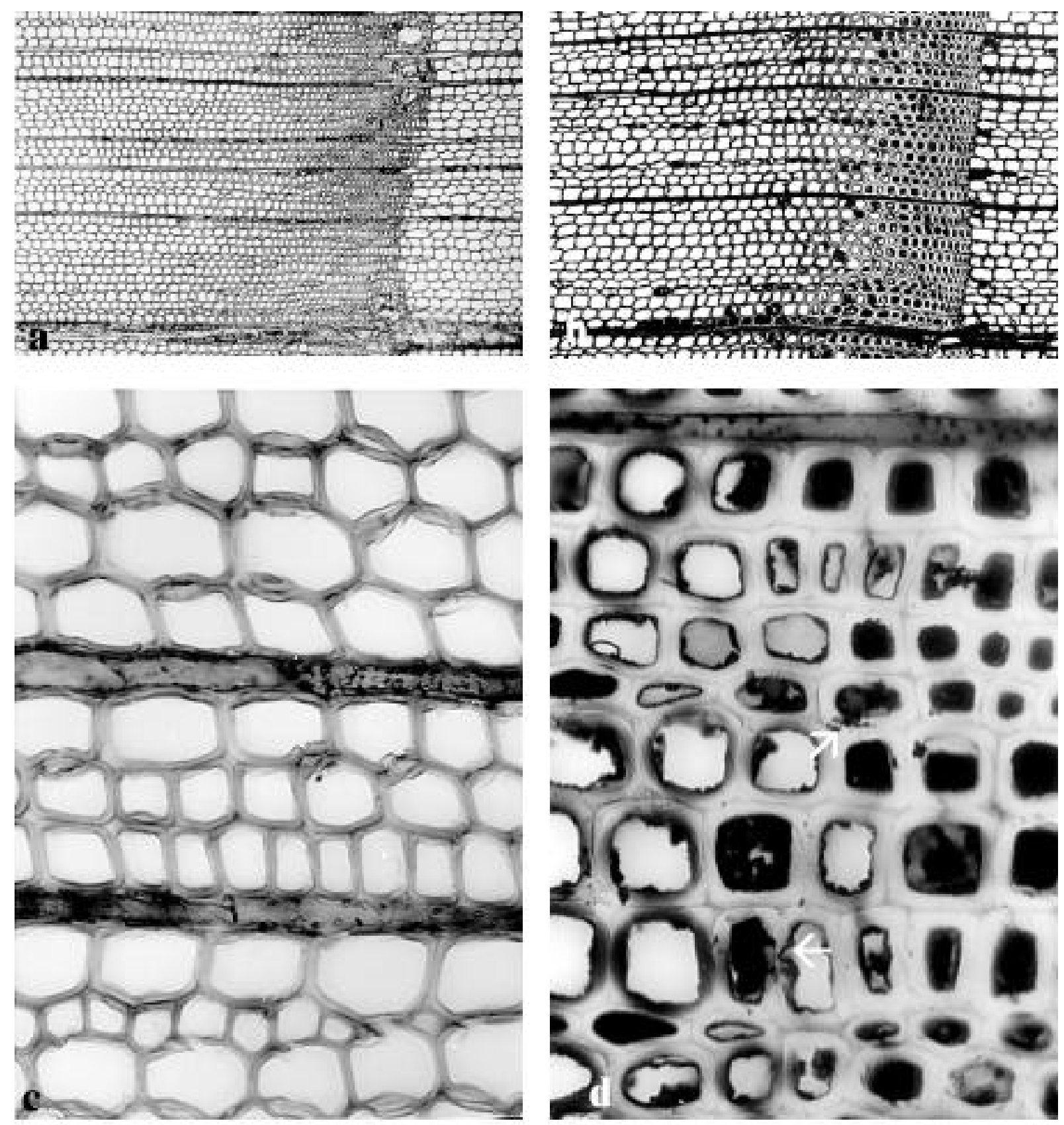

Abbildung 30

Querschnitte von Splintholz von Fichten aus der Steiermark

a) und c) Befallsfreies Fichtenholz, Kontrolle

b) und d) Rotfaules Fichtenholz mit Spuren der Besiedlung durch Heterobasidion annosum

Die Pfeile weisen auf teilweise abgebaute Sekundärwände. 

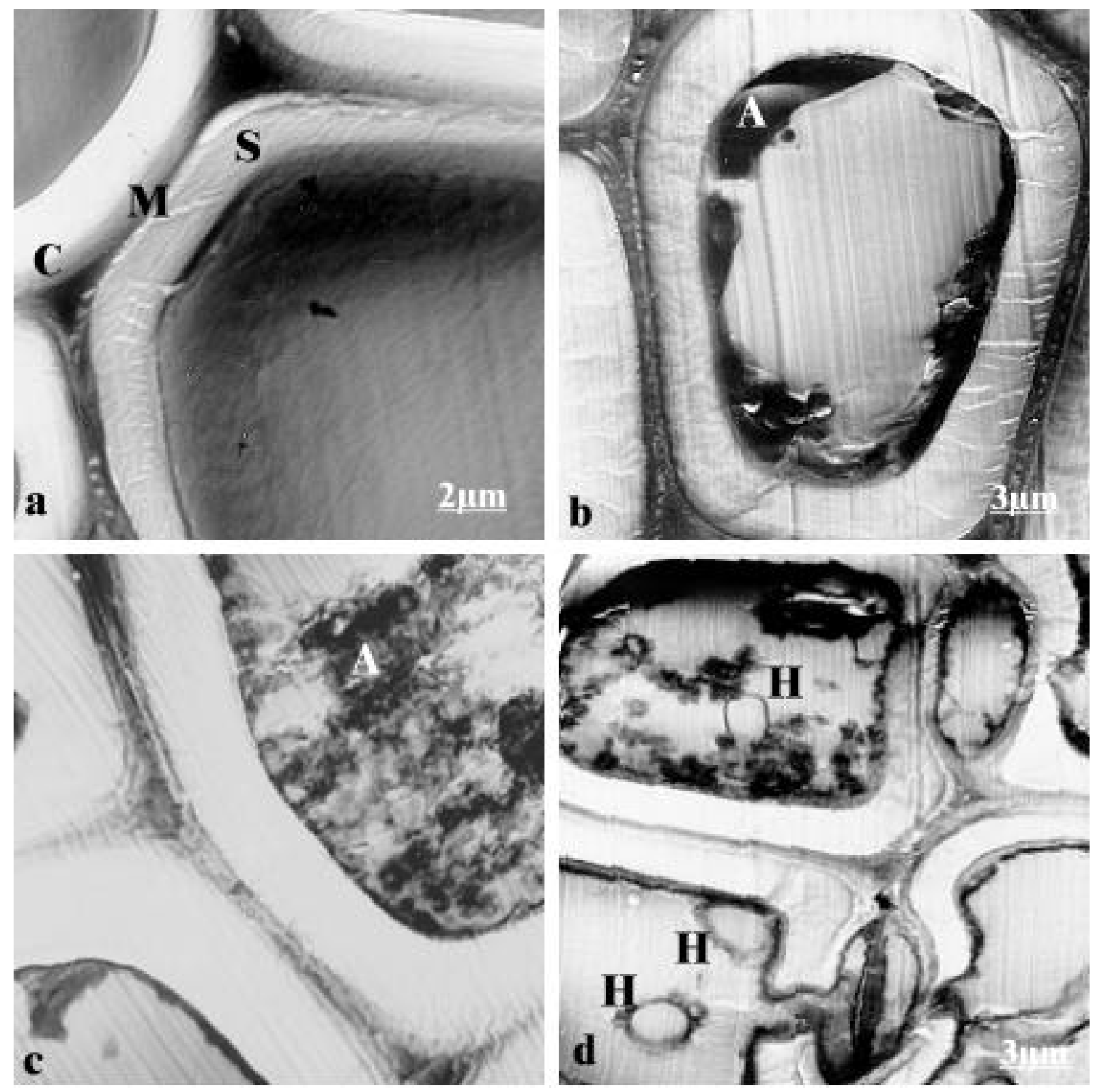

\section{Abbildung 31}

Mikrofotos von Fichtenholz

a) Kontrolle

Die Buchstaben bezeichnen die Referenzorte Zellecke (C), Mittellamelle (M) und Sekundärwand (S), an denen in einer Messreihe in Kontrollen und in infiziertem Holz die Elementkonzentration gemessen wurde.

b) Flächige Ablagerung (A)auf der Tertiärwand einer infizierten Tracheide

c) Amorphe Ablagerung (A) im Lumen einer infizierten Tracheide

d) Pilzhyphen $(\mathrm{H})$ im Lumen infizierter Tracheiden 


\section{Tabelle 4}

Auszug der Elementanalysen des veraschten Splintholzes von einer nichtinfizierten Fichte (K) und von vier rotfaulen Fichten der Standorte Gleinalm (G1 und G2) und Tamsweg (T3 und T4) (C. Tomiczek, persönliche Mitteilung)

$\begin{array}{cccc} & \text { Kalium } & \text { Calcium } & \text { Magnesium } \\ \text { K } & \% & \% & \% \\ \text { G1 } & 0,06 & 0,08 & 0,01 \\ \text { G2 } & 0,23 & 0,1 & 0,02 \\ \text { T3 } & 0,58 & 0,17 & 0,05 \\ \text { T4 } & 0,44 & 0,11 & 0,03 \\ & 0,77 & 0,14 & 0,07\end{array}$

Da die Zellwände der Tracheiden nur geringe Spuren des Abbaues durch Rotfäule aufwiesen, wurde auf eine Röntgenmikroanalyse der Ligninverteilung in situ verzichtet. Bei vergleichbarer Schädigung von Buchen- und Kiefernholz durch Weißfäule- und Braunfäulepilze im Laborversuch waren zuvor keine Änderungen im Ligningehalt der Zellwand gefunden worden (s.o.). Die Röntgenmikroanalyse wurde jedoch eingesetzt, um die Elementprofile der Zellwand infizierter und nicht-infizierter Tracheiden zu unterscheiden und um die Zusammensetzung der amorphen Ablagerungen zu identifizieren. In einer Messreihe wurde die Elementzusammensetzung der Zellecke, der zusammengesetzten Mittellamelle, der Sekundärwand und der Tertiärwand beziehungsweise der ihr aufgelagerten schwarzen Schicht erfasst. Elemente mit der Molmasse von Natrium und größer wurden durch ihr Röntgenemissionsspektrum identifiziert. Die drei häufigsten Elemente Kalium, Magnesium und Calcium wurden quantifiziert (Abb.32a-c). Außerdem wurden Spuren von Natrium, Silicium, Phosphor, Schwefel und Eisen gemessen (Daten nicht gezeigt). 
Die Kaliumkonzentration war in allen untersuchten Zellwandbereichen nach Rotfäulebefall deutlich höher als in nicht-befallenem Gewebe (Abb.32a). Am geringsten war der Anstieg in der Sekundärwand des Baumes G2, wo die 4fache Konzentration im Vergleich zur Kontrolle gemessen wurde. Der höchste Anstieg innerhalb der Zellwand wurde in den Zellecken der Tracheiden des Baumes T4 beobachtet. Die Kaliumkonzentration erreichte dort das 24fache des Kontrollwertes. Die höchsten lokalen Kaliumkonzentrationen überhaupt wurden jedoch in der schwarzen Ablagerung auf der Tertiärwand gemessen. In Proben der beiden Bäume T3 und T4 wurden innerhalb der Ablagerungen durchschnittliche Konzentrationen von $550 \mathrm{mM}$ beziehungsweise $400 \mathrm{mM}$ gefunden, während die Tertiärwand in nicht-infizierten Kontrollen nur $15 \mathrm{mM}$ Kalium enthielt. Die verstärkte Einlagerung von Kalium zeigte innerhalb der Tracheidenzellwände der vier befallenen Bäume keine Bevorzugung der Zellecke, der zusammengesetzten Mittellamelle oder der Sekundärwand. Stets wurde eine proportionale Steigerung in allen drei Bereichen gefunden. Auch die Magnesiumkonzentration war infolge des Rotfäulebefalls in den Zellwandschichten erhöht. Der Anstieg folgte dem schon bei Kalium beschriebenen Muster: Die Zunahme der Magnesiumkonzentration war in den drei untersuchten Zellwandbereichen stets proportional. Die absoluten Werte der Magnesiumkonzentrationen schwankten je nach Zellwandbereich zwischen $2 \mathrm{mM}$ in der Sekundärwand und $8 \mathrm{mM}$ in der Mittellamelle von Kontrollen und zwischen $4 \mathrm{mM}$ in der Sekundärwand im Baum G2 und $46 \mathrm{mM}$ in der Zellecke im Baum T4. Die höchste Konzentration wurde in der Ablagerung im Lumen der Tracheiden in den Bäumen T3 gemessen (128 mM).

Die Calciumkonzentrationen waren in der Zellecke, der zusammengesetzten Mittellamelle und der Sekundärwand der von Rotfäule befallenen Tracheiden niedriger als in vergleichbaren nicht-infizierten Tracheiden (Abb.32c). In der Auflage der Tertiärwand wurde eine uneinheitliche Änderung der Calciumkonzentration festgestellt. Während sie in den Bäumen G2 (76 mM) und T3 $(77 \mathrm{mM})$, bei großer Standardabweichung vom Mittelwert, deutlich höher als in der Kontrolle $(21 \mathrm{mM})$ war, wurden in den Bäumen G1 $(6 \mathrm{mM})$ und $\mathrm{T} 4(8 \mathrm{mM})$ kleinere Mengen Calcium gemessen. 

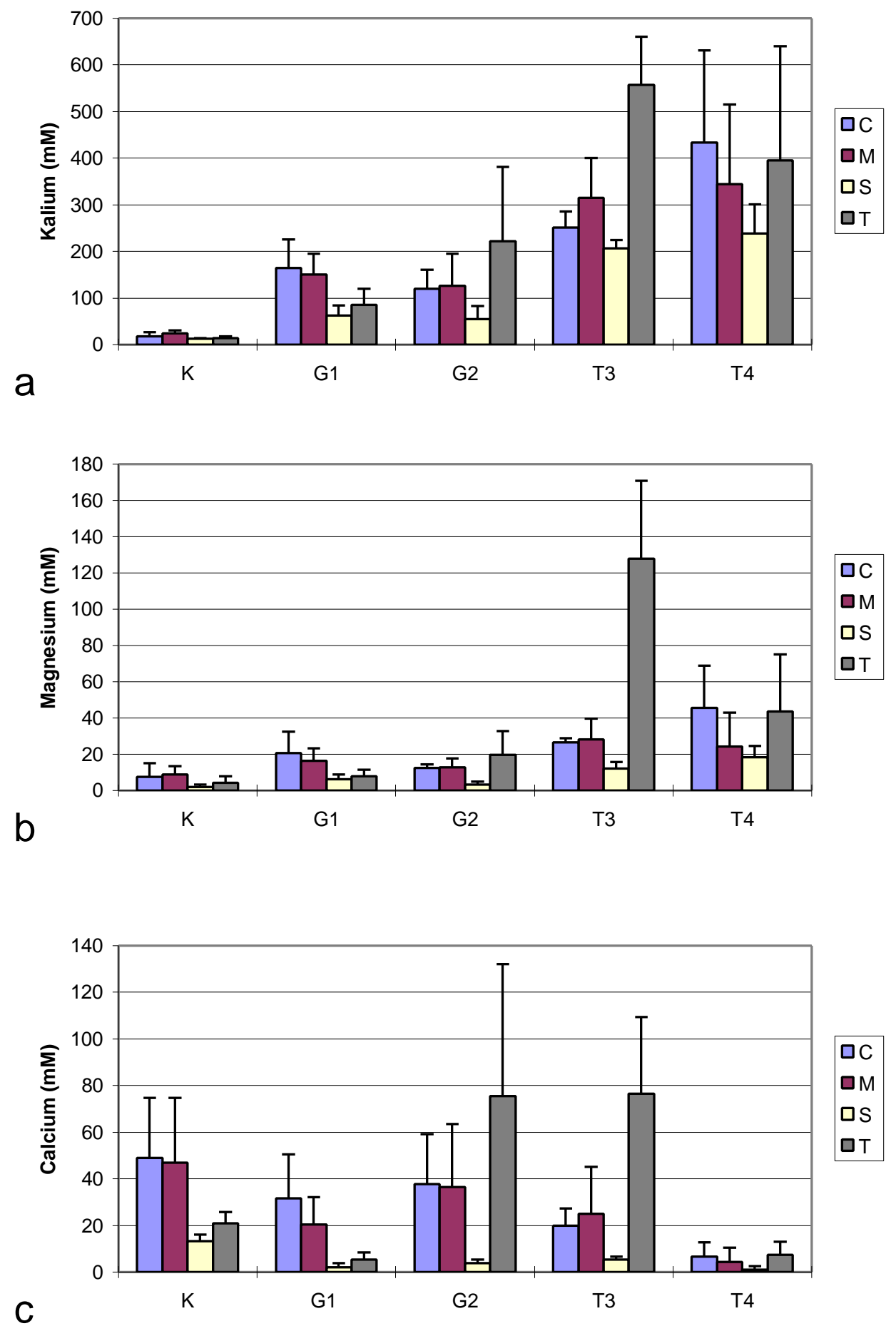

\section{Abbildung 32}

Röntgenmikroanalyse von rotfaulem Fichtenholz

Es wurde die Kaliumkonzentration (a), Magnesiumkonzentration (b) und Calciumkonzentration (c) in nicht-befallenem Fichtenholz (K) und in zwei rotfaulen Fichten vom Standort Gleinalm (G1 und G2) und in zwei rotfaulen Fichten vom Standort Tamsweg (T3 und T4) gemessen. Die Elementkonzentrationen wurden jeweils an den Referenzorten Zellecke (C), Mittellamelle (M), Sekundärwand (S) und Tertiärwandauflage ( $\mathrm{T}$ ) bestimmt. 
Die Beobachtungen zur Elementverteilung, die an pilzbefallenen Splintholzproben eines lebenden Baumes gemacht wurden, können folgendermaßen zusammengefasst werden: In Fichtenholztracheiden, die im Freiland mit dem Erreger der Rotfäule Heterobasidion annosum befallen waren, aber erst geringe Schäden durch Zellwandabbau aufwiesen, wurde eine umfassende Umverteilung von Kalium, Magnesium und Calcium in der Zellwand festgestellt. Während Kalium und Magnesium auch in tieferen Zellwandschichten angereichert wurden, wurde Calcium aus diesen Schichten entfernt. Amorphe Ablagerungen im Lumen der infizierten Tracheiden enthielten teilweise höhere Konzentrationen an Kalium, Magnesium und Calcium als Zellwandbereiche. 


\subsection{Lignin in biotechnologischen Holzwerkstoffen}

\subsubsection{Ligningehalt in Thermomechanischem Faserstoff (TMP) und daraus hergestellten Mitteldichten Faserplatten (MDF)}

\section{Thermomechanischer Faserstoff (TMP)}

Rasterelektronenmikroskopische Untersuchungen von Faserstoff, der im thermomechanischen Aufschlussverfahren bei $180{ }^{\circ} \mathrm{C}$ gewonnen wurden, belegten, dass die Auftrennung des gewachsenen Gewebeverbandes annähernd vollständig war (Abb.33a). Im Querschnitt wiesen die Fasern, deren Lumen zumeist kollabiert war, eine Zonierung in zwei Schichten auf (Abb.33b). Die innere, dickere Schicht wurde von der Sekundärwand gebildet, die außen von einer ungleichmäßigeren Schicht vollständig umhüllt wurde. Nach Merkurisierung des Lignins wurde in der Röntgenmikroanalyse in dieser äußeren Schicht ein vielfach größeres Hg-Lignin-Signal detektiert als in der Sekundärwand (Abb.33d). Diese Schicht bestand demnach aus Resten der stark lignifizierten ehemaligen Mittellamelle, die nach der Trennung auf der Faseroberfläche verblieben waren. Auf SEM-Bildern einiger freier Fasern war ein Aufplatzen und Abschilfern dieser Schicht aus ehemaligem Mittellamellenlignin zu beobachten (Abb.33c).

Aufgrund dieser Beobachtung lassen sich die Vorgänge beim Faseraufschluss folgendermaßen beschreiben: Die hohen Temperaturen oberhalb des Schmelzpunktes von Lignin während des Aufschlusses erlauben eine Aufteilung des Mittellamellenlignins auf benachbarte Fasern beim Angreifen großer Scherkräfte im Refiner. Nach dem Unterschreiten der Glas-Übergangs-Temperatur erstarrt das geschmolzene Lignin und bildet eine Haut oder starre Kruste um die Faser.

\section{Mitteldichte Faserplatten (MDF)}

Aus TMP wurden von R. Kharazipour nach dem von ihm entwickelten Verfahren (Deutsches Patent Nr. 4305411, 1993) Mitteldichte Faserplatten (MDF) ohne Zugabe eines Bindemittels hergestellt. In fünf verschiedenen MDF wurde die neue Faser-FaserBindung elektronenmikroskopisch und röntgenmikroanalytisch untersucht. Die MDF unterschieden sich in der Art der Vorbehandlung des Fasermaterials vor dem Verpressen: 


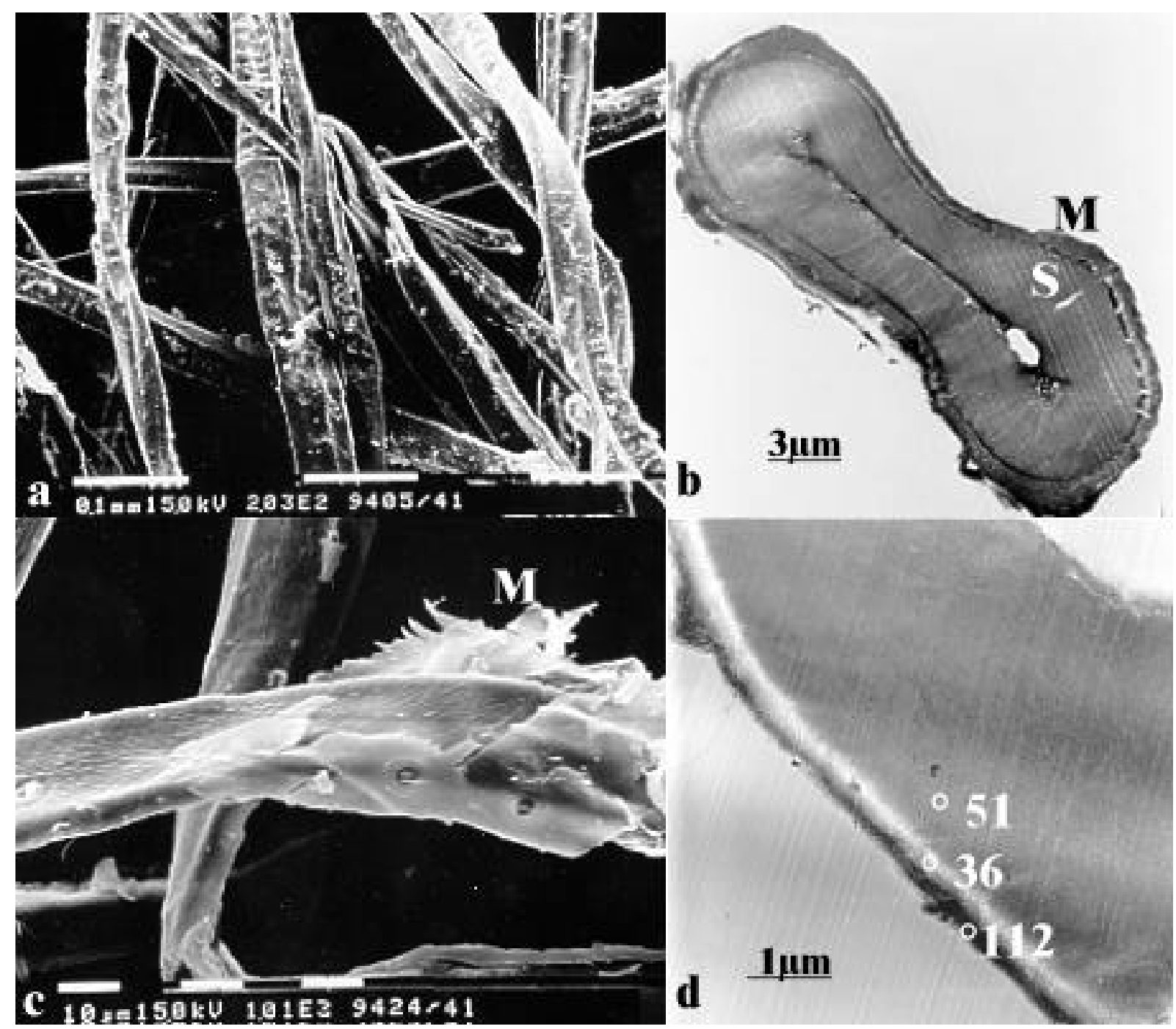

\section{Abbildung 33}

Thermomechanischer Faserstoff (TMP)

a) SEM-Mikrofoto von aufgeschlossenem Faserstoff

Im Refiner bei $180^{\circ} \mathrm{C}$ wird der Gewebeverband vollständig aufgelöst.

b) TEM-Mikrofoto einer einzelnen Faser im Querschnitt

Das Lumen der Faser ist kollabiert, ihre Sekundärwand (S) wird von einer Schicht aus ehemaligem Mittellamellen-Lignin (M) umhüllt.

c) SEM-Mikrofoto einer einzelnen Faser

Die ligninhaltige Schicht (M), die deutliche Aussparungen im Bereich der Hoftüpfel erkennen lässt, platzt bei einigen Fasern ab.

d) TEM-Mikrofoto eines Ausschnitts einer einzelnen Faser im Querschnitt

Die Zahlen geben die Röntgenemission merkurisierten Lignins in counts per second (cps) an. Der Ligningehalt in den Überresten der Mittellamelle auf der Außenfläche der Faser ist höher als in der Sekundärwand. 

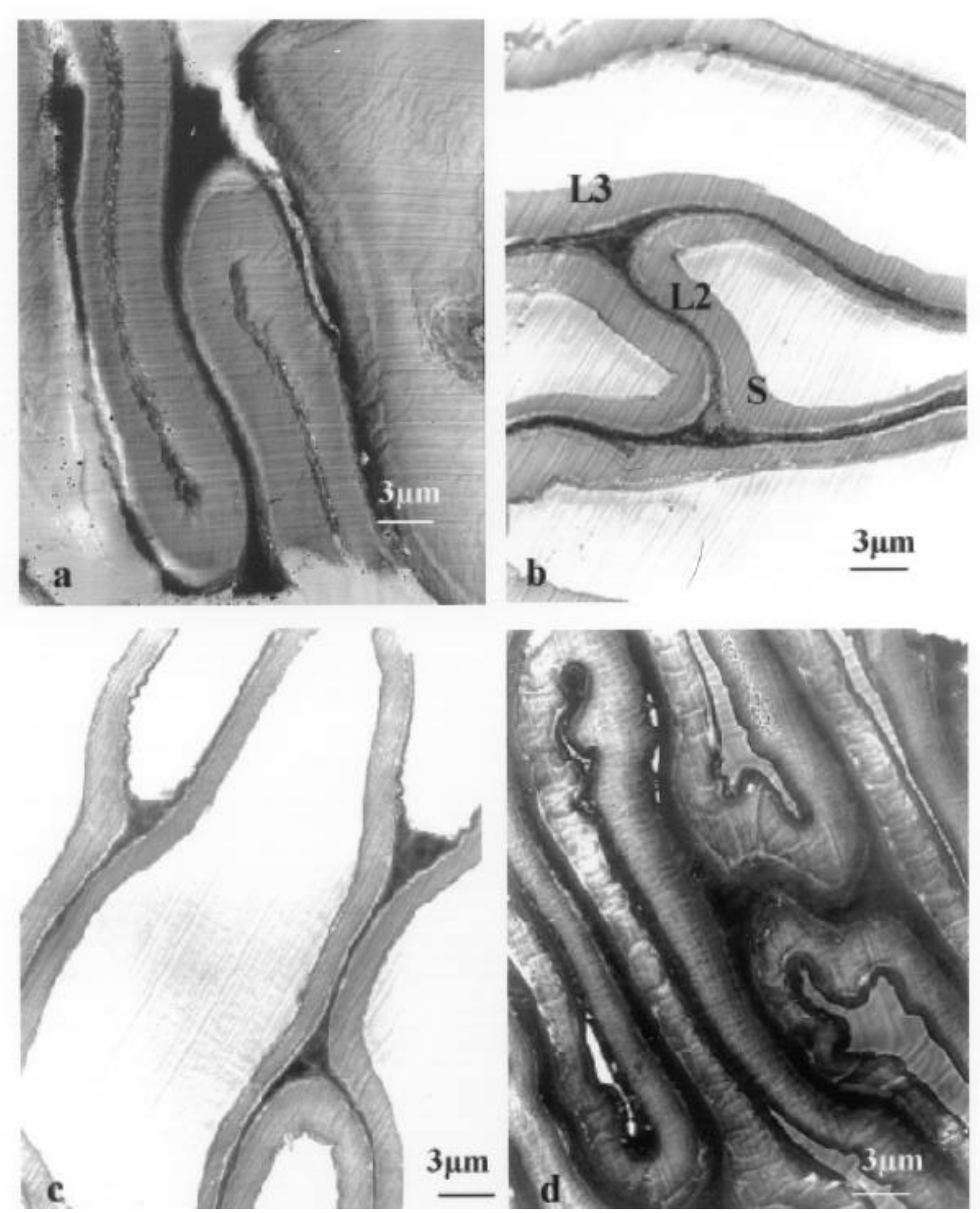

\section{Abbildung 34}

Mitteldichte Faserplatten

a) Nassverfahren ohne Enzym, Kontrolle

b) Nassverfahren mit Laccase

c) Trockenverfahren ohne Enzym, Kontrolle

d) Trockenverfahren mit Laccase

In einer Messreihe wurde der relative Ligningehalt in den Leimfugen zwischen 3 Fasern (L3), in den Leimfugen zwischen 2 Fasern (L2) und in der Sekundärwand (S) der Fasern bestimmt. 
(1) Nassverfahren, ohne Enzym (Kontrolle)

(2) Nassverfahren, mit Laccase

(3) Trockenverfahren, ohne Enzym (Kontrolle)

(4) Trockenverfahren, mit Laccase

(5) Trockenverfahren, mit Manganperoxidase

Unabhängig von der Auftragungsart, der Zugabe und der Art des Enzyms bei der Vorbehandlung des Fasermaterials bot sich in Querschnitten durch die MDF stets das gleiche Bild aneinander haftender Fasern (Abb.34). Die Fasern waren in der Mehrzahl unregelmäßig verformt und ihre Lumina kollabiert. Dabei musste berücksichtigt werden, dass die meisten Fasern schräg und nicht horizontal angeschnitten wurden. Die Leimfugen zwischen zwei Fasern waren gleichmäßig dick (etwa $0,5 \mu \mathrm{m}$ ) und mit einer amorphen Matrix ausgefüllt. Diese Matrix füllte auch den Raum in der Kontaktzone dreier Fasern aus. Insgesamt bildeten die Fasern unter Vermittlung der formbaren Matrix beim Verpressen ein Gefüge, welches dem gewachsenen Gewebe "Holz" sehr ähnlich sah.

In Proben der Kontroll-Faserplatten blieben nach Merkurisierung für die Röntgenmikroanalyse nur noch wenige Leimfugen erhalten. Die ausgeschnittenen Stifte quollen auf und die Fasern rückten auseinander. Proben der MDF aus enzymatisch vorbehandeltem Faserrohstoff wiesen dagegen eine höhere Nassfestigkeit und Stabilität auf. In merkurisierten Proben der fünf MDF wurde der Ligningehalt in der Leimfuge zwischen drei Fasern (L3), in der Leimfuge zwischen zwei Fasern (L2) und in der Sekundärwand (S) der Fasern mittels Röntgenmikroanalyse gemessen (Abb.35). Trotz der unterschiedlichen Vorbehandlungen des Fasermaterials wurde in allen fünf MDF an den drei Referenzorten L3, L2 und S jeweils ein ähnlicher Ligningehalt gemessen. Der Ligningehalt war in der Leimfuge zwischen drei Fasern 2,5mal so groß und zwischen zwei Fasern 2mal so groß wie in der Sekundärwand. Da die Sekundärwand von Nadelholztracheiden zu etwa $20 \%$ aus Lignin besteht (Wagenführ, 1984), konnte Lignin auf diese Weise indirekt als ein Hauptbestandteil der Matrix, die den Oberflächenkontakt der Fasern vermittelt, identifiziert werden. 


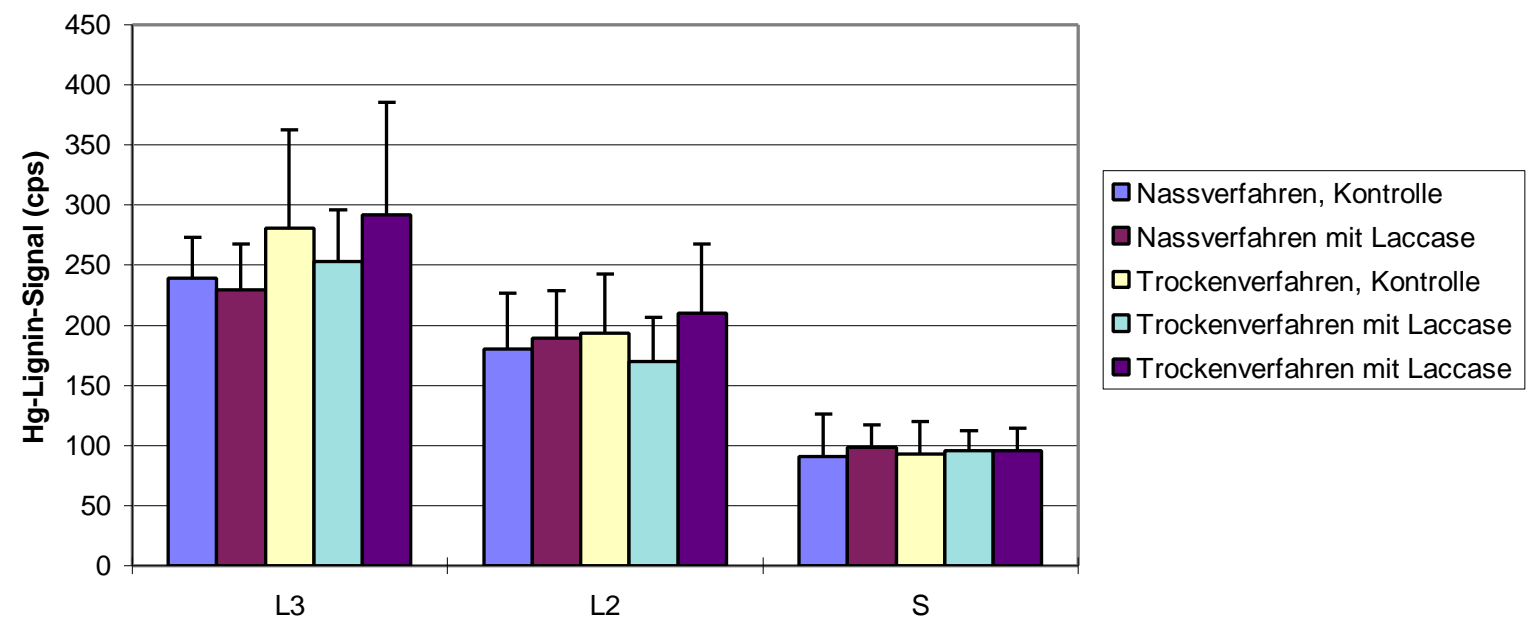

\begin{abstract}
Abbildung 35
Röntgenmikroanalyse von Mitteldichten Faserplatten

Fünf Mitteldichte Faserplatten (MDF) wurden ohne Zugabe eines synthetischen Bindemittels aus Thermomechanischem Faserstoff (TMP) gepresst. Der Faserstoff wurde zuvor mit ligninolytischen Enzymen inkubiert, die aus Kulturen von Weißfäulepilzen isoliert wurden. Die Röntgenmikroanalyse merkurisierten Lignins wurde in den Leimfugen zwischen 3 Fasern (L3), in den Leimfugen zwischen 2 Fasern (L2) und in der Sekundärwand (S) der Fasern durchgeführt.
\end{abstract}



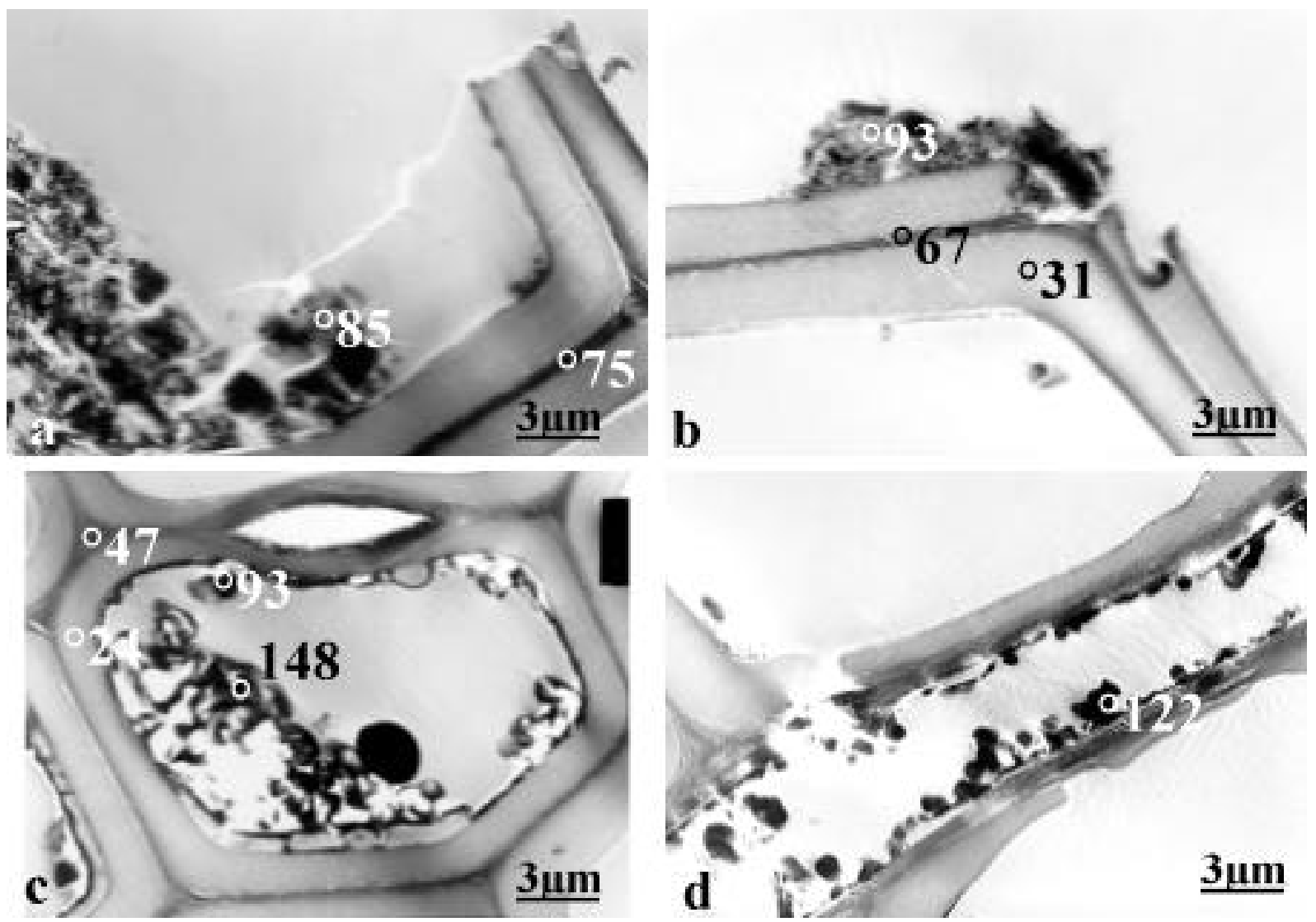

\section{Abbildung 38}

Röntgenmikroanalyse der Ablagerungen an und in beleimten Spänen

Angegeben ist die Röntgenemission merkurisierten Lignins in cps.

a) Ligninablagerung in einer aufgerissenen Tracheide

b) Ligninablagerung an einer exponierten Bruchstelle der Tracheidenzellwand

c) Ligninablagerung im intakten Lumen einer Tracheide

d) Ligninablagerung in einer Holzstrahl-Parenchymzelle

\section{Bioleim in Spanplatten}

Aus Spänen, auf deren Oberfläche reiner Lignin-Bioleim aufgebracht worden war, waren Spanplatten ohne Zugabe weiterer Bindemittel gepresst worden. Diese Spanplatten wurden mit einer verkanteten Rasierklinge aufgebrochen, um einen Einblick in das künstliche Gefüge des neuen Werkstoffes zu gewinnen. Bei Betrachtung der aufgebrochenen Spanplatte im SEM wurden auch hier granuläre Ligninablagerungen auf den freigelegten Außenflächen der beleimten Späne sichtbar (Abb.39a,b). Nur Ligninpartikel, die auf exponierten Bruchkanten der Tracheiden abgelagert waren, konnten einen Kontakt zur

Oberfläche des benachbarten Spans vermitteln. Ligninpartikel in den Rinnen der aufgebrochenen Tracheiden konnten aus sterischen Gründen keine Leimfuge zwischen zwei Spänen bilden. In Querschnitten nicht-merkurisierter, eingebetteter Proben wurde die Gestalt des Lignins in den Leimfugen näher untersucht. Die Ligninablagerung 

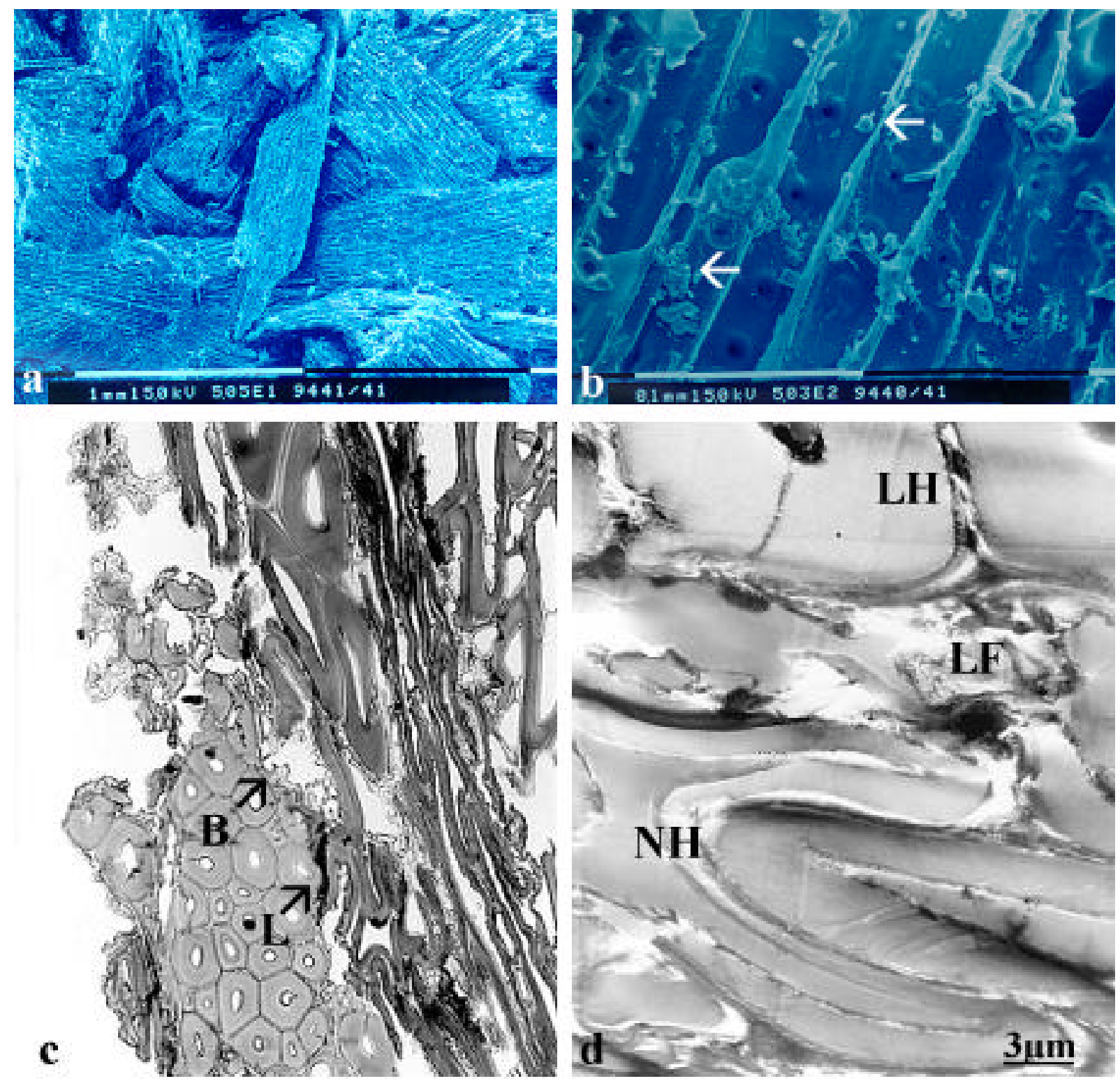

\section{Abbildung 39}

Spanplatte mit Bioleim

a) SEM-Mikrofoto, aufgebrochene Spanplatte, Übersicht

b) SEM-Mikrofoto, Spanoberfläche mit Ligninpartikeln (Pfeile)

c) LM-Foto, Leimfuge zwischen Laub- und Nadelholzspänen mit durchsichtigem flächigem Bioleim (B) und dunklem komprimiertem Bioleim in der Leimfuge (L)

d) TEM-Mikrofoto, Lignin in der Leimfuge (LF) zwischen Laubholzspan (LH) und Nadelholzspan (NH)

auf den Spänen erschien bei lichtmikroskopischer Betrachtung durchsichtig (Abb.39c). In den Leimfugen wies Lignin keine granuläre Struktur auf, sondern verband als flächiger amorpher Belag benachbarte Spanoberflächen. Die Röntgenmikroanalyse von Lignin in Leimfugen der Spanplatte war nicht möglich, da sich die Leimfugen während der Merkurisierung in kochendem essigsaurem Methanol auflösten. 

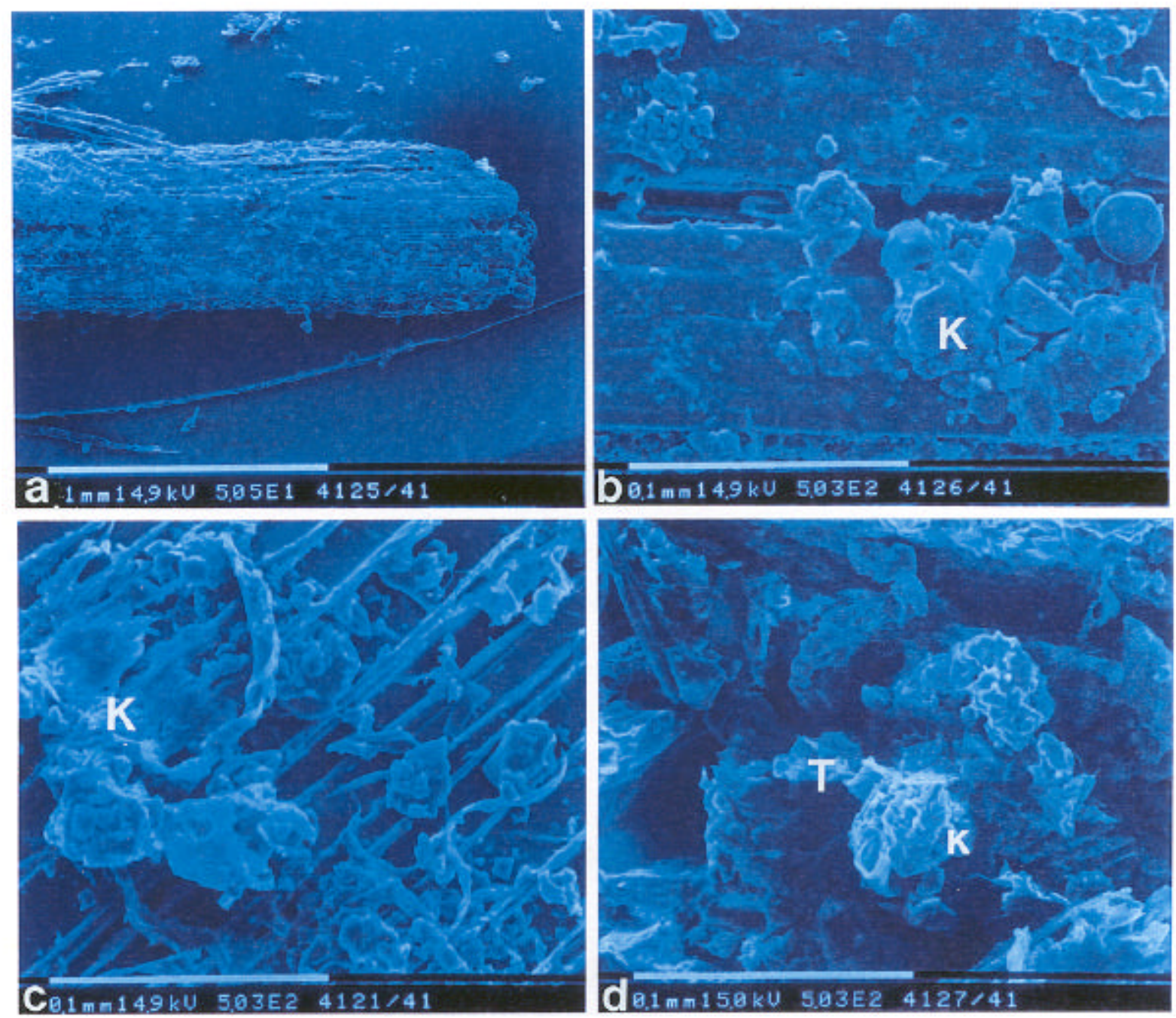

\section{Abbildung 40}

Span mit Bioleim und PMDI-Zusatz

a) Beleimter Span, Übersicht

b) Beleimter Span, Konglomerat aus Lignin und PMDI (K) auf Spanseitenfläche

c) Beleimter Span, Konglomerat aus Lignin und PMDI (K) auf Spanseitenfläche

d) Beleimter Span, Konglomerat aus Lignin und PMDI (K) auf Tracheidenbruchkante (T)

\section{Bioleim mit PMDI-Zusatz auf Spänen und in Spanplatten}

Eine modifizierte Verteilung von Bindemittelpartikeln wurde auf der Oberfläche von Spänen angetroffen, die mit einer 10:1 Mischung aus Bioleim und Phenylmethan-Diisocyanat (PMDI) benetzt worden waren. Der Bedeckungsgrad der Spanoberfläche mit Bindemittelpartikeln war bei diesem Leim mit 40\% doppelt so hoch wie ohne PMDI-Zusatz. Außerdem wurden zahlreiche Konglomerate aus kugelrunden, kubischen und amorphen Bindemittelpartikeln vorgefunden (Abb.40). Diese Konglomerate besaßen einen Durchmesser bis zu $100 \mu \mathrm{m}$ und waren daher teilweise groß genug, um angerissene Tracheiden zu verstopfen. Die genaue morphologische Zuordnung von Lignin- und PMDIAnteil in diesen inhomogenen Strukturen mittels Röntgenmikroanalyse war nicht möglich, weil sie die Merkurisierung nicht intakt überstanden. 


\subsubsection{Verteilung von Lignin-Bioleim auf Spänen und in Spanplatten}

\section{Bioleim auf Spänen}

Lignin war in wässriger Suspension als enzymatisch reaktivierter Bioleim auf Holzspäne aufgebracht worden. Diese Auftragungsart entspricht dem Verfahren, das auch für synthetische Bindemittel verwendet wird. Für die Holzspäne war eine Gewichtszunahme um etwa 10\% ihres Trockengewichtes durch anhaftendes Lignin beobachtet worden (A. Hüttermann, persönliche Mitteilung). Die Aufgabe war nun, mittels mikroskopischer Techniken in Verbindung mit der Röntgenmikroanalyse das Lignin auf den Spänen zu lokalisieren und seine Morphologie zu beschreiben. Insbesondere galt es, Ursachen dafür zu finden, dass durch Behandlung der beleimten Späne mit $\mathrm{NaOH}$ nie mehr als $50 \%$ des eingesetzten Lignins von den Spänen wieder gelöst werden konnten (A. Hüttermann, persönliche Mitteilung).

Unbeleimte Nadelholzspäne wiesen bei der Betrachtung im SEM in der Seitenansicht eine rauhe Oberfläche mit vielen parallelen Rinnen in Längsrichtung auf (Abb.36a,b). Diese Rinnen waren entstanden, als beim Materialaufschluss der Gewebeverband aufgebrochen worden war. In Querschnitten konnten diese Rinnen als Tracheidenfragmente identifiziert werden (Abb.37a,b). Die bevorzugte Bruchstelle von Nadelholz in Längsrichtung beim Zerspanen ist demzufolge nicht die Mittellamelle wie beim Faseraufschluss im Refiner, sondern die Sekundärwand.

Auf der Oberfläche von beleimten Spänen wurden zahlreiche granuläre Ablagerungen beobachtet (Abb.36c,d,e,f). Die Ablagerungen mit einer Korngröße bis zu 10 $\mu$ m bedeckten etwa $20 \%$ der Oberfläche, wie die Auswertung von acht 200 x $300 \mu$ m großen Flächen mit einem Bild-Analyse-System ergab. Der Großteil der granulären Ablagerungen war in den Rinnen, den aufgerissenen Lumen der Tracheiden, deponiert. In geringerem Maße waren die Körnchen auch auf den longitudinalen und transversalen Bruchkanten der Tracheiden zu finden. Sie waren jedoch nicht groß genug, um die Lumen der quergebrochenen Tracheiden $\mathrm{zu}$ verstopfen.

Beleimte Späne wurden merkurisiert und eingebettet, um an Querschnitten die Verteilung und Zusammensetzung der granulären Ablagerungen zu untersuchen. Schon bei lichtmikroskopischer Betrachtung der angefertigten Semidünnschnitte wurden stark lichtbrechende Ablagerungen an der Außenfläche der Späne, aber auch in weiter innen 

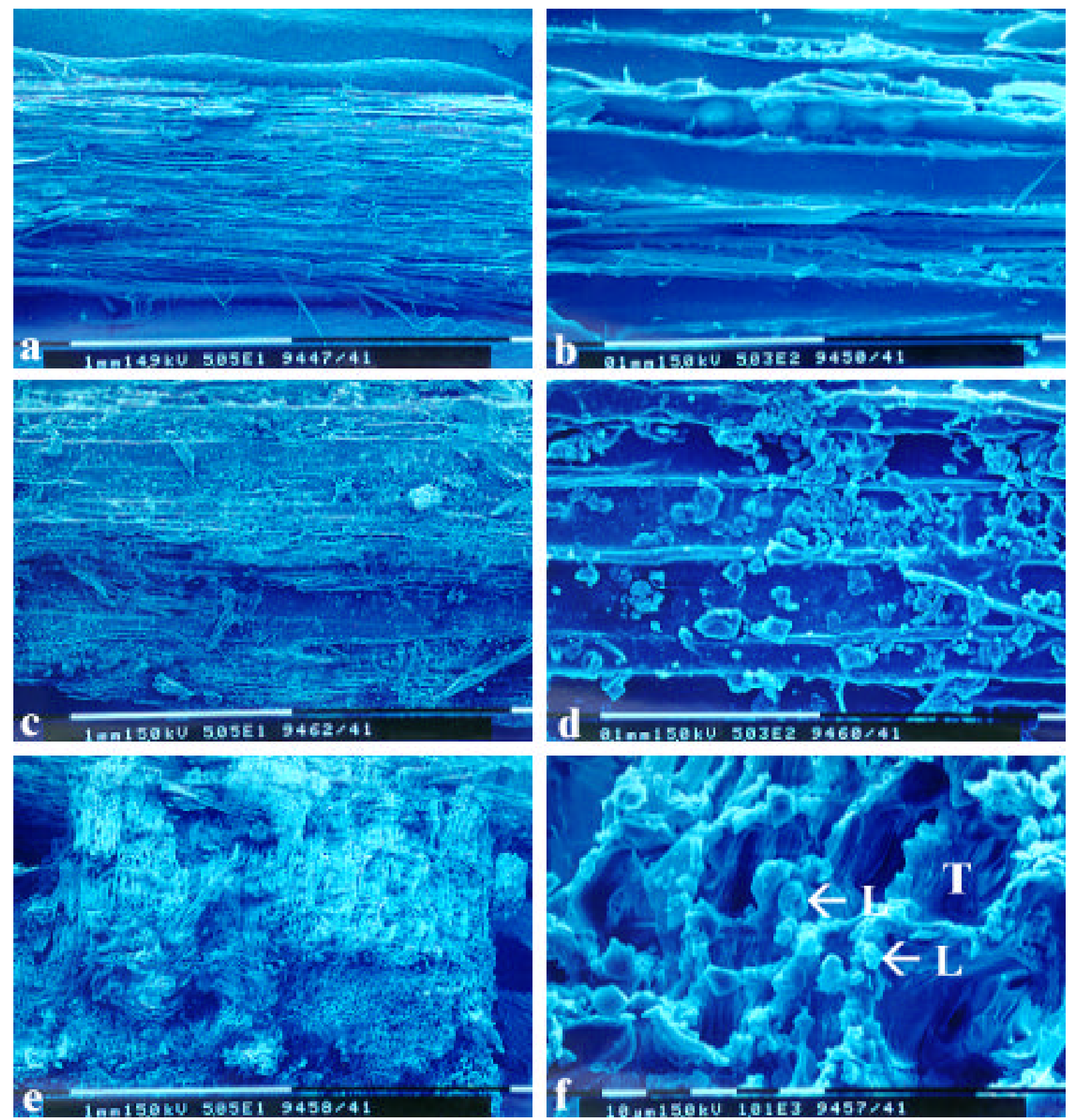

\section{Abbildung 36}

Holzspan ohne und mit Bioleim

a) Unbeleimter Span (Kontrolle), Übersicht Seitenfläche

b) Unbeleimter Span, in Längsrichtung aufgerissene Tracheiden

c) Beleimter Span, Übersicht Seitenfläche

d) Beleimter Span, Ligninpartikel in aufgerissenen Tracheiden

e) Beleimter Span, Übersicht Stirnfläche

f) Beleimter Span, Ligninpartikel (L) liegen auf den Bruchkanten von Tracheiden (T). 


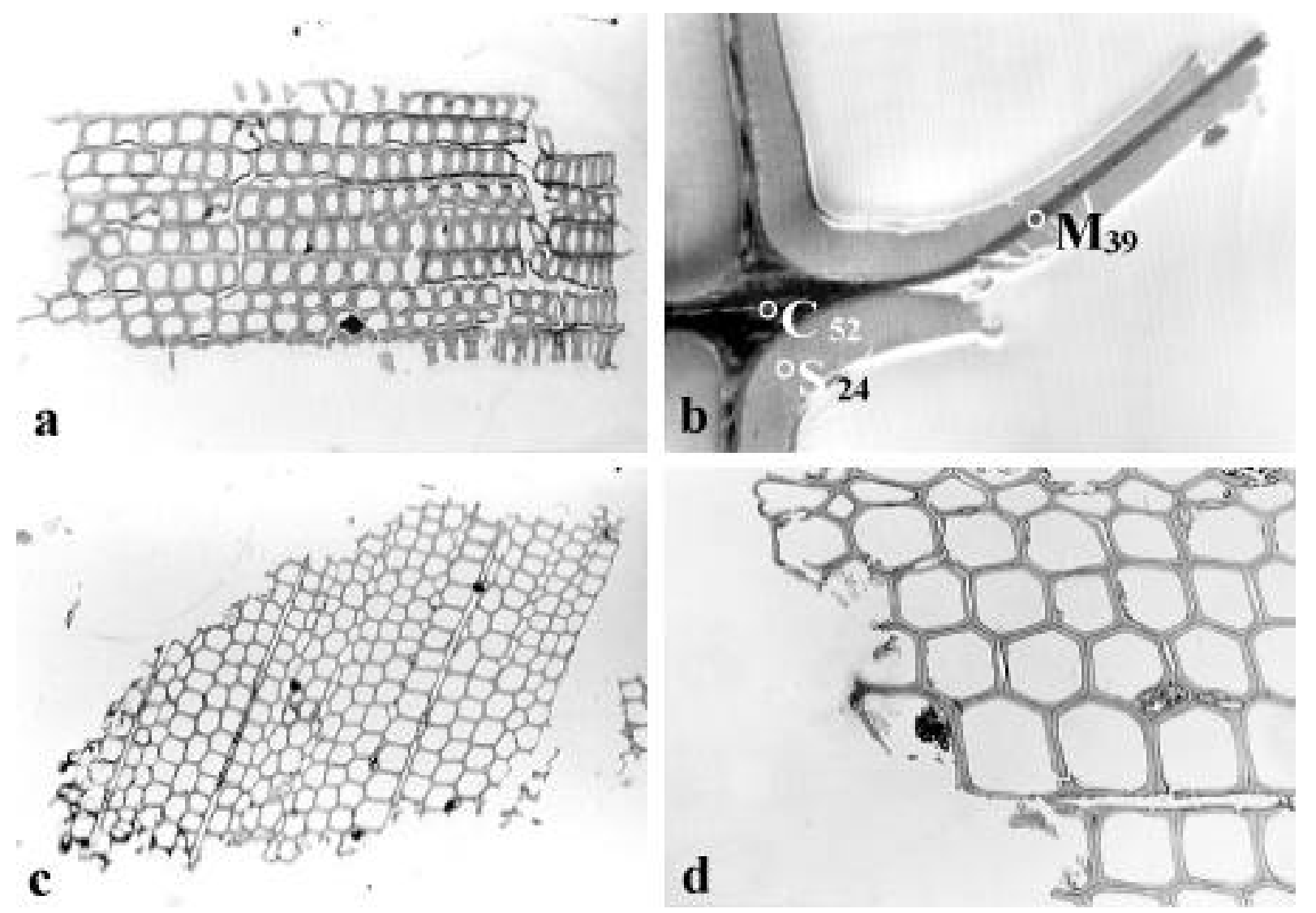

\section{Abbildung 37}

Span ohne und mit Bioleim im Querschnitt

a) LM-Foto eines unbeleimten Spans, Übersicht

b) TEM-Mikrofoto eines unbeleimten Spans

Einzelmessungen der Röntgenemission des merkurisierten Zellwandlignins erfolgten in der Zellecke (C), in der Mittellamelle (M) und in der Sekundärwand (S) (Angabe in cps).

c) LM-Foto eines beleimten Spans, Übersicht

d) LM-Foto eines beleimten Spans, Ausschnitt

liegenden Bereichen beobachtet (Abb.37c,d). Bei stärkerer Vergrößerung im TEM wurde noch ein deutlicheres Bild von der Kontaktzone zwischen Holz und Ablagerung erhalten.

Die Ablagerung mit uneinheitlicher elektronenoptischer Dichte hatte sich teilweise der Holzoberfläche angepasst. Andere Körnchen mit granulärer Gestalt wiesen nur eine geringere Kontaktfläche zum Holz auf. Der Belag an exponierten Bruchkanten der Tracheiden, im aufgerissenen Lumen der Tracheiden und im intakten Lumen innenliegender Tracheiden und Holzstrahl-Parenchymzellen konnte durch die Röntgenmikroanalyse zweifelsfrei als Lignin identifiziert werden (Abb.38). Die räumliche Konzentration innerhalb der Ablagerung überstieg oftmals die natürliche Ligninkonzentration im benachbarten Gewebe. 


\section{Lignifiziertes Sulfitzellstoff-Vlies}

Freie Sulfitzellstoff-Fasern waren mit Lignin und Laccase inkubiert worden und anschließend zu einem Vlies verpresst worden (Schröter, 1998). Die zuvor weißen Fasern hatten bei dieser Behandlung eine hellbraune Farbe angenommen und eine Ligninmenge gebunden, die etwa 10\% ihres Anfangstrockengewichtes betrug. Zur Wiederfindung des Lignins im Werkstoff wurden die Rasterelektronenmikroskopie und die Röntgenmikroanalyse eingesetzt.

Bei mittlerer Vergrößerung (50fach) des lignifizierten Vlieses wurde kein Unterschied in der Oberflächenstruktur im Vergleich zu der nicht-lignifizierten Kontrolle beobachtet (Abb.43a,b). Bei stärkerer Vergrößerung (500fach) wurde hingegen ein rauher, flächiger bis netzartiger Belag auf lignifizierten Fasern sichtbar, während Kontrollfasern eine relativ glatte Oberfläche aufwiesen (Abb.43c,d). In quergeschnittenen Vliesen war im SEM-Bild keine Strukturveränderung durch die Lignifizierung feststellbar (Abb.43f). In flüssigem Stickstoff gefrorene und gebrochene lignifizierte Fasern zeigten stumpfe Bruchkanten und keine überstehenden Reste des applizierten Belags (Abb.43h).

Für die Röntgenmikroanalyse wurden Proben des nicht-lignifizierten und des lignifizierten Vlieses merkurisiert und in Kunstharz eingebettet. Querschnitte der nicht-lignifizierten Fasern wiesen bei der Betrachtung im TEM massive Auflösungserscheinungen auf (Abb.44a). Die lamellenartigen Unterschichten der Sekundärwand wichen auseinander, ohne zu zerreißen. Röntgenmikroanalytisch konnte in keinem Zellwandbereich Hg-Lignin nachgewiesen werden. Lignifizierte Sulfitzellstoff-Fasern waren durch die aggressiven Bedingungen bei der Merkurisierung weniger beschädigt worden. An ihrer Außenfläche und auch in der Kontaktzone zwischen mehreren Fasern wurde mittels Röntgenmikroanalyse Hg-Lignin nachgewiesen (Abb.44b). In geringerer Konzentration als im anhaftenden Belag wurde $\mathrm{Hg}$-Lignin auch in der Sekundärwand der Fasern detektiert. 

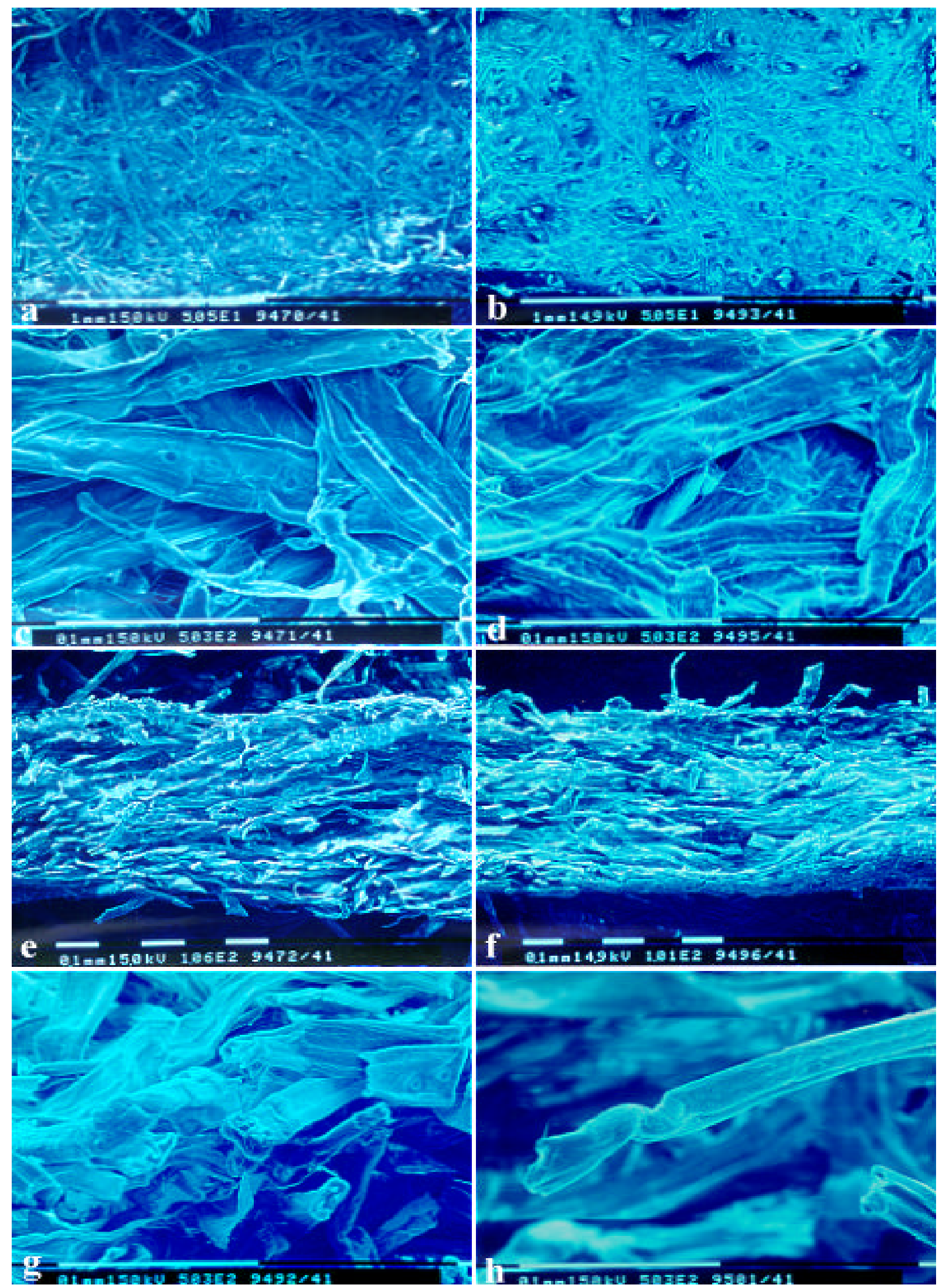

\section{Abbildung 43}

Unbeschichtetes Sulfitzellstoff-Vlies (links) und beschichtetes Sulfitzellstoff-Vlies (rechts) im Vergleich a) und b) Aufsicht bei mittlerer Vergrößerung

c) und d) Aufsicht bei starker Vergrößerung

e) und f) Querschnitt

g) und h) Einzelne in Stickstoff gebrochene Fasern 

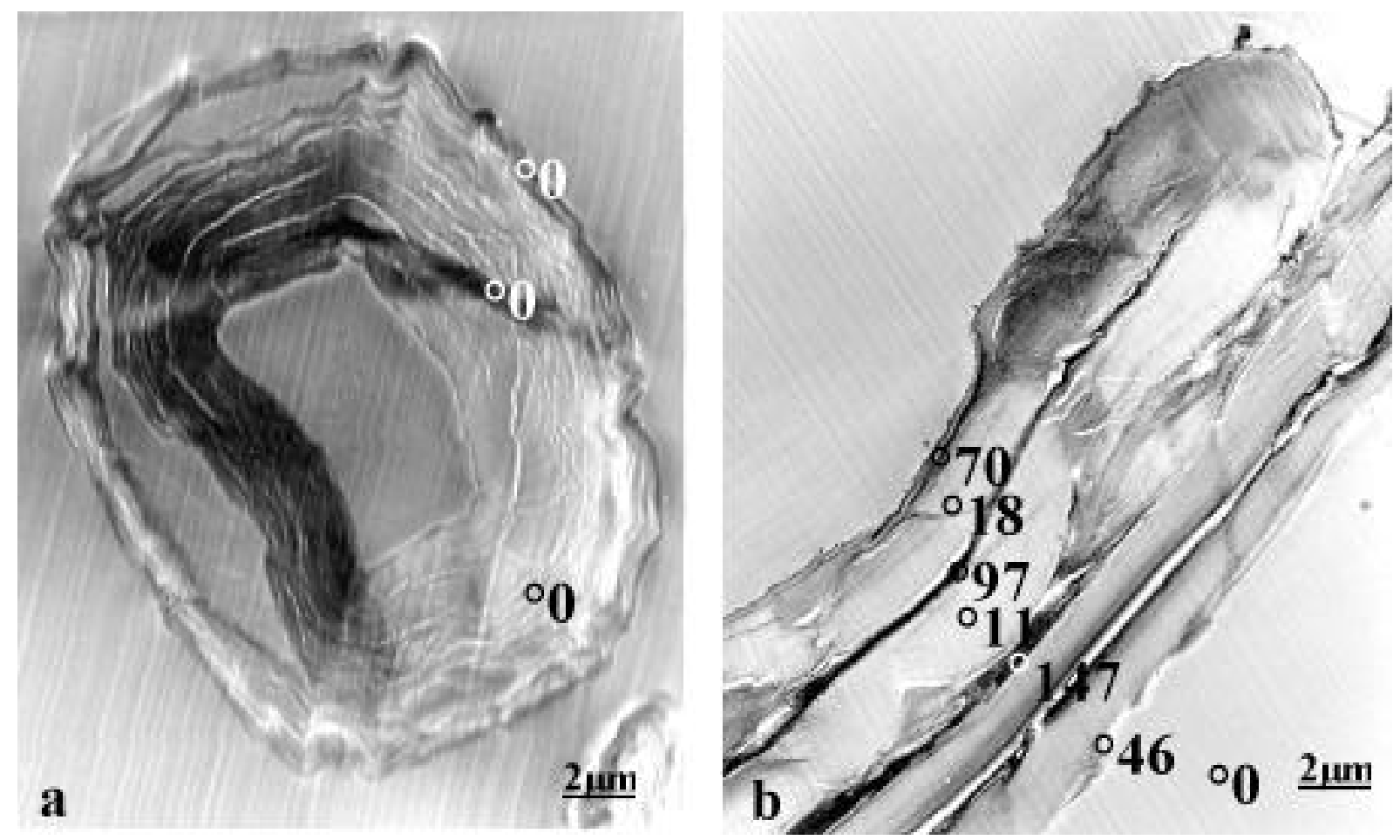

\section{Abbildung 44}

Röntgenmikroanalyse von unbeschichtetem Sulfitzellstoff-Vlies und beschichtetem Sulfitzellstoff-Vlies

a) Unbeschichtete Faser mit starken Auflösungserscheinumgen nach der Merkurisierung

b) Beschichtete Fasern, die auf ihrer Außenfläche, in der Sekundärwand, im Lumen und in der Kontaktzone zwischen Fasern Lignin enthalten

Die Zahlen geben die Röntgenemission des merkurisierten Lignins in cps an. 


\subsubsection{Ligninverteilung in Werkstoffen aus Zellstoff und appliziertem Lignin}

\section{Lignifiziertes Filterpapier}

Filterpapier war im Tauchverfahren mit Laccase-aktiviertem Lignin beschichtet worden, wobei eine Gewichtszunahme um 10\% beobachtet worden war (Schröter, 1998). Die Oberfläche des nach der Lignifizierung braungefärbten Papiers zeigte bei Betrachtung im SEM bei 50facher Vergrößerung zunächst keine Unterschiede im Vergleich zu unbehandeltem Filterpapier (Abb.41a,b). Bei stärkerer Vergrößerung (500fach) wurde jedoch beobachtet, dass nach der Lignifizierung die Fasern nicht mehr frei auf der Oberfläche lagen, sondern von einer gleichmäßigen Schicht überzogen waren (Abb.41d). Diese Schicht trat deutlich hervor, wenn sie bei intensiver Bestrahlung durch Elektronen des SEMs aufriss. Im Querschnitt wurden keine Unterschiede zwischen unbehandeltem und behandeltem Filterpapier beobachtet (Abb.41e,f). In Filterpapier, das in flüssigem Stickstoff gefroren und gebrochen worden war, wurde die Bruchkante von Fasern an der Papieroberfläche untersucht. Die Bruchkante von Fasern in unbehandeltem Papier war stumpf und unregelmäßig (Abb.41g). Sehr ähnlich erschien die Bruchkante von Fasern an der Oberfläche des beschichteten Filterpapiers (Abb.41h).

Bei der Röntgenmikroanalyse merkurisierter, eingebetteter Proben wurde in nichtlignifiziertem Filterpapier kein Lignin gefunden (Abb.42a,c). Weder in der Sekundärwand, noch außen an freien Fasern oder in den Kontaktzonen mehrerer Fasern wurde ein Hg-LSignal detektiert. An der Außenfläche und auch in der Sekundärwand von Fasern, die an der Oberfläche des behandelten Filterpapiers lagen, wurde jedoch Hg-Lignin nachgewiesen (Abb.42b,d). Lignin wurde auch im kollabierten Lumen dieser Fasern und in den Kontaktzonen zwischen Fasern lokalisiert. 

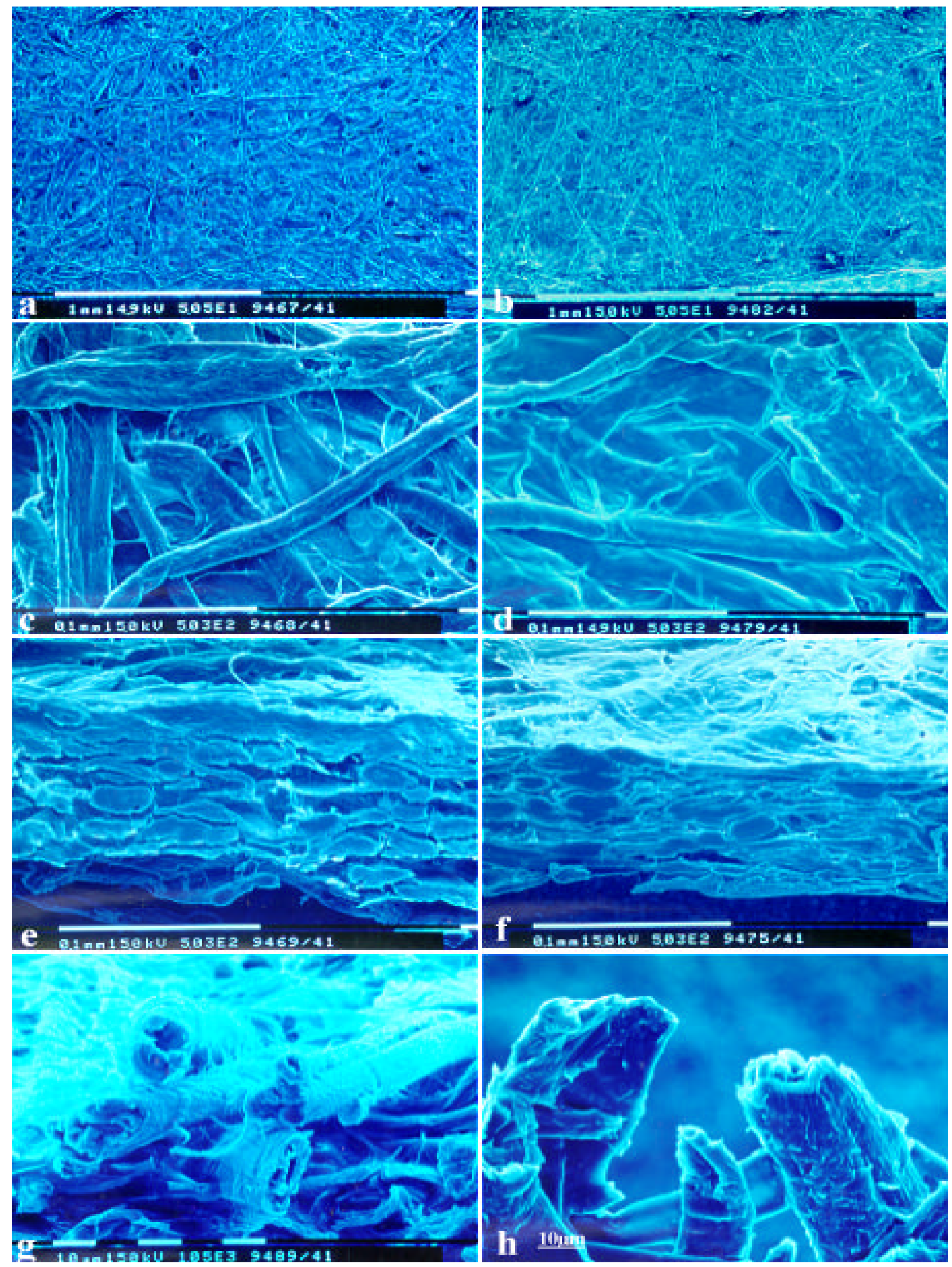

\section{Abbildung 41}

Unbeschichtetes Filterpapier (linke Seite) und beschichtetes Filterpapier (rechte Seite) im Vergleich

a) und b) Aufsicht bei mittlerer Vergrößerung

c) und d) Aufsicht bei starker Vergrößerung

e) und f) Querschnitt

g) und h) Einzelne in Stickstoff gebrochene Fasern an der Oberfläche der Filterpapiere 

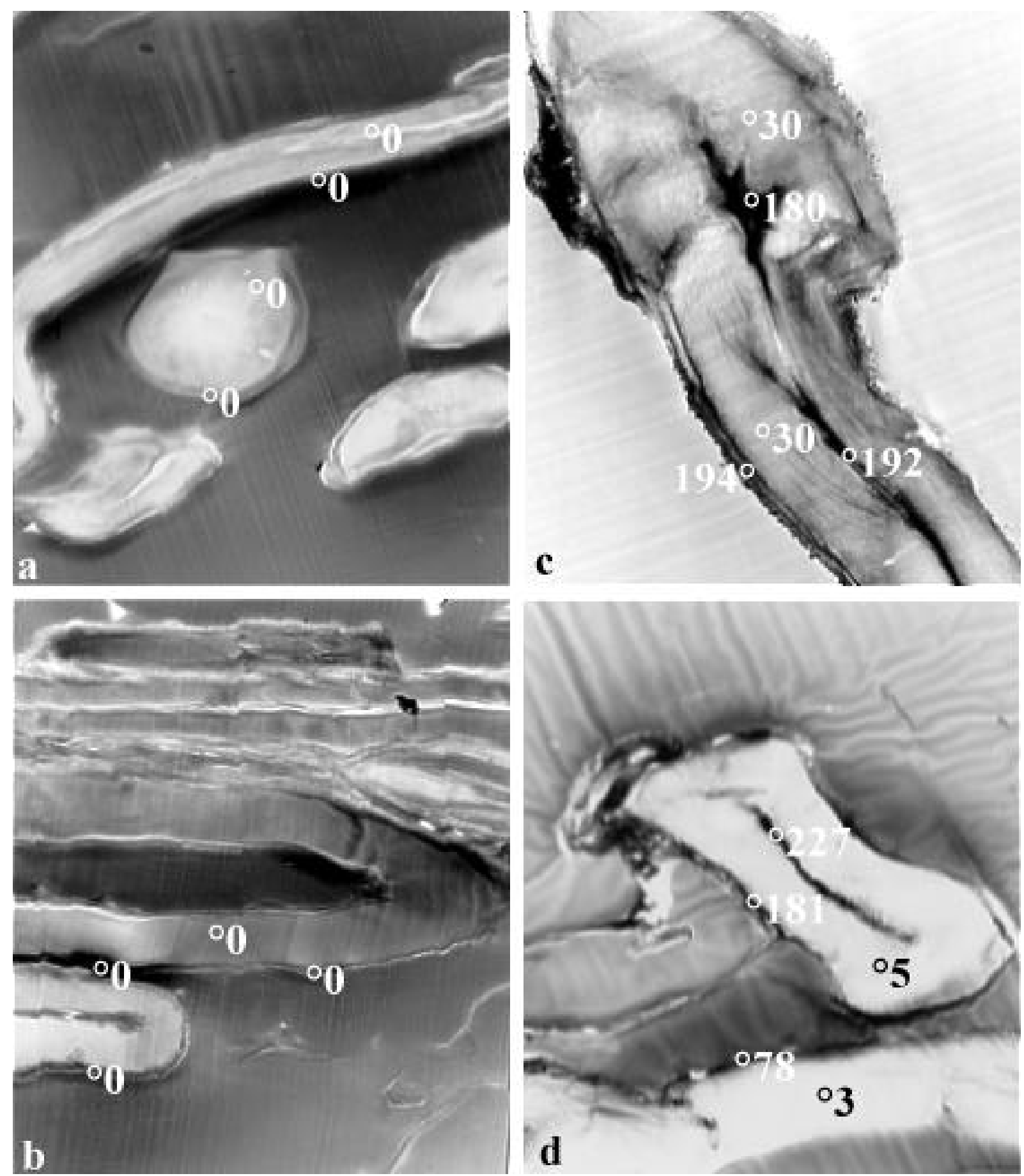

\section{Abbildung 42}

Röntgenmikroanalyse von unbeschichtetem Filterpapier (linke Seite) und beschichtetem Filterpapier (rechte Seite)

a) und b) Freiliegende Fasern

c) und d) Kontaktzonen zwischen Fasern

Die Zahlen geben die Röntgenemission des merkurisierten Lignins in cps an. 


\section{DISKUSSION}

\subsection{Die quantitative Bestimmung von Lignin in situ}

Die Röntgenmikroanalyse erwies sich in den hier vorgestellten Untersuchungen als eine effiziente Methode, um Lignin nach spezifischer Markierung mit Quecksilberacetat in sehr unterschiedlichen Schnittpräparaten im TEM-Bild zu lokalisieren und zu quantifizieren. Licht- und elektronenmikroskopische Methoden wurden in der Vergangenheit bereits mehrfach eingesetzt, um den Ligningehalt in verschiedenen Zellwandbereichen verholzter Gewebe zu messen. Mehrere Autoren berechneten auf dieser Grundlage den Anteil des Lignins am Gesamtvolumen oder Gesamtgewicht einzelner Zellwandbereiche oder des ganzen Gewebes (zusammengestellt bei Saka et al., 1982, Donaldson, 1985b, Westermark, 1985). Ob diese Berechnungen jedoch die natürlichen Verhältnisse zutreffend beschreiben, ist zweifelhaft. Rechnerisch wurde in der Mittellamelle zwischen Nadelholztracheiden ein Ligningehalt von 50-60\% (UV-Lichtmikroskopie, Fergus et al., 1969) beziehungsweise 75\% (Br-TEM-EDXA, Saka et al., 1981 und 1982) ermittelt. Chemische Analysen von Mittellamellenfragmenten, die zuvor mit einer Siebtechnik isoliert worden waren, ergaben jedoch stets geringere Ligninkonzentrationen zwischen 40\% (Westermark, 1985) und 50\% (Whiting et al., 1981). Fehlerquellen in mindestens vier Bereichen beeinflussen die mikroskopische Quantifizierung von Lignin in unbekanntem Maße:

\section{(1) Präparationsartefakte}

Alle üblichen Kunstharz-Einbettungsmedien schrumpfen beim Auspolymerisieren um 5 bis 20\% und mit ihnen teilweise auch das Präparat (Dawes, 1988).

\section{(2) Empfindlichkeit der Messung}

Weil Coniferyl-Lignin und Sinapyl-Lignin unterschiedliche Absorptionsmaxima besitzen beziehungsweise verschiedene Mengen Brom binden, kommt es zu Fehlinterpretationen des Ligningehaltes durch die quantitative UV-Mikroskopie und Br-TEM-EDXA, solange die genaue Zusammensetzung des Lignins aus den Grundbausteinen im jeweils untersuchten Zellwandbereich nicht bekannt ist. Die Merkurisierung bietet nach jetzigem Erkenntisstand die stöchiometrisch sicherste, für alle drei Ligningrundbausteine gleichermaßen spezifische Markierung und wurde deshalb für die hier vorgestellten Untersuchungen eingesetzt. 
(3) Variabilität im Präparat

Der Ligningehalt des Holzes variiert zwischen verschiedenen genetischen Klonen einer Art (Donaldson et al., 1997). Auch innerhalb eines Individuums wird verschieden viel Lignin in die Zellwände eingelagert, abhängig von der Lage des untersuchten Holzes im Querschnitt und in der Höhe des Stammes (Donaldson, 1985b).

(4) Bilanzierung des Ligningehaltes

Um Ligninbilanzen erstellen zu können, muss der relative Anteil eines Zelltyps am Gesamtvolumen oder am Gesamtgewicht eines Gewebes bestimmt werden. $\mathrm{Zu}$ diesem Zweck können computergestützte Bildanalysesysteme eingesetzt werden. Eine andere Möglichkeit bietet die Fraktionierung von Holz in verschiedene Zellwandbereiche mittels Dichtegradiententechnik mit anschließender gravimetrischer Bestimmung (Whiting et al., 1981). Diese Technik schließt immer das Risiko einer Verunreinigung durch unvollständige Trennung der Fraktionen oder durch Reaktionsholz anderer Ligninzusammensetzung ein.

Unter Wissenschaftlern entstand aufgrund der verschiedenen Gewichtung dieser Fehlerquellen eine Kontroverse über die konkrete Vergleichbarkeit ihrer Forschungsergebnisse (Saka et al., 1981 und 1982, versus Westermark, 1985). Erst die parallele Analyse identischer Proben mit Interferenzmikroskopie, UV-Mikroskopie, Br- und Hg-Röntgenmikroanalyse könnte hier Klarheit schaffen. Da aber kein holzbiologisches Labor über alle Geräte und das erforderliche präparative Geschick verfügt, wird es nie einen direkten Vergleich dieser Methoden geben. In der hier vorliegenden Arbeit wurde auf eine Darstellung der gemessenen Ligningehalte in absoluten Mengen daher verzichtet. Viel aufschlussreicher ist die Angabe des relativen Verhältnisses des Lignin-Signals in verschiedenen morphologischen Bereichen, denn damit ist ein Parameter gefunden, der einen Vergleich mit Ergebnissen anderer Messmethoden zuläßt. 


\subsection{Die Ultrastruktur der verholzten Zellwand in Buche und Kiefer}

\subsubsection{Ligningehalt}

Die Ligninverteilung in der Ultrastruktur von Holzfaserzellen der Buche (Fagus sylvatica) und von Tracheiden der Kiefer (Pinus sylvestris) wurde hier erstmalig mit Hilfe der Röntgenmikroanalyse beschrieben. In der zusammengesetzten Mittellamelle zwischen zwei Faserzellen wurde ein 2,5fach beziehungsweise 1,7fach höherer kleinräumiger Ligningehalt gemessen als in der Sekundärwand. Damit wurde im Verbund von Faserzellen dieser beiden Spezies ein ähnliches Lignifizierungsmuster wie bereits bei anderen Laub- und Nadelholzarten vorgefunden.

In der Mittellamelle zwischen Primärwänden in unverholzten Pflanzenteilen ist kein Lignin enthalten. Durch die verstärkte Einlagerung von Lignin in die Mittellamelle während des Wachstums der verholzten Zellwand erhöhen holzbildende Pflanzen die Stabilität der Verbindung zwischen den einzelnen Faserelementen. Die Ergebnisse der hier vorgestellten Untersuchungen unterstützen die Modellvorstellung, nach der die stark lignifizierte Mittellamelle im Verbundstoff Holz die Funktion einer gleichzeitig stabilisierenden und verbindenden Matrix zwischen den Faserzellen übernimmt.

\subsubsection{Elementkonzentration}

Mittels Röntgenmikroanalyse konnten geringe Mengen der Nährelemente Kalium, Calcium, Magnesium und Mangan in verschiedenen Zellwandschichten in Buchen- und Kiefernholz lokalisiert werden. In lebenden Zellen sind diese Elemente essentielle Cofaktoren von Enzymen, Signalstoffe und Ladungsräger in vielen biologischen Reaktionen und Wachstumsprozessen (Marschner, 1995). Der Grund für ihr Vorkommen im abgestorbenen Holz ist jedoch weitgehend unbekannt. In den Zellwandbereichen von Holzfaserzellen der Birke variiert der Anteil der anorganischen Elemente zwischen 0,14\% in der Sekundärwand und 0,54\% in der Mittellamelle (Saka und Mimori, 1994). Der Anteil der Alkali- und Erdalkali-Elemente am Gesamtgehalt anorganischer Bestandteile beträgt dort etwa $88 \%$. In der noch unverholzten Primärwand wird zweiwertigen Calcium- und Magnesiumionen die Aufgabe zugeschrieben, als Salzbrücke zwischen zwei Galacturon-säureresten den Zusammenhalt der Pektine zu vermitteln (Mohr und Schopfer, 1992). In der verholzten Zellwand kommen Pektine jedoch nicht vor, so dass diese Möglichkeit ausscheidet. 
Masson und Mitarbeiter (1997) untersuchten die vertikale Verteilung der häufigsten neun Elemente im Holz von Eichenstämmen. Sie stellten fest, dass die Konzentration zweiwertiger Ionen ( $\mathrm{Ca}, \mathrm{Mg}, \mathrm{Mn}$ ) mit wachsender Entfernung vom Boden abnahm, während die Konzentration an Kalium und Natrium zunahm. Die Autoren machten für diesen Effekt eine höhere Mobilität der einfach geladenen Teilchen im XylemTranspirationsstrom verantwortlich. Zu ähnlichen Ergebnissen kamen Kuhn und Mitarbeiter (1997) bei der Untersuchung des Transportes stabiler Isotope von Magnesium, Kalium und Calcium im Xylem zweijähriger Fichten. Auch sie beobachteten eine bevorzugte Entnahme von Calcium aus der Xylemflüssigkeit im unteren Sprossbereich. Die Mechanismen zur Entnahme von Ionen aus dem Transpirationsstrom sind nicht unbedingt direkt an die lebende Pflanzenzelle gebunden. Ein großes sink für Kationen ist die Ionen-AustauschKapazität der verholzten abgestorbenen Zellwand. Hydroxyl- und Carboxylgruppen der Zellwandbausteine binden viele Kationen, wobei Calcium meist bevorzugt wird (Van de Geijn und Petit, 1979, Momoshima und Bondietti, 1990). Außerdem werden Kationen im Apoplasten immobilisiert, wenn sie mit Oxalat oder Citrat als Komplex ausgefällt werden (Bradfield, 1976).

Wahrscheinlich handelt es sich bei den Elementen $\mathrm{K}, \mathrm{Ca}, \mathrm{Mg}$ und $\mathrm{Mn}$, die im Xylem von Buche und Kiefer mittels Röntgenmikroanalyse nachgewiesen wurden, um Kationen, die passiv aufgrund ihrer Ladung an Ionenaustauscher der Zellwand gebunden wurden. Die aktive Oberfläche der Tracheiden und Holzfasern beschränkt sich dabei nicht auf ihr Lumen, sondern schließt sogar bevorzugt tiefere Schichten ein, wie die höheren Konzentrationen in der Zellecke und in der Mittellamelle belegen.

Die Funktion der Nährelemente in der verholzten Zellwand ist bislang kaum erforscht. Von Westermark (1982) stammt der Vorschlag, dass Calcium bei der Lignifizierung beteiligt ist. Divalente Calciumkationen üben demnach während der phenolischen Bindung von Coniferylalkohol eine stabilisierende Wirkung auf Superoxidradikale aus. Interessanterweise wurde in Buchen- und Kiefernholz dieselbe Abstufung im Ligningehalt wie auch in der Calciumkonzentration zwischen den untersuchten Zellwandschichten nachgewiesen. Das proportionale Auftreten von Calcium und Lignin in der verholzten Zellwand kann deswegen sehr wohl auf eine katalytische Beteiligung der Calciumkationen an der Lignifizierung zurückzuführen sein. 


\subsection{Mikromorphologische Veränderungen im Frühstadium des Holzabbaues durch Fäulepilze}

\subsubsection{Ligningehalt und mechanische Festigkeit}

Weißfäulepilze wurden in Laborversuchen bereits erfolgreich eingesetzt, um in Laubholzund Nadelholz-Hackschnitzeln die mechanische Stabilität gezielt herabzusetzen. Vorinkubation von Pappelholz mit Ceriporiopsis subvermispora erlaubte eine Reduktion des Energieeinsatzes beim anschließenden Faseraufschluss im Refiner um mindestens 25\% (Leatham et al., 1990, Akhtar et al., 1993). Kiefernhackschnitzel, die zuvor 10 Tage mit dem Braunfäulepilz Fomitopsis pinicola inkubiert worden waren, erforderten $30 \%$ weniger Energie beim Faseraufschluss als unbehandelte Hackschnitzel (S. Körner, 1990).

Im experimentellen Teil der vorliegenden Arbeit wurden Pilzstämme isoliert, die nach nur dreiwöchiger Inkubation die Scherfestigkeit von Buchen- und Kiefern-Probehölzern um teilweise mehr als 50\% herabsetzten. Die isolierten Pilze Gloeophyllum trabeum und Trametes hirsuta zeigten sich besonders geeignet zur biotechnologischen Vorbehandlung von Nadelholz beziehungsweise Laubholz. Weiterführende Experimente am Institut für Holz- und Papiertechnik der TU Dresden mit G. trabeum bestätigten diese Ergebnisse: Nach nur 9-tägiger Inkubation von Kiefern-Hackschnitzeln wurden Energieeinsparungen von fast $40 \%$ beim Faseraufschluss bei gleichzeitig verbesserten Eigenschaften des Faserstoffs erreicht (H. Unbehaun, persönliche Mitteilung). Aus diesem Faserstoff gepresste bindemittelfreie Mitteldichte Faserplatten wiesen eine um 50\% bessere Biegefestigkeit, eine um 100\% bessere Querzugsfestigkeit und eine fast 50\% niedrigere Dickenquellung auf als Kontrollplatten aus nicht-inkubierten Fasern.

Ein gezielter Abbau des Lignins in Zellwandbereichen, die für die mechanische Stabilität von Holz entscheidend sind, stand von Anfang an unter dem Verdacht, für den Kollaps der stabilisierenden Strukturen verantwortlich zu sein (Wagenführ, 1988). Von der kooperierenden Arbeitsgruppe an der Hebrew University in Rehovot/Israel wurde deswegen der Gehalt ligninolytischer Enzyme in Probehölzern untersucht, die in Göttingen gezielt mit Fäulepilzen infiziert worden waren. Dort konnte nachgewiesen werden, dass bereits fünf Tage nach Inkubationsbeginn $T$. hirsuta und $M$. tremellosus in Buchenholz aktive Ligninperoxidase, Manganperoxidase und Laccase produzierten (R. Cohen, persönliche Mitteilung). In Kiefern-Probehölzern, die in Israel unter gleichen Bedingungen wie in Göttingen mit G. trabeum infiziert worden waren, war ebenfalls zu diesem frühen Zeitpunkt 
mit Modellsubstanzen Laccase-Aktivität messbar, während Ligninperoxidase-Aktivität nicht beobachtet werden konnte.

Aufgabe dieser Doktorarbeit war es, mögliche Ursachen der erwünschten Materialschwächung in der durch abbauende Pilze modifizierten Ultrastruktur von Holz zu finden. Die Röntgenmikroanalyse wurde dazu eingesetzt, die Ligninverteilung in Buchen- und Kiefernholz zu bestimmen, das jeweils mit einem der drei getesteten Fäulepilze drei Wochen inkubiert worden war. Die Messung des merkurisierten Zellwandlignins konnte jedoch nachweisen, dass in diesem frühen Stadium der Infektion das Lignin in keiner Zellwandschicht messbar abgebaut wurde. Auch der Beitrag des Lignins zur Trockenmasse der Probehölzer zeigte keine Veränderung, während die Trockenmasse selbst nur um 4 bis 6\% abnahm. Unterschiede in der Abbaustrategie zwischen simultaner Weißfäule, selektiver Weißfäule und Braunfäule wurden in dieser Frühphase der Infektion nicht deutlich.

Die vorangestellte Hypothese, dass für die Schwächung der Stabilität des Holzgefüges im Frühstadium der Infektion durch Fäulepilze ein gezielter Ligninabbau verantwortlich sei, muss aufgrund der hier beschriebenen Ergebnisse verworfen werden. Da die deutlichen Scherfestigkeitsverluste des pilzinfizierten Buchen- und Kiefernholzes weder an eine

Delignifizierung bestimmter Zellwandschichten noch an eine Abnahme des Gesamtligningehaltes oder des Gesamtgewichtes gebunden sind, müssen andere Modifikationen der Pilze die Auflockerung des Gewebeverbandes verursacht haben.

Möglich ist, dass nur die Polymergröße der Cellulose-, Hemicellulose- oder Ligninmakromoleküle reduziert wurde, ohne dass diese vollständig abgebaut wurden. Es ist ferner denkbar, dass die Bindungen der drei Zellwandkomponenten untereinander durch die Aktivität der Pilze verändert wurden. Diese Modifikationen konnten mit den gewählten Analysemethoden nicht erfasst werden. HPLC-Analysen der möglichst schonend voneinander getrennten Zellwandkomponenten pilzbefallenen Holzes bieten eine Möglichkeit, Veränderungen ihrer mittleren Molekülgröße bei Pilzbefall offenzulegen.

Eine alternative oder auch zusätzliche Modifikation von Zellwandbausteinen bietet die Reaktivierung des Zellwandlignins durch direkte oder indirekte Wirkung von pilzlichen, ligninolytischen Enzymen. Ligninolytische Enzyme, deren Aktivität in den pilzinfizierten Probehölzern mit reduzierter Scherfestigkeit nachgewiesen wurde, konnten bei der Produktion biotechnologischer Holzwerkstoffe erfolgreich zur Neupolymerisierung von Lignin eingesetzt werden (siehe 3.3). In diesem Zusammenhang erhält die Beobachtung besonderes Gewicht, dass auch Faserplatten, die aus Fasern aus mit Braunfäule-inkubierten Kiefernhackschnitzeln hergestellt wurden, verbesserte Festigkeitseigenschaften aufwiesen. 
Bevor es zu einer Neupolymerisierung von Zellwandlignin kommt, müssten enzymatisch aktivierte radikalische Ligninzwischenprodukte entstehen. Wenn Ligninradikale beispielsweise mit ESR-Spektroskopie in Extrakten pilzinfizierten Holzes nachgewiesen werden könnten, so wäre dies ein unterstützendes Indiz für eine Aktivierung von Zellwandlignin in der Frühphase der Infektion von Holz.

Auch die anatomischen Untersuchungen des infizierten Holzes zeigten, dass zu diesem frühen Zeitpunkt noch keine mikroskopisch erkennbare Schädigung der Zellwandbausteine eingesetzt hatte. Lediglich G. trabeum verursachte kleinräumig begrenzte Zerstörungen im dünnwandigen Frühholz der Kiefer. Diese Ergebnisse stimmen überein mit Berichten von Otjen und Blanchette (1985), die nach vierwöchiger Inkubation von Pappel-Probehölzern mit Ischnoderma resinosum, Poria medulla-panis oder Xylobolus frustulatus ebenfalls keine rastermikroskopisch sichtbaren Anzeichen des Holzabbaus feststellen konnten.

Chemische "Modifikationen", die dem Zellwandabbau zeitlich vorausgehen, wurden in tieferen Zellwandschichten in der vorliegenden Arbeit beschrieben. Neuartige ToluidinblauFärbungsmuster in der Sekundärwand von Buchenzellen sind ein Indiz für Veränderungen durch die Aktivität der Pilze im Holz. Ähnliche Beobachtungen einer stadienspezifischen Anfärbbarkeit von Sekundärwänden mit Uranylacetat wurden im Frühstadium des Befalls mit Ceriporiopsis subvermispora in Holzfaserzellen der Pappel gemacht (Blanchette, 1995). Die Erforschung der Prozesse, die in der Frühphase der Pilzinfektion zu einer Abschwächung der mechanischen Stabilität des befallenen Holzes führen, hat soeben erst begonnen. Ein interessantes Detail liefert diese Dissertation mit dem Nachweis der zeitlichen Trennung von Stabilitätsverlust und Lignin- oder Zellwandabbau. Fest steht jetzt schon der hohe potentielle Nutzen dieser mikrobiellen Prozesse bei der biotechnologischen Vorbehandlung von Hackschnitzeln. Ökonomisch und ökologisch attraktive Einsparungen beim Energieeinsatz für den Faseraufschluss und beim Bindemitteleinsatz bei der Fertigung von Faserwerkstoffen sind möglich (I. Körner, 1990, S. Körner, 1990, Akhtar et al., 1992). 


\subsubsection{Veränderungen der Elementkonzentration in Holz bei Pilzbefall}

Nachdem gezeigt werden konnte, dass die Schwächung der mechanischen Stabilität der Zellwand durch kurzzeitigen Pilzbefall nicht auf einen selektiven Ligninabbau oder generellen Zellwandabbau zurückzuführen ist, wurde die Röntgenmikroanalyse angewendet, um mögliche Veränderungen in der Elementzusammensetzung in der Ultrastruktur des pilzfaulen Holzes zu untersuchen.

Die Untersuchung der vier häufigsten Elemente $(\mathrm{Mg}, \mathrm{K}, \mathrm{Ca}$ und $\mathrm{Mn})$ ergab, dass die Konzentration von Magnesium, Calcium und Mangan in allen Schichten der Zellwand in diesem frühen Stadium der Infektion abnahm. In infizierten Tracheiden beobachtete Ablagerungen auf der Lumenseite der Tertiärwand wiesen in der Röntgenmikroanalyse eine Akkumulation genau dieser Elemente auf.

Diese Beobachtungen wurden an Kiefern-Probehölzern gemacht, die über Malzagarkulturen im Laborversuch von Fäulepilzen infiziert worden waren. Um zu überprüfen, ob die Veränderungen im Elementgehalt des Holzes in der Frühphase der pilzlichen Infektion die natürlichen Bedingungen widerspiegeln, wurden pilzinfizierte Holzproben aus dem Freiland untersucht, in denen die Zellwand ebenfalls nur in geringem Maße angegriffen war. Die Proben stammten von Fichten, die im Wurzelbereich und unteren Stammholz eine Infektion mit dem Erreger der Rotfäule Heterobasidion annosum aufwiesen. Es war nicht bekannt, wielange $H$. annosum schon im Holz lebte, ohne die Zellwandstrukturen aufzulösen. Es sind jedoch andere Berichte veröffentlicht, nach denen dieser Pilz 10 Jahre und länger im Wirt parasitiert, ohne ihn letal zu schwächen (Hüttermann und Haars, 1987).

Die Röntgenmikroanalyse wies in rotfaulem Fichtenholz aus dem Freiland ebenso wie in infiziertem Kiefernholz im Laborversuch eine Reduktion der Calciumkonzentration in der Mittellamelle und in der Sekundärwand infolge des Pilzbefalles nach. Auch hier wurden Ablagerungen in den Tracheiden entdeckt, die das Lumen teilweise vollständig ausfüllten. Diese Ablagerungen gelten schon länger als typisches Merkmal für Rotfäulebefall in Fichten (v. Aufsess, 1972 ). Von Aufsess beobachtete bereits 10 Tage nach Infektion von Fichtenholz im Laborversuch die Ausbildung dünner Häutchen im Lumen infizierter Tracheiden. Nach 90 und 150 Tagen waren die dünnen Häutchen zu grobkörnigen Ablagerungen angewachsen. Von Aufsess vermutete, dass es sich dabei um Stoffwechselprodukte des Pilzes handelte. In der hier vorliegenden Arbeit wurde erstmalig der hohe Anteil von $\mathrm{K}, \mathrm{Ca}$ und $\mathrm{Mg}$ in diesen Ablagerungen beschrieben. In Ablagerungen auf der Tertiärwand von Tracheiden zweier infizierter Fichten vom Standort Tamsweg 
wurden durchschnittliche Konzentrationen von $400 \mathrm{mM}$ und $560 \mathrm{mM}$ Kalium gemessen, während die Tertiärwand in nicht-infizierten Kontrollen nur 15 mM Kalium enthielt.

Anders als die Calciumkonzentration war die Kalium- und Magnesiumkonzentration in den Wandschichten der Fichtentracheiden jedoch stark erhöht. Die Elemente, die bei Pilzbefall eines ganzen Baumes im Lumen infizierter Tracheiden in großen Mengen akkumuliert werden, stammen demnach nicht oder nicht nur aus den angrenzenden Zellwänden, sie müssen zusätzlich von anderen Quellen zugeführt werden. Eine Hauptaufgabe des Xylems ist neben dem Wasserferntransport der Transport im Wasser gelöster Nährelemente zu den Verbrauchsorten. Interessanterweise waren die untersuchten rotfaulen Fichten im Bestand durch die äußeren Schadbilder Nadelvergilbung und Kronenverlichtung aufgefallen. Analysen von chlorotischen Nadeln rotfauler Fichten des Standortes Gleinalm belegten eine deutliche Unterversorgung mit den Nährelementen Kalium und Calcium im Kronenbereich, während Nadeln gesunder Kontrollbäume von diesem Standort keinen Nährelementmangel aufwiesen (Tomiczek, 1995). Eine Akkumulation dieser Elemente wurde durch die Röntgenmikroanalyse im unteren pilzinfizierten Stammbereich nachgewiesen. Es ist daher anzunehmen, dass die im infizierten Holz angehäuften Ionen aus der Xylemflüssigkeit stammten.

Veränderungen in der Verteilung der Nährelemente im Holz bei Pilzbefall wurden bereits mehrfach beschrieben (Safford et al., 1974, Ostrowski et al., 1997). Manche Autoren vermuten, dass die Umverteilung von Nährelementen Teil einer gezielten Strategie des Baumes ist, um die pilzliche Infektion einzudämmen. Im Stammholz sind jedoch nur wenige lebende Zellen $\mathrm{zu}$ einer aktiven Reizantwort in der Lage. Holzparenchymzellen sind beispielsweise für die Thyllenbildung in den Gefäßen der Laubhölzer verantwortlich, die bei Embolie oder Pilzinfektion induziert wird. Die überwiegende Mehrheit der Holzzellen ist jedoch am Ende ihrer Wachstumsphase abgestorben. Weil es aber sogar in pasteurisierten Probehölzern zu massiven Veränderungen der Nährelementverteilung bei Pilzbefall kommt, ist es sehr wahrscheinlich, dass die beobachteten Modifikationen Auswirkungen des pilzlichen Stoffwechsels sind.

Ablagerungen von Calciumoxalat, Mangandioxid und Magnesium wurden in pilzbefallenem Holz schon beschrieben (Blanchette, 1984, Blanchette, 1995). Eine kausale Verknüpfung der Akkumulation von zweiwertigen Ionen mit dem Zellwandabbau oder der vorangehenden Schwächung des Gewebeverbandes wird heutzutage diskutiert, sie ist im Detail aber noch nicht nachgewiesen (Jellison et al., 1997). Möglicherweise erleichtert das 
gezielte Herauslösen von Kationen aus der Zellwand dem Pilz den Zugang zu den polymeren Bestandteilen. Ligninolytische Enzyme selbst sind zu groß, um in die Poren der intakten Zellwand einzudiffundieren (Blanchette, 1995). Die von ihnen generierten Formen des aktiven Sauerstoffs, wie das Hydroxylradikal, stellen jedoch ein mögliches Agens dar, das Modifikationen an den Ionenaustauschern der Zellwand bewirken kann.

Es ist aber auch denkbar, dass Fäulepilze gezielt Nährelemente aus der Zellwand herauslösen, um sie selbst für ihren Stoffwechsel zu nutzen. Pilzhyphen benötigen eine ständige Nachlieferung von Nährelementen, um das nährstoffarme Wirtsgewebe Holz erfolgreich zu durchwachsen. Zusätzlich haben spezielle Ionen, beispielsweise Mangan als Cofaktor für die Manganperoxidase, eine wichtige Funktion beim extrazellulären Zellwandabbau (Bonnarme und Jeffries, 1990).

Um die hier angestellten oder zitierten Beobachtungen über die Umverteilung von Ionen durch Pilze in einen allgemeinen funktionellen Zusammenhang mit den Prozessen im Frühstadium des Pilzbefalls zu stellen, sind weiterführende Studien nötig. Eine besondere Beachtung erfordern die Herkunft und die Transportrichtung der Ionen unter Berücksichtigung einer möglichen Beteiligung des lebenden Wirtes. Festzuhalten ist jedoch, dass eine lokale Infektion mit Weißfäulepilzen Konsequenzen für die Nährelementversorgung des gesamten Baumes haben kann.

\subsection{Lignin in der Leimfuge biotechnologischer Faserplatten}

Die Holzwerkstoffindustrie versucht in letzter Zeit verstärkt, Konzepte und Grundmuster aus der biologischen Ligninforschung in die Technik zu übertragen. Ein angestrebtes Ziel ist beispielsweise die Entwicklung von Verbundstoffen auf der Basis nachwachsender Rohstoffe, die ohne Zusatz von petrochemischem Kunstharz ähnliche Eigenschaften aufweisen, wie bewährte Werkstoffe. Der Einsatz biotechnologischer Verbundstoffe bietet mehrere Vorteile. Erstens spart der Verzicht auf den Einsatz petrochemischer Kunstharze in der Produktion Kosten und schont die limitierten Ressourcen. Zweitens wird die Problematik umgangen, die mit der Freisetzung von Formaldehyd bei der Produktion und während des Einsatzes konventioneller Verbundstoffe verbunden ist (vgl. Roffael, 1982).

Drittens stellen biotechnologische Verbundstoffe nach ihrer Nutzung kein Entsorgungsproblem dar, sondern sind biologisch abbaubar oder in Zukunft sogar ein Rohstoff für weitere Anwendungen. 
Von Kharazipour und Mitarbeitern wurde ein Verfahren entwickelt, um Faserplatten ohne Zugabe eines Bindemittels zu fertigen (Europäisches Patent 1993). Die Besonderheit dieses Verfahrens ist die Vorbehandlung des Faserstoffes mit ligninolytischen Enzymen, die aus Weißfäulepilzen isoliert wurden. Man nimmt an, dass während der Inkubation mit diesen Enzymen Bindungskräfte auf der Faseroberfläche reaktiviert werden, so dass beim anschließenden Verpressen zu Faserplatten ein neues stabiles Gefüge entstehen kann. Es konnte dabei ausgeschlossen werden, dass der verbesserte Zusammenhalt aufgrund einer unspezifischen Verklebung der Fasern durch den Kohlenhydrat- oder Proteinanteil der Enzymlösung zustandekommt (Felby et al., 1997).

Die anatomische und chemische Beschaffenheit dieser neuartigen Faser-Faser-Bindung war bisher unerforscht. Sie wurde hier erstmalig beschrieben. Die gleichmäßig dünne Leimfuge zwischen Holzfasern in biotechnologischen Faserplatten wies einen sehr hohen Gehalt an Lignin auf, das als ehemaliges Mittellamellen-Lignin identifiziert werden konnte. Dieselbe strukturelle und quantitative Anordnung von Lignin wurde aber auch in der Leimfuge von Kontroll-Faserplatten vorgefunden, die aus nicht enzymatisch vorbehandelten Fasern gepresst worden waren. Für die räumliche Verteilung des Lignins in der Leimfuge waren demzufolge die Temperatur und der angewandte Druck beim Verpressen ausschlaggebend und nicht die Enzymwirkung. Für die Festigkeit des Lignins in der Leimfuge war die enzymatische Vorbehandlung der Fasern jedoch von entscheidender Bedeutung. Erst durch sie erhielten biotechnologische Faserplatten eine Stabilität, die teilweise den Anforderungen von Industrienormen gerecht wurde (Kharazipour et al., 1997, Kharazipour et al., 1998). Wegen der Substratspezifität der verwendeten ligninolytischen Enzyme muss die Reaktivierung fasereigener Bindekräfte auf einer enzymatischen Modifikation des ehemaligen Mittellamellen-Lignins beruhen. Von Ligninperoxidase und Laccase ist bekannt, dass sie Ein-Elektronen-Oxidationen von phenolischen Hydroxylgruppen unter Reduktion von $\mathrm{H}_{2} \mathrm{O}_{2}$ und $\mathrm{O}_{2}$ katalysieren können. Die Produkte dieser Reaktionen sind stabile Phenoxyradikale und Wasser. Als Reaktionsmechanismus wird deswegen eine oxidative Radikalisierung von Ligninmakromolekülen auf der Faseroberfläche mit anschließender erneuter Polymerisierung vorgeschlagen (Hüttermann et al., 1998). Modifiziertes Mittellamellen-Lignin nimmt in biotechnologischen Faserplatten als stabilisierende und verbindende Matrix dieselbe Position und Funktion wie im natürlichen Verbundstoff Holz ein. 
Einen weiteren Hinweis für die maßgebliche Modifikation des Mittellamellen-Lignins auf der Faseroberfläche durch ligninolytische Enzyme lieferte die Beobachtung der Widerstandsfähigkeit der Faserplattenproben während der Merkurisierung für die Röntgenmikroanalyse. Proben der Kontroll-Faserplatten lösten sich bei der achtstündigen Reaktion mit Quecksilberacetat in siedendem Methanol weitgehend auf, so dass nur noch wenige messbare Leimfugen erhalten blieben. Proben der Platten aus enzymatisch vorbehandelten Fasern zeigten geringere Auflösungserscheinungen während der Merkurisierung. Ähnliche Bedingungen wie bei der Merkurisierung werden bei der Zellstoffgewinnung im Acetosolv- und Organosolv-Verfahren eingesetzt, um Lignin aus Faserstoff herauszulösen (Lin und Dence, 1992). Weil Lignin in Leimfugen diesen aggressiven Bedingungen standhielt, ist anzunehmen, dass es untereinander und mit anderen Bindungspartnern sehr stabil, wahrscheinlich sogar kovalent verbunden ist.

\subsection{Enzymatisch aktiviertes Lignin als Bioleim in Spanplatten}

Die Werkstoffeigenschaften von Verbundstoffen werden ganz entscheidend durch die Morphologie und Oberfläche der strukturgebenden Komponente geprägt. Holzfasern eignen sich aufgrund ihrer Flexibilität und glatten, konvexen Oberfläche sehr gut zum Verpressen in Verbundwerkstoffen. Holzspäne besitzen eher den Charakter von Partikeln als von Fasern.

Sie sind starr und haben eine rauhe und poröse Oberfläche. Im Vergleich zu Faserplatten entsteht daher in Spanplatten ein grundsätzlich anderes Gefüge.

Auf der Suche nach einer ökonomisch, ökologisch und technisch sinnvollen Verwendungsmöglichkeit für Kraft-Lignin aus der Sulfatzellstoffproduktion wird die Eignung als Bioleim in Spanplatten getestet (Kharazipour, 1996). Eine Spanplatte, die zu Versuchszwecken aus 90\% Spanmaterial und 10\% Bioleim gepresst wurde, wies nur ungenügende Festigkeitseigenschaften auf (A. Kharazipour, persönliche Mitteilung). Mikroskopische Methoden zur Erkennung von Zellwandlignin und appliziertem Lignin wurden angewendet, um die Ligninverteilung in diesem Verbundstoff und die Beteiligung von appliziertem Lignin bei der Vermittlung von Oberflächenkontakten aufzuklären.

Durch die mikroskopische Analyse beleimter Späne konnten zunächst die Vorgänge beim Aufbringen des Bioleimes rekonstruiert werden. Bei der Benetzung der getrockneten Holzspäne mit Kraft-Lignin in wässriger Suspension wurde Wasser und mit ihm kolloidales Lignin von der kapillaren Saugspannung der röhrenförmigen Holzzellen aufgesogen. Die Ligninpartikel wurden anschließend beim Trocknen an der inneren Oberfläche der 
Holzspäne gebunden. In Querschnitten beleimter Späne wurden im Lumen verschiedener röhrenförmiger Zelltypen viele Ligninpartikel aufgefunden. Der Saugeffekt reduzierte die Verfügbarkeit des applizierten Lignins für die Verklebung der Späne untereinander ganz erheblich. Aber auch auf der äußeren Spanoberfläche abgelagerter Bioleim stand nur begrenzt für die Verklebung zur Verfügung, weil die meisten Ligninpartikel in den konkaven Rinnen aufgerissener Faserzellen und nicht an hervorstehenden Bruchkanten lokalisiert waren.

In einer Spanplatte aus Spänen, die mit Kraft-Lignin in wässriger Suspension beleimt wurden, war die Anzahl der Kontakt und Stabilität vermittelnden Leimfugen deswegen nicht ausreichend, um dem Endprodukt die gewünschte Festigkeit zu verleihen.

Die mikroskopische Identifizierung des Lignins auf Spänen und in der Spanplatte konnte die Schwachpunkte der angewendeten Beleimungsmethode demonstrieren. Gleichzeitig weist sie aber auch auf Verbesserungsmöglichkeiten der Beleimung hin. Eine größere Körnung der Ligninpartikel könnte verhindern, dass ein großer Teil des applizierten Lignins von den Poren der Spanoberfläche aufgenommen wird. Dadurch wäre eine flächigere Beleimung der Oberfläche mit mehr Kontaktzonen zu anderen Spänen möglich. Eine ähnliche Wirkung hätte eine Steigerung der eingesetzten Menge an Kraft-Lignin. Eine weitere Verbesserungsmöglichkeit bietet der Einsatz eines Emulgators, der eine gleichmäßigere Verteilung des wasserunlöslichen Lignin auf der hydrophoben Spanoberfläche ermöglicht. Um die Festigkeit der Bioleim-Spanplatte zu erhöhen, war in einem zweiten Ansatz dem Bioleim PMDI-Kunstharz zugesetzt worden. Die resultierende Spanplatte besaß tatsächlich eine höhere Stabilität (A. Kharazipour, persönliche Mitteilung). Enzymatisch aktiviertes Lignin und PMDI reagieren nachweislich nicht unter Ausbildung kovalenter Bindungen zu neuen Polymeren (Kharazipour, 1996). Die beobachtete Stabilitätssteigerung ist aber möglicherweise die Folge einer Wirkung des bifunktionellen PMDI als Emulgator für wasserunlösliches Lignin. Hinweise dazu wurden bei der rastermikroskopischen Betrachtung von Spänen, die mit PMDI-Zusatz im Bioleim besprüht worden waren, in der vorliegenden Arbeit gewonnen. PMDI bewirkte demnach nicht nur eine flächendeckendere Beleimung der Späne, sondern war auch für die Ausbildung größerer BindemittelKonglomerate verantwortlich. Beide Effekte tragen zu einer besseren Oberflächenhaftung der Späne im Gefüge der Spanplatte nach dem Verpressen bei. 


\subsection{Lignin als Imprägniermittel von biologisch abbaubarem Verpackungsmaterial}

Die Industrienationen müssen heutzutage mit ständig wachsenden Müllbergen zurechtkommen. Es besteht daher ein großes Interesse, das Aufkommen von Verpackungsmaterial $\mathrm{zu}$ reduzieren oder den anfallenden Verpackungsabfall neuen Stoffkreisläufen zuzuführen. Die biotechnologische Forschung hat ihre Aufgabe erkannt und versucht, durch die Entwicklung neuer Materialien auf der Basis nachwachsender Rohstoffe synthetische Kunststoffe zu ersetzen. Außerdem ist die Landwirtschaft an diesem neuen Forschungszweig interessiert, weil sie sich derzeit neben der klassischen Versorgung mit Nahrungsmitteln ein zweites Standbein als Produzent von kohlenhydrat-, öl- und faserhaltigen Rohstoffen für verarbeitende Industrien schafft. Der Hauptvorteil dieser neuen Materialien gegenüber petrochemischen Kunststoffen liegt in der guten biologischen Abbaubarkeit. Unter den Biopolymeren, die in großer Menge kostengünstig für die Produktion von Verpackungsmaterialien zur Verfügung stehen, besitzt Zellstoff in Papier, Pappe und Karton schon lange einen bedeutenden Marktanteil. Folien und Formteile aus Stärke sind erst dabei, sich als Verpackungsmittel zu etablieren. Zellstoff und Stärke als Kohlenhydrate erweisen sich wegen ihrer Quellfähigkeit jedoch ungeeignet, um als wasserfeste Barriere zwischen Produkt und Umwelt zu fungieren.

Es ist daher üblich, Pappe als Verpackungsmaterial für Flüssigkeiten mit synthetischen Wachsen, Kunststoff-Folien oder Metall-Folien zu beschichten. Diese Verbundstoffe sind biologisch aber nicht mehr abbaubar und ihre Wiederverwertung ist technisch sehr aufwendig. Aus der biotechnologischen Materialforschung stammt der Vorschlag, wie in der Natur Lignin als wasserfestes Imprägniermittel für kohlenhydrathaltige Oberflächen einzusetzen. Neben der Funktion als stabilisierende Matrix zwischen Cellulose-Fibrillen beziehungsweise Holzzellen besitzt Lignin nämlich noch die zweite wichtige biologische Funktion als Imprägniermittel der Wasserleitungsbahnen im Holz. Technisches Lignin als Beiprodukt der Zellstoff-Fabrikation steht als günstiger Rohstoff für die Entwicklung und Produktion neuer biologisch abbaubarer Verbundstoffe zur Verfügung. Folien, die aus pulverisiertem Ligninsulfonat und Weizenstärke hergestellt wurden, wiesen zwar gute mechanische Festigkeitseigenschaften auf, erreichten jedoch nicht die erforderliche Wasserfestigkeit (Baumberger et al., 1997). Die Autoren führten dieses Ergebnis auf die 
Verwendung eines wasserlöslichen Lignins zurück, das auch bei Erwärmung auf $140{ }^{\circ} \mathrm{C}$ seine Hydratisierbarkeit nicht verliert.

Ligninolytische Enzyme, die aus Weißfäulepilzen isoliert wurden, wurden bereits erfolgreich eingesetzt, um Lignin auf der Oberfläche von Holzfasern zu reaktivieren und damit eine erneute Polymerisierung durch Druck und Temperatur zu ermöglichen (Kharazipour, 1996). Schröter (1998) nutzte dieses Konzept und inkubierte Papiere beziehungsweise freien Zellstoff mit Ligninsulfonat und pilzlicher Laccase, um ein neues wasserfestes Verpackungsmaterial auf der Basis von Cellulose und Lignin zu gewinnen. Die Reißfestigkeit des hergestellten Sulfitzellstoff-Vlieses aus ligninbeschichteten Fasern war doppelt so groß wie diejenige von Kontrollvlies aus unbeschichteten Fasern. Außerdem besaß lignifiziertes Vlies eine messbare Nassfestigkeit, während sich das Kontrollvlies in Wasser wieder in Fasern auflöste.

Die morphologische Beschreibung dieser neuen Verbundstoffe gehörte zu den Aufgaben, die in der vorliegenden Arbeit behandelt wurden. Das applizierte Lignin konnte als eine homogene Ablagerung auf der Oberfläche des Papiers beziehungsweise der freien Fasern identifiziert werden. Der Kontakt zwischen der Auflage aus Lignin und der Oberfläche aus Cellulose war so stabil, dass das Lignin bei mechanischem Bruch der Faser nicht flächig aufriss. Auch die aggressiven Bedingungen während der Merkurisierung für die Röntgenmikroanalyse, die den Bedingungen bei der Delignifizierung im OrganosolvVerfahren sehr ähnlich sind, vermochten nicht, das aufgelagerte Lignin abzulösen. Es ist daher anzunehmen, dass zwischen enzymatisch aktiviertem Ligninsulfonat und der nukleophilen Matrix aus Cellulose stabile chemische, möglicherweise sogar kovalente Bindungen geknüpft wurden.

In der verholzten Zellwand natürlicher Gewebe wurden bisher keine Bindungen zwischen Lignin und Cellulose nachgewiesen (Higuchi, 1997). Hemicellulosen vermitteln dort den Kontakt zwischen den beiden anderen Zellwandkomponenten. Die hier beschriebene Bindung zwischen Ligninsulfonat und Cellulose stellt eine in der Natur bisher unbekannte Verknüpfung dar, die in nächster Zeit noch intensiver untersucht werden muss, um mögliche Anwendungen in biotechnologischen Verbundstoffen zu optimieren.

Unbeschichtete merkurisierte Sulfitzellstoff-Fasern wiesen in der Sekundärwand keine natürlichen Ligninreste mehr auf. Lignin, das in der Sekundärwand beschichteter merkurisierter Fasern detektiert wurde, musste deshalb während der Inkubation mit Ligninsulfonat durch Poren eindiffundiert sein. Die Zellwand der Fasern wurde demnach nicht nur an ihrer Oberfläche, sondern auch in tieferen Schichten mit Lignin imprägniert. 
Die Lignifizierung der Zellstoff-Fasern hatte außerdem Folgen für den Zusammenhalt der Fasern untereinander. In den Kontaktzonen, die die aggressiven Bedingungen der Merkurisierung überstanden hatten, wurden mittels Röntgenmikroanalyse kleinräumig hohe Ligningehalte bestimmt. Appliziertes, enzymatisch aktiviertes und anschließend polymerisiertes Ligninsulfonat trug ähnlich wie Mittellamellen-Lignin im natürlich gewachsenen Gewebe oder wie aktiviertes Mittellamellen-Lignin im künstlichen Gefüge biotechnologischer Faserplatten zu einer Stabilisierung des Vlieses bei. Auf höherer Strukturebene war dieser stabilisierte Zusammenhalt lignifizierter Fasern als erhöhte Reißfestigkeit des Vlieses messbar. 


\section{ZUSAMMENFASSUNG}

In der vorliegenden Arbeit, wurde die Ligninverteilung in gewachsenem Holz und in neuartigen Verbundstoffen, die auf der Basis von Holzprodukten hergestellt wurden, untersucht. Die Röntgenmikroanalyse in Verbindung mit mikroskopischen Techniken erwies sich als effektive und vielseitig einsetzbare Methode, um Lignin im natürlichen Gewebe und im künstlichen Gefüge in situ zu lokalisieren und zu quantifizieren. Neue Erkenntnisse über die Modifikation und Aufgabe von Lignin in Verbundstoffen konnten abgeleitet werden. Es wurden folgende Ergebnisse erzielt:

(1) Die Röntgenmikroanalyse von quecksilbermarkiertem Lignin wurde als Methode zum quantitativen mikroskopischen Nachweis von Lignin in situ am Institut für Forstbotanik etabliert.

(2) Mittels Röntgenmikroanalyse wurden erstmalig die Ligninverteilung und die Elementverteilung in verschiedenen Schichten der Zellwand von Faserzellen der Rotbuche (Fagus sylvatica) und der Waldkiefer (Pinus sylvestris) beschrieben. Das Verteilungsmuster von Lignin und zweiwertigen Nährelementen wies dabei eine hohe Übereinstimmung auf. Ein Literaturvergleich unterstreicht den generellen Charakter dieser Ergebnisse und die Eignung der angewendeten Messmethode.

(3) In einem Screening mit 31 Weißfäule- und Braunfäulepilzen wurden zwei Pilzstämme isoliert, die in nur drei Wochen die Scherfestigkeit von Probehölzern deutlich reduzierten: Der Weißfäulepilz Trametes hirsuta erniedrigte die mechanische Stabilität von Buchenholz um über 50\% und der Braunfäulepilz Gloeophyllum trabeum diejenige von Kiefernholz um 35\%. Die Anwendung dieser Pilze bei der biotechnologischen Vorbehandlung von Hackschnitzeln ermöglicht Energieeinsparungen beim Faseraufschluss und den partiellen oder vollständigen Verzicht auf synthetische Bindemittel bei der Weiterverarbeitung zu Faserwerkstoffen. 
(4) Die Reduktion der mechanischen Stabilität von Holz in der Frühphase der Infektion mit Fäulepilzen erfolgt, bevor es zu einem messbaren Abbau der stabilisierenden Ligninnatrix oder anderer Zellwandbausteine kommt. Modifikationen in der Ultrastruktur der infizierten Zellwände werden beschrieben und diskutiert.

(5) Während der Infektion durch Fäulepilze ändert sich der Nährelementgehalt der verholzten Zellwand radikal. In inkubierten Probehölzern wurde beobachtet, dass zweiwertige Zellwandionen aus der Mittellamelle infizierter Zellen entfernt und an der Grenze zum Lumen akkumuliert werden. Im rotfaulen Splintholz von Fichten erfolgt außer der Akkumulation von Nährelementen im Lumen infizierter Zellen eine große Anreicherung von Kalium in allen Zellwandschichten. Die Nachlieferung der Nährelemente wird durch den Xylemstrom im lebenden Baum ermöglicht.

(6) Die Leimfuge aus enzymatisch aktiviertem ehemaligem Mittellamellenlignin im Verbundstoff Mitteldichte Faserplatte (MDF) imitiert die Mittellamelle im gewachsenen Holz morphologisch, chemisch und funktionell.

(7) Die mangelnde Stabilität von Spanplatten, denen als einziges Bindemittel enzymatisch aktiviertes technisches Lignin zugesetzt worden war, konnte auf eine unzureichende Beleimung der Spanoberflächen zurückgeführt werden. PMDI als Zusatz zum Bioleim hat eine Emulgatorwirkung auf Lignin.

(8) Für eine höhere Reißfestigkeit und Nassfestigkeit von Filterpapier und SulfitzellstoffVlies nach Inkubation mit enzymatisch aktiviertem technischen Lignin, ist die stabile Bindung von Lignin an die Zellstoff-Fasern verantwortlich. Weil diese Bindung den Angriff von Methanol, Säure und Hitze während der Merkurisierung für die Röntgenmikroanalyse übersteht, muss es sich um eine neuartige kovalente Bindung zwischen Lignin und Cellulose handeln. 


\section{LITERATURVERZEICHNIS}

Adler, E., Björkquist, J. und Häggroth, S. (1948): Über die Ursache der Farbreaktionen des Holzes. Acta Chem. Scan. 2:93-94.

Akhtar M., Attridge M.C., Blanchette R.A., Myers G.C., Wall M.B., Sykes M.S., Koning J.W. und Burgess R.R. (1992): The white rot fungus Ceriporiopsis sub. saves electrical energy and improves strength properties during biomechanical pulping of wood. 5th International Conference on. Biotechechnology in the Pulp and Paper Industry, Kyoto.

Akhtar, M., Attridge, M.C., Myers, G.C. und Blanchette, R.A. (1993): Biomechanical pulping of loblolly pine chips with selected white-rot fungi. Holzforschung 47(1):3640.

Ander P. und Eriksson K.E. (1977): Selective degradation of wood components by whiterot fungi. Physiol.Plant 41:239-248.

Baumberger, S., Lapierre, C., Monties, B., Lourdin, D. und Colonna, P. (1997): Preparation and properties of themally moulded and cast lignosulfonates-starch blends. Industrial Crops and Products 6:253-258.

Beck, T., Öhlinger, R. und Baumgarten, A. (1995): Substrate-induced respiration. In: F. Schirmer, R. Öhlinger, E. Kandeler und R. Margesin (eds.): Methods in soil biology. Springer Berlin, Heidelberg 1995, 64-67.

Blanchette, R.A. (1984): Manganese accumulation in wood decayed by white rot fungi. Phytopathology 74(6):725-730.

Blanchette, R.A. (1991): Delignification by wood-decay fungi. Ann. Rev. Phytopathol. 29:381-398.

Blanchette, R.A. (1995): Degradation of the lignocellulose complex in wood. Can. J. Bot. 73 (Suppl. 1):S999-S1010.

Blanchette, R.A., Otjen, L. und Carlsson, M.C. (1987): Lignin distribution in cell walls of birch wood decayed by white-rot basidiomycetes. Phytopathology 77(5):684-690.

Bland, D.E., Foster, R.C. und Logan, A.F. (1971): The mechanism of permanganate and osmium tetroxide fixation and the distribution of lignin in the cell wall of Pinus radiata.Holzforschung 25(5):137-143

Bonnarme, P. und Jeffries, T. (1990): Manganese (II) regulation of lignin peroxidases and manganese-dependent peroxidases from lignin-degrading white rot fungi. Appl. Environ. Microbiol. 56(1):210-217.

Boutelje, J.B. (1972): Calculation of lignin concentration and porosity of cell wall regions by interference microscopy. Svensk Paperstidn 75:683-686.

Boutelje, J.B. und Eriksson, I. (1984): Analysis of lignin in fragments from thermomechanical spruce pulp by ultraviolet microscopy. Holzforschung 38:249252.

Bradfield, E.G. (1976): Calcium complexes in the xylem sap of apple shoots. Plant Soil 44:495-499.

Cliff G. und Lorimer, G.W. (1975): The quantitative analysis of thin specimens. Journal of Microscopy 103(2):203-207.

Dawes, C.J. (1988): Introduction to biological electron microscopy: Theory and techniques. Ladd Research Industries, Burlington, USA.

Donaldson, L.A. (1985a): Critical assesment of interference microscopy as a technique for measuring lignin distribution in cell walls. N. Z. J. For. Sci. 15:349-360.

Donaldson, L.A. (1985b): Within- and between-tree variation in lignin concentration in the tracheid cell wall of Pinus radiata. N. Z. J. For. Sci. 15:361-369. 
Donaldson, L.A. (1986): Between tree variation in lignin concentration in Pinus radiata tracheids with growth rate, stem eccenticity, site, and silvicultural treatment. N. Z. J. For. Sci. 16:118-123.

Donaldson, L.A. (1991): Seasonal changes in lignin distribution during tracheid development in Pinus radiata (D.Don.). Wood Sci. Technol. 25:15-24.

Donaldson, L.A. (1992): Interference microscopy. In: S.Y. Lin und C.W. Dence: Methods in lignin chemistry. Springer Verlag Berlin, 122-132.

Donaldson, L.A., Croucher, M. und Uprichard, J.M. (1997): Clonal variation of wood chemistry variables in radiata pine (Pinus radiata D. Don.) wood. Holzforschung 51:537-542.

Dünisch, O., Bauch, J., Puls, J. und Müller, M. (1996): Biological and chemical wood properties of long-term polluted spruce (Picea abies [L.] Karst.) at high-altitude stands of the Erzgebirge. Holzforschung 50:497-506.

Effland, M. (1977): Modified procedure to determine acid-insoluble lignin in wood and pulp. TAPPI J. 60(10)143-144

Ek, M. und Eriksson, K.E. (1980): Utilization of the white rot fungus Sporotrichum pulvurentum for water purification and protein production on mixed ligno-cellulosic wastewaters. Biotechnology and Bioengineering 22:2273-2284.

Eriksson I., Lidbrandt O. und Westermark U. (1988): Lignin distribution in birch (Betula verrucosa) as determined bymercurization with SEM- and TEM-EDXA. Wood Sci.Technol 22:251-257.

Eriksson, K., Blanchette, R.A. und Ander, P. (1990): Microbial and enzymatic degradation of wood and wood components. Springer Verlag, Berlin.

Eriksson, Ö., Goring, D.A. und Lindgren, BO. (1980): Structural studies on the chemical bonds between lignins and carbohydrates in spruce wood. Wood Sci. Technol. 14:267-279.

Falck, R. (1926): Über die korrosive und destruktive Holzzersetzung und ihre biologische Bedeutung. Ber. Dtsch. Bot. Ges. 44:652-664.

Felby, C., Pedersen, L.S. und Nielsen, B.R. (1997): Enhanced auto adhesion of wood fibres using phenol oxidases. Holzforschung 51:281-286

Fengel, D. und Wegener G.(1989): Wood: Chemistry, ultrastructure, reactions. Walter de Gruyter, Berlin, New York..

Fengel, D., Wegener, G. und Greune, A. (1989): Studies on the delignification of spruce wood by organosolv pulping unsing SEM-EDXA and TEM. Wood Sci. Technol. 23, $123-130$.

Fergus B.J. und Goring D.A. (1970): The distribution of lignin in birch wood as determined by ultraviolet microscopy. Holzforschung 24:118-124.

Fergus, B.J., Procter, A.R., Scott, J.A. und Goring, D.A. (1969): The distribution of lignin in sprucewood as determined by ultraviolet microscopy. Wood Sci. Technol. 3:117138

Freudenberg, K., Sohns, F., Dürr, W. und Niemann, C. (1931): Über Lignin Coniferylalkohol und Saligenin. Cellulosechemie 12, 263 - 275.

Fritz, E. (1989): X-ray microanalysis of diffusible elements in plant cells after freeze-drying, pressure infiltration with ether and embedding in plastic. Scanning Microscopy 3:517-526.

Fritz, E. (1991): The use of adhesive coated grids for the X-ray microanalysis of dry cut sections in the TEM. Acta Histochemica 86:263-278.

Fritz, E. und Jentschke, G. (1994): Agar standards for quantitative X-ray microanalysis of resin-embedded plant tissues. Journal of Microscopy 174(1):47-50.

Fukazawa, K. (1992): Ultraviolet Microscopy. In: S.Y. Lin und C.W. Dence: Methods in lignin chemistry. Springer Verlag Berlin, 110-121. 
Fukazawa, K. und Imagawa, H. (1981): Quantitative analysis of lignin using an V microscope image analyzer. Variation within one growth increment. Wood Sci. Technol. 15:45-55.

Glenn, J.K. und Gold H.M. (1985): Purification and charakterization of an extracellular Mn(II)-dependent peroxidase from Phanerochaete chrysosporium. Arch. Biochem. Biophys. 242:329-341.

Glenn, J.K., Morgan, M.A., Mayfield, M.B., Kuwahara, M. and Gold M.H.(1983): An extracellular $\mathrm{H}_{2} \mathrm{O}_{2}$-requiring enzyme preparation involved in lignin biodegradation by the white rot basidomycete Phanerochaete chrysosporium. Biochem. Biophys. Res. Commun. 114:1077-1082.

Green, F. und Highley T.L.(1997): Mechanism of brown-rot decay: Paradigm or paradox. International Biodeterioration \& Biodegradation 39 (2-3):113-124.

Haider, K. und Trojanowski J. (1980): A comparison of the degradation of ${ }^{14} \mathrm{C}$-labelled DHP and cornstalk lignins by micro- and macrofungi and bacteria. In: T.K. Kirk, T. Higuchi and H.-M. Chang (eds.): Lignin biodegradation: Microbiology, chemistry, and potential applications. CRC Press, Boca Raton, Vol. I. , pp. 111-134.

Hartig, R. (1878): Die Zersetzungserscheinungen des Holzes der Nadelholzbäume und der Eiche in forstlicher, botanischer und chemischer Richtung. Springer Verlag, Berlin, Heidelberg.

Heilmann, B. (1995): Substrate-induced heat output. In: F. Schirmer, R. Öhlinger, E. Kandeler und R. Margesin (eds.): Methods in soil biology. Springer Verlag Berlin, Heidelberg, 68-72.

Higuchi, T. (1997): Biochemistry and molecular biology of Wood. Springer, Berlin, Heidelberg, New York.

Hubert, E.E. (1924): The diagnosis of decay in wood. J. of Agricultural Research 29: 523 567

Hüttermann, A. und Haars, A. (1987): Biochemical control of forest pathogens inside the tree. In: I. Chet (ed.): Offprints from innovative approaches to plant disease control. John Wiley and Sons, Inc., 275-296.

Hüttermann, A., Kharazipour, A. und Mayer, F. (1990): Verfahren zur Gewinnung von phenoloxidierenden Enzymen aus Kulturen von Weißfäulepilzen Patent P 4033 246.2 .

Hüttermann, A. und Majcherczyk, A. (1998): Bioremediation: Pesticides and other agricultural chemicals. In: A. Altmann (ed.): Agricultural biotechnology. Marcel Dekker Inc., New York, 367-386.

Hüttermann, A., Kharazipour, A., Schindel, K., Fastenrath, M., Noetzold, S., Schroeter, M., Hüttermann, J., Hüttermann, A.H., von Kiedrowski, G., Baumberger, S., Lapierre, C. und Monties, B. (1998): Enzymatic reactions of activated lignin with nucleophiles as a basis for the design of compound materials with lignin.

Proceedings of the 7th International Conference on Biotechnology in the Pulp and Paper Industry, Vancouver.

Hüttermann, A., Majcherczyk, A., Mai, C., Braun-Lüllemann, A., Fastenrath, M. und Noetzold, S. (1998): Zwischenprodukt für die Herstellung von Ligninpolymerisaten und dessen Verwendung für die Herstellung von Verbundwerkstoffen aus pflanzlichen Fasern, wasserfesten Papieren und Pappe sowie Duroplasten aus Ligninderivaten. Deutsches Patent PCT/DE 98/00254.

Jellison, J., Conolly, J., Goodell, B., Doyle, B., Illmann, B., Fekete, F. und Ostrofsky, A. (1997): The role of cations in the biodegradation of wood by the brown rot fungi. International Biodeterioration and Biodegradation 39(2-3):165-179. 
Joseleau J.P., Gharibian S., Comtat J., Lefebvre A. und Ruel K. (1994): Indirect involvement of lignilolytic enzyme systems in cell wall degradation. FEMS Microbiology Reviews 13:255-264.

Kerem, Z. und Hadar, Y. (1998): Lignin-degrading fungi: Mechanisms and utilization. In: A. Altmann (ed.): Agricultural biotechnology. Marcel Dekker Inc., New York, 351365.

Kersten, P.J., Tien, M. und Kalyaraman B.(1985): The ligninase of Phanerochaete chrysosporium generates cation radicals from methoxybenzenes. J. Biol. Chem. 260:2609-2612.

Kersten, P. J., Kalyaraman, B., Hammel, K. E., Reinhammar, B. and Kirk T. K. (1990): Comparison of lignin peroxidase, horseradish peroxidase and laccase in the oxidation of methoxybenzenes. Biochem. J. 268:475-480.

Kharazipour, A. (1996): Enzyme von Weißfäulepilzen als Grundlage für die Hestellung von Bindemitteln für Holzwerkstoffe. Sauerländer Verlag, Frankfurt am Main.

Kharazipour, A., Haars, A., Shekholeslami, M. und Hüttermann, A. (1991): Enzymatische Behandlung von Holzfasern als Weg zur vollständig bindemittelfreien Holzwerkstoffen. In: A. Hüttermann und A. Kharazipour (eds.): Die pflanzliche Zellwand als Vorbild für Holzwerkstoffe. Sauerländer Verlag, Frankfurt, 83-98.

Kharazipour, A., Hüttermann, A., Kühne, G. und Rong, M. (1993): Verfahren zum Verkleben von Holzfragmenten sowie dadurch hergestellter Formkörper. Deutsches Patent P 4305411.

Kharazipour, A., Schindel, K. und Hüttermann, A. (1997): Enzymatic activation of wood fibres for wood composite production. In: K. Eriksson (ed.): Enzyme applications in fiber processing. ACS Symposium Series Nr 687.

Kharazipour, A., Hüttermann, A. und Lüdemann, H.D. (1997): Enzymatic activation of wood fibres as a means for the production of wood composites. J. Adhesion Sci. Technol. 11(3):419-427.

Kharazipour, A., Hüttermann, A. und Nonninger, K. (1998): Properties of fibre boards obtained by activation of the middle-lamella lignin of wood fibres with peroxidase and $\mathrm{H}_{2} \mathrm{O}_{2}$ before conventional pressing. J. Adhesion Sci. Technol. im Druck.

Kirk, T.K. und Farell R.L.(1987): Enzymatic "Combustion": The microbial degradation of lignin. Ann. Rev. Microbiol. 41:465-505.

Körner, I., (1990): Untersuchungen zum Wirkungsmechanismus ausgewählter Braunfäulepilze. Ingenieurbeleg, TU Dresden.

Körner, S. (1990): Verfahren zur stofflichen Modifikation des Rohholzes für die Holzwerkstoffherstellung. Dissertation TU Dresden.

Koshijima, T., Watanabe, T. und Yaku F. (1989): Structure and properties of the lignincarbohydrate complex polymer as an amphipathic substance. In: W.G. Glasser und S. Sarkanen (eds.): Lignin: Properties and material. ACS Symposium Series 397:1128.

Kuhn, A.J., Schröder, W.H. und Bauch, J. (1997): On the distribution and transport of mineral elements in xylem, cambium and phloem of spruce (Picea abies [L.] Karst.). Holzforschung 51:487-496.

Lange, P.W. (1954): The distribution of lignin in the cell wall of normal and reaction wood from spruce and a few hardwoods. Svensk Papperstidn. 57:525-532.

Leatham, G.F., Myers, G.C., Wegner, T.H. und Blanchette, R.A. (1990): Energy savings in biomechanical pulping. In: T.K. Kirk und H.-M. Chang (eds.): Biotechnology in pulp and paper manufactures, applications and fundamental investigations. Butterworths-Heinemann, Boston.

Levy, J.F. (1987): The natural history of the degradation of wood. Phil. Trans. R. Soc. Lond. 321:423-433. 
Lin, S.Y. und Dence, C.W. (1992): Methods in lignin chemistry. Springer Verlag, Berlin, Heidelberg.

Little, B.F.P. (1991): Recent developments in the application of lignin. Proceedings of the 1st workshop on lignocellulosis and pulp, Hamburg 1991, 15-22.

Majer, C., Kilian, W. und Mutsch, F. (1989): Die Böden im Gleinalmgebiet. Mitteilungen der Forstlichen Bundesversuchsanstalt Wien, Nr. 163(1):33-128.

Marschner, H. (1995): Mineral nutrition in higher plants. Academic Press London 1995, 1024.

Marshall, A.T. (1980): Principles and instrumentation. In: M.A. Hayat (ed.): X-ray microanalysis in biology. University Park Press 1980, 1-64.

Masson, G., Cabanis, M.T., Cabanis, J.C. und Puech, J.-L. (1997): The amounts of inorganic elements in cooperage oak. Holzforschung 51:497-502.

Messner, K. und Srebotnik, E. (1994): Biopulping- an overview of developments in an environmentally safe paper-making technology. FEMS Microbiol. Rev. 13:351.

Milstein, O., Gersonde, R., Hüttermann, A., Chen, M.-J. und Meister, J.J. (1992): Fungal Biodegradation of lignopolysterene graft copolymers. Appl. Environ. Microbiol. 58:3225-3232.

Mohr, H. und Schopfer P.(1992): Pflanzenphysiologie, 4. Auflage. Springer, Berlin, Heidelberg, New York.

Momoshima, N. und Bondietti, E.A. (1990): Cation binding in wood: Applications to understanding historical changes in divalent cation availability to red spruce. Can. J. For. Res. 20:1840-1849.

Nakano, J. und Meshitsuka, G. (1992): The detection of lignin. In: S.Y. Lin und C.W. Dence: Methods in lignin chemistry. Springer Verlag Berlin, 21-32.

Nimz, H., Razvi, A., Marquharab, I. und Clad, W. (1972): Bindemittel bzw. Klebemittel zur Herstellung von Holzwerkstoffen sowie zur Verklebung von Werkstoffen verschiedener Art. DOS 2221353.

Ostrofsky, A., Jellison, J., Smith, K.T. und Shortle, W.C. (1997): Changes in cation concentrations in red spruce wood decayed by brown rot and white rot fungi. Can. J. For. Res. 27:567-571.

Otjen, L. und Blanchette, R.A. (1985): Selective delignification of aspen wood blocks in vitro by three white rot basidiomycetes. Appl. Environ. Microbiol. 50(3):568-572.

Otjen L., Blanchette R.A. und Leatham G.F. (1988): Lignin distribution in wood delignified by white-rot fungi: $x$-ray microanalysis of decayed wood treated with bromine. Holzforschung 42:281-288.

Pecina, H., Kühne, G., Bernaczyk, Z. und Wienhaus, O. (1991): Lignin-Phenol-Bindemittel für die Holzwerkstoffherstellung. Lignin-Phenol-Bindemittel als Alternative für herkömmliche Phenolklebstoffe. Holz Roh- und Werkstoff 49:391-397

Pedersen, A.H. und Rasmussen, J.J. (1962): Improvements in and relating to the manufacture of chipboard or the like. GB-Patent Nr. 993693.

Peng, F. und Westermark, U. (1997): Distribution of coniferyl alcohol and coniferaldehyde groups in the cell wall of spruce fibres. Holzforschung 51:531-536.

Raven, P.H., Evert, R.F. und Curtis, H. (1988): Biologie der Pflanzen. de Gruyter, Berlin.

Reinhammar, B. (1984): Laccase. In: R. Lontie (ed.): Copper protein and copper enzymes. CRC Press, Boca Raton, Vol. 3:1-31.

Roffael, E. (1982): Die Formaldehydabgabe von Spanplatten und anderer Werkstoffe. DRW-Verlag, Stuttgart.

Roffael, E. und Rauch, W. (1971): Über die Herstellung von Holzspanplatten auf Basis von Sulfitablauge II. Über ein neues und schnelles Verfahren zur Herstellung Sulfitablauge-gebundener Spanplatten. Holzforschung 25:149-155. 
Roffael, E. und Rauch, W. (1974): Sulfitablauge als Spanplattenbindemittel. Holz-Zbl. 100:1461-1462.

Roomans, G.M. (1980): Quantitative X-ray microanalysis of thin sections. In: M.A. Hayat (ed.): X-ray microanalysis in biology. University Park Press 1980, 401-454.

Ruel K., Ambert K. und Joseleau J.P. (1994): Influence of the enzyme equipment of whiterot fungi on the patterns of wood degradation. FEMS Microbiol Rev 13:241-254.

Safford, L.O., Shigo, A.L. und Ashley, M. (1974): Gradients of cation concentration in discolored and decayed wood of red maple. Can. J. For. Res. 4:435-440.

Saka S., Thomas R.J. und Gratzl J.S. (1978): Lignin distribution Determination by energydispersive analysis of X-rays. Tappi J. 61:73-76.

Saka, S., Thomas, R.J. und Gratzl, J.S. (1981): Lignin distribution in douglas fir and loblolly pine as determined by energy dispersive X-ray analysis. International Symposium on Wood and Pulping Chemistry, Ekmandagarna 1981, SPCI Rep. 38(1):35-51.

Saka S. und Thomas R.J. (1982): A study of lignification in loblolly pine tracheids by the SEM-EDXA technique. Wood Sci. Technol. 16:167-179.

Saka S., Whiting P., Fukazawa K. und Goring D.A. (1982): Comparative studies on lignin distribution by UV microscopy and bromination combined with EDXA. Wood Sci.Technol 16:269-277.

Saka, S. und Goring, D. (1983): The distribution of inorganic constituents in black spruce as determined by TEM-EDXA. Mokuzai Gakkaishi 29(10):648-656.

Saka, S. und Goring, D.A. (1988): The distribution of lignin in white birch as determined by bromination with TEM-EDXA. Holzforschung 42:149-153

Saka, S., Hoyosa, S., St.Germain, F.G. und Goring, D.A. (1988): A comparison of the bromination of syringyl- and guaiacyl-type lignins. Holzforschung 42:79-83.

Saka, S. und Mimori, R. (1994): The distribution of inorganic constituents in white birch wood as determined by SEM-EDXA. Mokuzai Gakkaishi 40(1):88-94.

Salmen, L. und Olson A.-M.(1998): Interaction between hemicelluloses, lignin and cellulose: Structure-property relationships. Journal of Pulp and Paper Science 24 (3):99-103.

Schmidt, O. (1994): Holz- und Baumpilze, Biologie, Schäden, Schutz, Nutzen. Springer Verlag Berlin, Heidelberg.

Schröter, M. (1998): Umsetzung von enzymatisch aktiviertem Lignin mit Zellstoff als Grundlage für die Herstellung von Nassfestmitteln für Papiere und Pappen. Diplomarbeit, Universität Göttingen.

Scott, J.A., Procter, A.R., Fergus, B.J. und Goring, D.A. (1969): The application of ultraviolet microscopy to the distribution of lignin in wood. Description and validity of the technique. Wood Sci. Technol. 3:73-92.

Sermanini G.G. et al. (1994): Characteristics of paper handsheets after combined biological pretreatments and conventional pulping of wheat straw. Tappi J. 77:151.

Smidt, S. und Leitner, J. (1991): Immissionsmessungen im Gleinalmgebiet. Mitteilungen der Forstlichen Bundesversuchsanstalt Wien,. 163(4):51-64.

Spurr, A.R. (1969): A low viscosity epoxy resin embedding medium for electron microscopy. Journal of Ultrastructural Research 26:31-43.

Stewart, H. (1984): Cedar, tree of live to the northwest coast indians. Douglas and McIntyre, Ltd. Vancouver, p. 182.

Tien, M. und Kirk T.K.(1983): Lignin degreding enzyme from the hymenomycete Phanerochaete chrysosporium. Nature 326:520-523.

Tomiczek, C. (1995): Nutrient deficiency of spruce needles caused by root and butt rots - a factor in forest decline. Journal of Arboriculture 21(3):113-117. 
Van de Geijn, S.C. und Petit, C.M. (1979): Transport of divalent cations. Cation exchange capacity of intact xylem vessels. Plant Physiology 64:954-958.

von Aufsess, H. (1972): Einige licht- und rasterelektronenmikroskopische Untersuchungen an rotfaulem Fichtenholz. Forstw. Cbl. 91:98-105.

Wagenführ, A. (1988): Anwendung der Biotechnologie in der Holz- und Faserwerkstofftechnik. Dissertation TU Dresden.

Wagenführ, R. (1984): Anatomie des Holzes unter besonderer Berücksichtigung der Holztechnik. Fachbuchverlag Leipzig.

Westermark, U. (1982): Calcium promoted phenolic coupling by superoxide radical - a possible lignification reaction in wood. Wood Sci. Technol. 16(1):71-78.

Westermark U. (1985): Bromination of different morphological parts of spruce wood (Picea abies). Wood Sci.Technol. 19:323-328.

Westermark, U., Lidbrandt, O. und Eriksson, I. (1988): Lignin distribution in spruce (Picea abies) determined by mercurization with SEM-EDXA technique. Wood Sci. Technol. 22:243-250.

Whiting, P., Favis, B.D., St. Germain, F.G. und Goring, D.A. (1981): Fractional separation of middle lamella and secondary wall tissue from spruce wood. Journal of Wood Chemistry and Technology 1(1):29-42.

Willkomm, M. (1866): Die mikroskopischen Feinde des Waldes. G. Schönfeld's Buchhandlung, Dresden.

Wood, J.R. und Goring, D.A. (1971): The distribution of lignin in stem wood and branch wood of douglas fir. Pulp and Paper Canada 72:61-68.

Yamaguchi, H., Maeda, Y. und Sakata, I. (1992): Applications of the phenol dehydrogenative polymerization by laccase to bonding among woody fibres. Mokuzai Gakkaishi 38:931-937. 


\section{DANKSAGUNG}

Bei Professor Dr. A. Hüttermann bedanke ich mich herzlich für die Überlassung des Themas, das mich von botanisch-anatomischer und pathologischer Grundlagenforschung bis hin zu den angewandten Materialwissenschaften biotechnologischer Holzwerkstoffe führte. Seine Unterstützung bei Konzeption, Durchführung und Diskussion dieses Forschungsvorhabens war sehr wertvoll. Im besonderen schätze ich seine Ermunterung, die aktuellen Ergebnisse auf Reisen zu unseren Projektpartnern an der TU Dresden und der HU Rehovot/Israel auszutauschen und interdisziplinär zu diskutieren.

Professor Dr. G. Kühne, Dipl.-Ing. H. Unbehaun und Dipl.-Ing. M. Wolff (TU Dresden) und Professor Dr. I. Chet, Professor Dr. Y. Hadar, MSc. R. Cohen, MSc. E. Cohen und BSc. K. Ziv (HU Rehovot) danke ich für die produktive Zusammenarbeit im gemeinsamen Forschungsprojekt: "Mechanismen der mykologischen Transformation von Holz für die Holzwerkstoffherstellung." Dieses Projekt wird finanziell von der Deutschen Forschungsgemeinschaft gefördert (Ku 860/2-1; Hu 141/18-2).

Dr. C. Tomiczek von der Forstlichen Bundesversuchsanstalt Wien gilt mein besonderer Dank für die Übersendung der Proben rotfaulen Fichtenholzes aus der Steiermark und für die Einladung nach Wien.

Ich möchte mich bei PD Dr. A. Kharazipour und A. Grimme vom Institut für Forstbotanik für die Bereitstellung von Proben ihrer biotechnologischen Holzwerkstoffe für die mikroskopische Analyse bedanken.

M. Schröter belieferte mich dankenswerterweise mit lignifizierten Verpackungsmaterialien und Informationen zu ihrer Herstellung und ihren Eigenschaften.

K. Wehr und Dr. E. Fritz danke ich für ihre Geduld und Hilfsbereitschaft, auf die ich gerne und oft zugriff, um die Bedienung der Elektronenmikroskope zu erlernen.

Jeder Kollegin und jedem Kollegen im Labor für Technische Mykologie des Instituts für Forstbotanik gilt ein eigenes "Dankeschön" für die freundliche Arbeitsatmosphäre, in der diese Dissertation gedeihen konnte. 


\section{LEBENSLAUF}

15.08.1968 geboren in Göttingen, Niedersachsen

1974-1978 Adolf-Reichwein-Grundschule, Geismar/Göttingen und Grundschule Herberhausen/Göttingen

1978-1987 Max-Planck-Gymnasium, Göttingen; Abitur

Okt. 1987 Grundwehrdienst im Truppensanitätsdienst in Marburg und Göttingen bis Sept.1988

Okt. 1988 Aufnahme des Studienganges Diplombiologie an der Albert-LudwigsUniversität in Freiburg im Breisgau

Juli 1991 Auslandsaufenthalt in Kanada; ein akademisches Jahr (8 Monate) davon als bis Vollzeitstudent an der Partneruniversität Trent in Peterborough, Ontario mit Aug. 1992 Abschluss Bachelor of Science (BSc.)

Juli 1993 Diplomprüfung im Nebenfach Klimatologie/Meteorologie

Aug. 1993 Wissenschaftliche Hilfkraft bei Freilandversuchen des Fraunhofer Instituts für atmosphärische Umweltforschung, Garmisch-Partenkirchen

Jan. 1994 Diplomprüfungen in Pflanzenphysiologie, Biochemie und Genetik

Feb. 1994 Biologie-Diplomarbeit am Institut für Baumphysiologie der Forstwissenbis schaftlichen Fakultät der Universität Freiburg bei Prof. Dr. H. Rennenberg Feb. 1995 zu einem ökophysiologischen Thema

März 1995 Abschluss als Diplom-Biologe

Juli 1995 Praktikant und wissenschaftliche Hilfskraft bei Freilandversuchen des Instituts für Baumphysiologie in Bayern und Italien

Sep. 1995 Beschäftigung als Patienten- und Gerätebetreuer im Labor für bis Jan.1996 Polysomnographie ("Schlaflabor") des Universitäts-Klinikums Freiburg März 1996 Beginn der Dissertation am Institut für Forstbotanik der Fakultät für Forstwissenschaften und Waldökologie, Georg-August-Universität Göttingen bei Prof. Dr. A. Hüttermann und einer 2jährigen Anstellung als Wissenschaftlicher Mitarbeiter

Juni 1998 Abgabe der Dissertation 